Argonne Rational Laboratom

THICKNESS CORRECTIONS FOR NEUTRON-ACTIVATED GOLD FOILS

by

George S. Stanford and

James H. Seckinger 


\section{DISCLAIMER}

This report was prepared as an account of work sponsored by an agency of the United States Government. Neither the United States Government nor any agency Thereof, nor any of their employees, makes any warranty, express or implied, or assumes any legal liability or responsibility for the accuracy, completeness, or usefulness of any information, apparatus, product, or process disclosed, or represents that its use would not infringe privately owned rights. Reference herein to any specific commercial product, process, or service by trade name, trademark, manufacturer, or otherwise does not necessarily constitute or imply its endorsement, recommendation, or favoring by the United States Government or any agency thereof. The views and opinions of authors expressed herein do not necessarily state or reflect those of the United States Government or any agency thereof. 


\section{DISCLAIMER}

Portions of this document may be illegible in electronic image products. Images are produced from the best available original document. 
The facilities of Argonne National Laboratory are owned by the United States Government. Under the terms of a contract (W-31-109-Eng-38) between the U. S. Atomic Energy Commission, Argonne Universities Association and The University of Chicago, the University employs the staff and operates the Laboratory in accordance with policies and programs formulated, approved and reviewed by the Association.

\section{MEMBERS OF ARGONNE UNIVERSITIES ASSOCIATION}

The University of Arizona Carnegie-Mellon University Case Western Reserve University The University of Chicago University of Cincinnati Illinois Institute of Technology University of Illinois Indiana University Iowa State University The University of Iowa
Kansas State University The University of Kansas Loyola University Marquette University Michigan State University The University of Michigan University of Minnesota University of Missouri Northwestern University University of Notre Dame
The Ohio State University Ohio University

The Pennsylvania State University Purdue University

Saint Louis University

Southern Illinois University

University of Texas

Washington University

Wayne State University

The University of Wisconsin

\section{LEGAL NOTICE}

This report was prepared as an account of Government sponsored work. Neither the United States, nor the Commission, nor any person acting on behalf of the Commission:

A. Makes any warranty or representation, expressed or implied, with respect to the accuracy, completeness, or usefulness of the information contained in this report, or that the use of any information, apparatus, method, or process disclosed in this report may not infringe privately owned rights; or

B. Assumes any liabilities with respect to the use of, or for damages resulting from the use of any information, apparatus, method, or process disclosed in this report.

As used in the above, "person acting on behalf of the Commission" includes any employee or contractor of the Commission, or employee of such contractor, to the extent that such employee or contractor of the Commission, or employee of such contractor prepares, disseminates, or provides access to, any information pursuant to his employment or contract with the Commission, or his employment with such contractor.

Printed in the United States of America

Available from

Clearinghouse for Federal Scientific and Technical Information National Bureau of Standards, U.S. Department of Commerce

Springfield, Virginia 22151

Price: Printed Copy $\$ 3.00 ;$ Microfiche $\$ 0.65$ 


\section{ARGONNE NATIONAL LABORATORY 9700. South Cass Avenue Argonne, Illinois 60439}

THICKNESS CORRECTIONS FOR

NEUTRON-ACTIVATED GOLD FOILS

b.y

George S. Stanford and James H. Seckinger

Reactor Physics Division

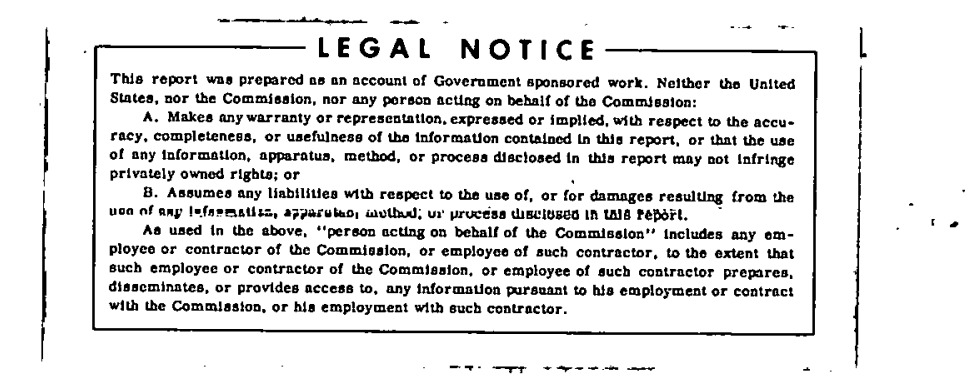

February 1969

This report incorporates a thesis

by James H. Seckinger

Submitted to the Faculty of the Graduate School of Vanderbilt University

' in partial fulfillment of the requirements

for the degree of

MASTER OF SCIENCE'

in Physics 


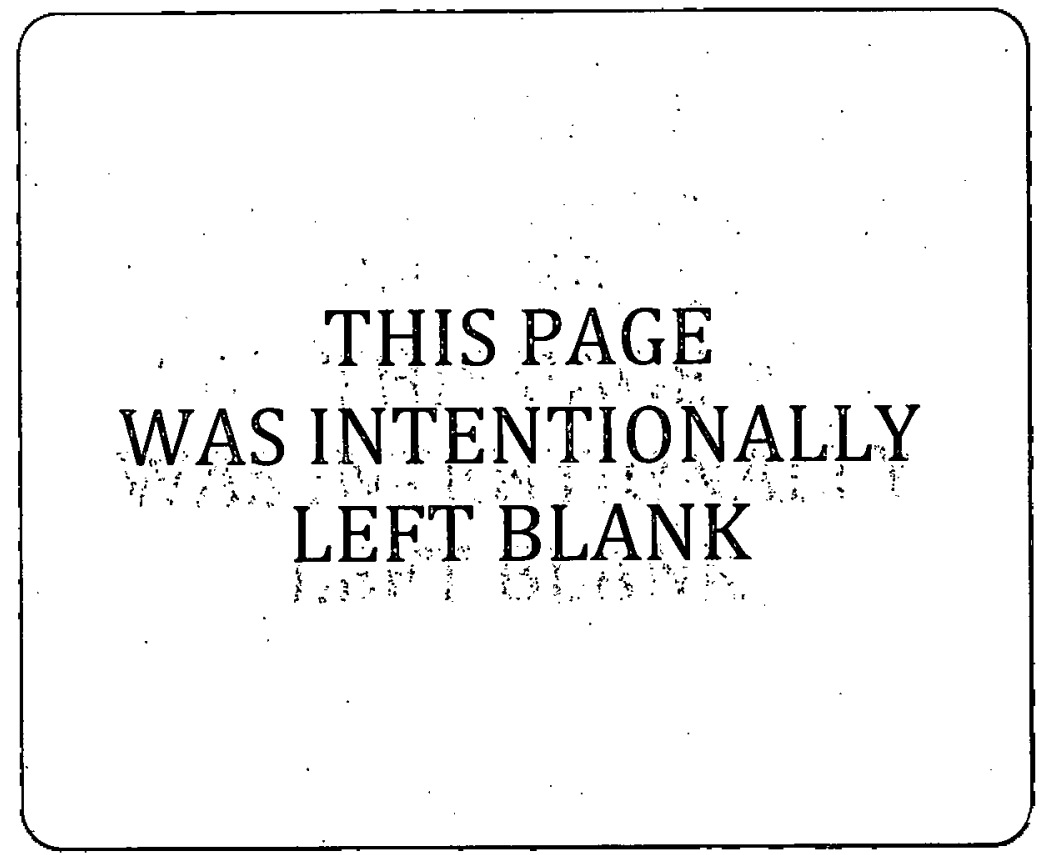

8 
T̈̈BLE OF CONTENTS

$\underline{\text { Page }}$

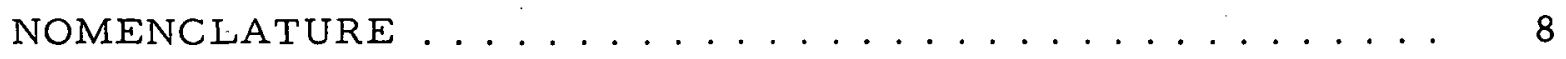

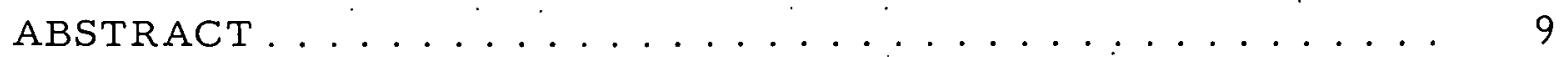

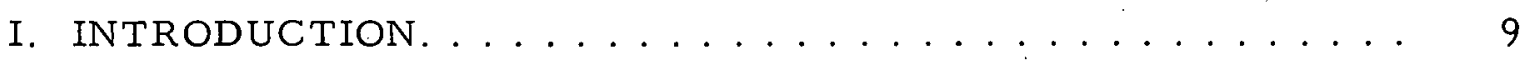

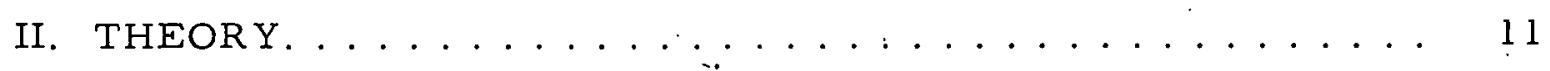

A. Weight-correcting Unmatched Foils ............. 11

B. Thermal H-function. ................. i 12

C. Resonance $\mathrm{H}$ function ................. i 3

D. Formula for the Weight-correction Factors ........ is

III. EXPERIMENTAL TECHNIQUES ................ 16

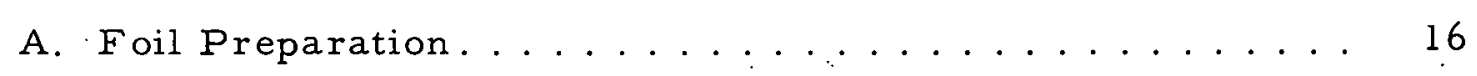

B. Irradiation ...................... 17

C. Counting ...................... 17

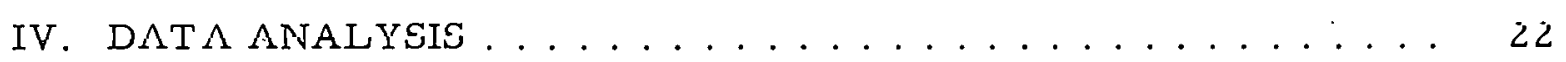

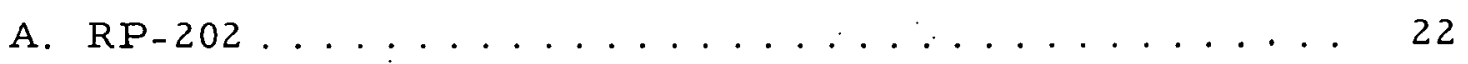

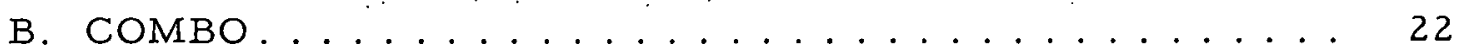

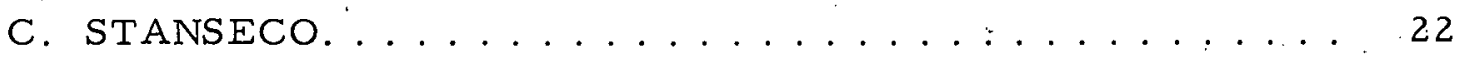

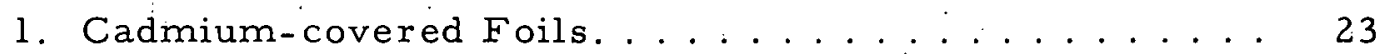

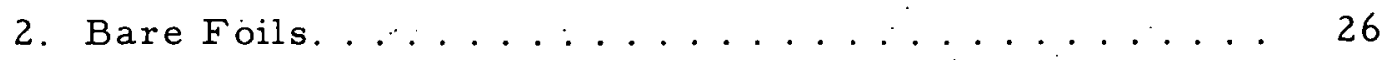

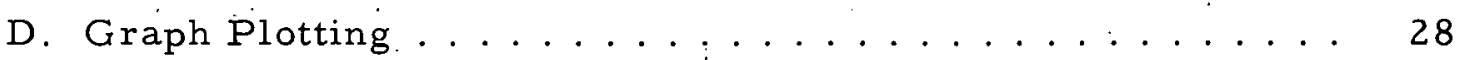

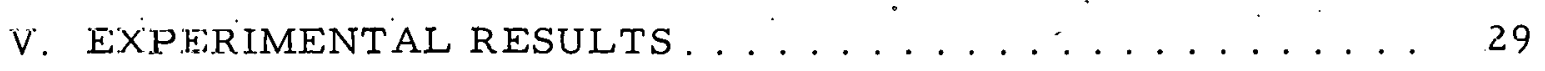
A. Correction Factor for Gamma Scattering and

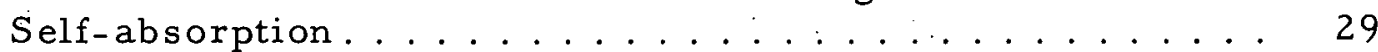
B. Ratio of Low - to High-bias Counts as a Function of

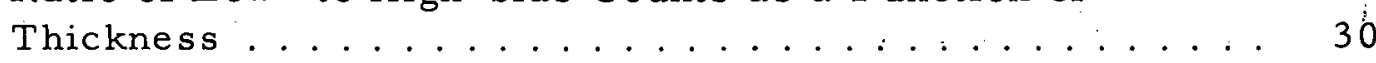

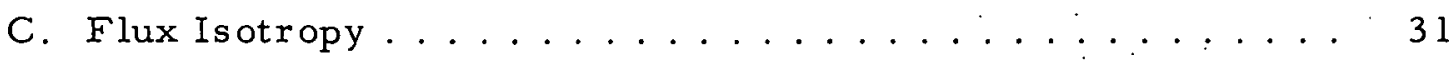
D. Epicadmium Self-shielding ............... 32 
TABLE OF CONTENTS

$\underline{\text { Page }}$

E. Thermal Self-shielding . . . . . . . . . . . 38

F. Cadmium Ratios. ...................... 38

G. Weight-correction Curves .............. 43

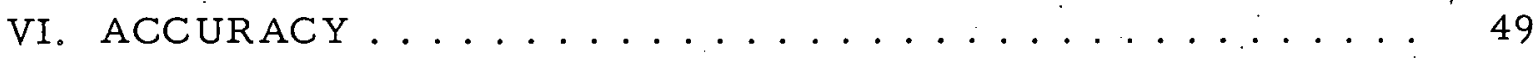

A. Approximations . . . . . . . . . . . . . . . . . 49

1. Accurate Formulas ................... 49

2. Effect of Error in $\operatorname{CdR}(\mathrm{t}) \ldots \ldots \ldots \ldots . \ldots . \ldots 50$

3. Further Approximations ................ 50

4. Unmatched Foils and the Effect of Approximations... 5. 5.1

B. Nonuniform Foils ...................... 52

1. Thick Foil ..................... 52

2. Thin Foil with Voids................. 53

VII. SUMMARY AND CONCLUSIONS . . . . . . . . . . . . 54

APPENDIXES

A. Error Analysis ...................... 56

B. Foil Weights ........................... 59

C. FORTRAN Listings for Program STANSECO ........60

D. Examples of STANSEECO Output ............ 68

E. Least-squares Coeffiçients ............... 73

F. Experiment Concerning Gamma-ray Scattering and Self-absorption ..................... 74

ACKNOWLEDGMENTS . . . . . . . . . . . . . . . . 77

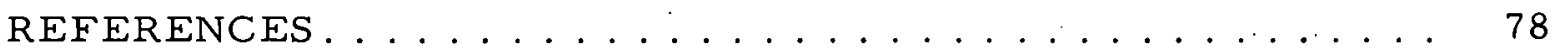




\section{LIST OF FIGURES}

No.

Titlè

$\underline{\text { Page }}$

1. Top View of Mask Arrangement for Preparing Evaporated Gold Foils. : . . . . ................... 16

2. ATSR Facility, Showing Location of Wheel Assembly . . . . . 18

3. Automatic Foil-counting Facility.............. 19

4. Correction Factor for Gamma Scattering and Self-absorption in a Gold Foil as a Function of Foil Thickness . . . . . . . . .

5. Experimental and Theoretical Epicadmium Activation as a Function of Foil Thickness, with a Three-coefficient Fit to

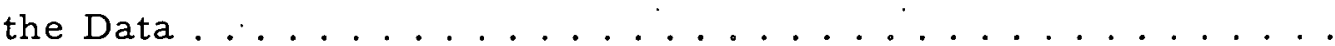

6. Experimental and Theoretical Epicadmium Activation as a Function of Foil.Thickness, with a Four-coefficient Fit to

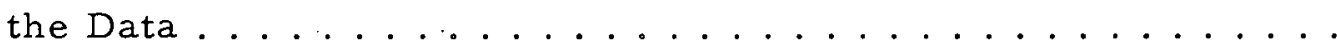

7. Comparison of Experimental Epicadmium Self-shielding Curve for a Three-coefficient Fit with That for a Four-coefficient

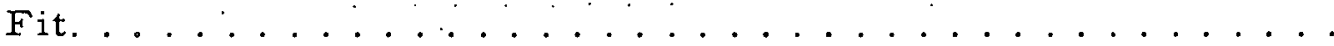

8. Comparison of Experimental Epicadmium Self-shielding Curve for High-bias Counting. with That for Low-bias Counting . . . . .

9. Comparison of Experimental Epicadmium Self-shielding Curve for the North Counting Room with That for the South Counting

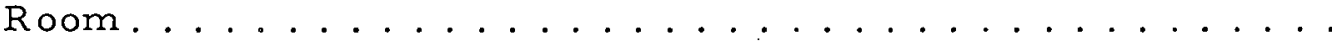

10. Experimentally Determined Subcadmium Activation as a Function of Foil Thickness for a Four-coefficient Fit to the Data, Compared with Theory; Low-bias Counting............

11. Experimentally Determined Subcadmium Activation as a Function of Foil Thickness for a Four-coefficient Fit to the Data, Compared with Theory: High-bias Counting. . . . . . . . .

12. Comparison of Experimental Subcadmium Self-shielding Factor for a IIigh Bias with That for a Low Bias . . . . . . . . .

13. Comparison of Experimental Subcadmium Self-shielding Factor for North Counting Room with That for South Counting Room; Low-bias Counting ..................

14. Comparison of Experimental Cadmium Ratio from Present Work with Cadmium Ratio Determined by Jacks; High-bias Counting . . . . . . . . . . . . . . . . 


\section{LIST OF FIGURES}

No.

$\underline{\text { Title }}$

$\underline{\text { Page }}$

15. Comparison of Experimental Cadmium Ratio from Present Work with Cadmium Ratio Determined by Jacks; Low-bias

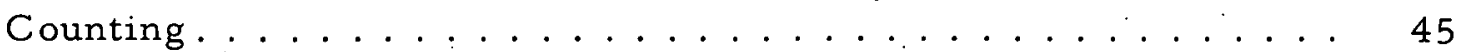

16. Thickness-correction Function for Resonance Activation of Gold Foils........................ 46

17. Thickness-correction Function for Thermal Activation of Gold

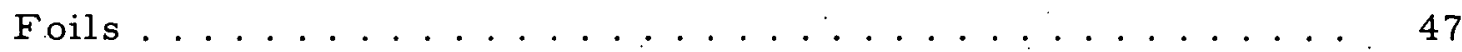

18. Calculated Thickness-correction Function for Thermal Activation of Gold Foils. . . . . . . . . . . . . .. 48

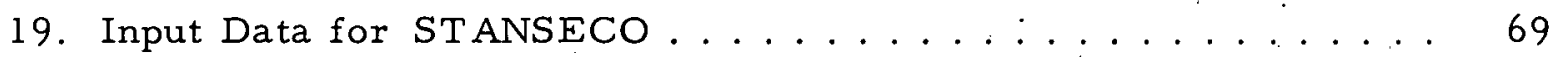

20. Four-coefficient Output Data from STANSECO for Cadmiumcovered Foils ........................ 70

21. The Four Coefficients for Bare-foil Data ........... 71

22. STANSECO Output for Bare-foil Data, Based on the Four

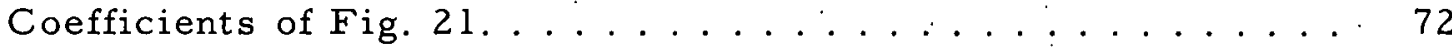




\section{LIST OF TABLES}

No.

Title

$\underline{\text { Page }}$

I. Effects of Approximations ................... 52

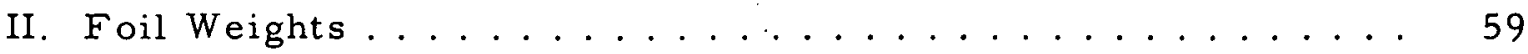

III. Coefficients for the Least-squares Fits As Determined by

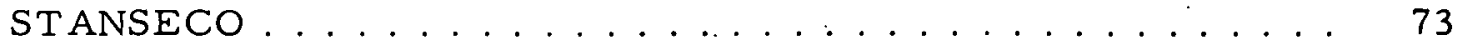

IV. Data from Gamma-ray Self-absorption Test. . . . . . . 75

V. Response Ratios. ......................... 75 
A

$A_{0}$

Abare

$A_{i}$

A $_{\text {epi }}$

Aepi-fit

Aepi-norm

$A_{\text {th }}$

Ath-fit

Ath-norm

Ábare

$A_{\text {epi }}^{\prime}$

$A_{\text {sub }}^{\prime}$

$C_{1}, C_{2}, \ldots$

$\mathrm{CdR}$

D

$D_{1}, D_{2}, \ldots$

$E_{n}(\tau)$

$f(\tau)$

$F_{t}$

$G(\tau)$

$\mathrm{H}_{\text {epi }}(\tau)$

$\mathrm{H}_{\text {th }}(\tau)$

$\mathrm{t}$

$t_{0}$

$t_{i}$

$a$

$\gamma(\mathrm{t})$

$\delta_{\text {epi }}$

$\delta_{\text {th }}$

$\Sigma_{\text {a }}$

$\tau$

$\tau_{0}$

$\tau_{\mathbf{i}}$

$\tau_{\text {th }}$

$\phi$

$\bar{\phi}$

$\phi_{0}$

Specific activation (activation per unit mass) of foil. (Throughout this report, the word "activation" means "specific activation.")

Activation of a foil with thickness $t_{0}$.

Observed activation of a bare foil corrected for gamma self-absorption.

Activation of a foil with thickness $t_{i}$.

Observed activation of a cadmium-covered foil, corrected for gamma self-absorption, epicadmium absorption by the cadmium cover, and subcadmium transmission by the cadmium cover.

Fitted values of the corrected cadmium-covered foil activation.

Normalized fitted values of the corrected cadmium-covered foil activation.

Calculated thermal activation of a bare foil; $A_{\text {th }}=A_{\text {bare }}-A_{\text {epi-fit }}$.

Fitted values of the thermal activation of a bare foil.

Normalized fitted values of the thermal activation of a bare foil.

Observed activation of a bare foil.

Observed aclivation of a cadmium-covered foil.

Subcadmium component of $A_{\text {epi }}^{\prime}$.

Coefficients for least-squares fit of the epicadmium activation.

Cadmium ratio that would be observed for an ideal filter that changes sharply from black to transparent at the cadmium cutoff energy; $C d R=A_{\text {bare }} / A_{\text {epi }}$.

Fractional deviation of foil thickness from nominal; defined by Eq. 17.

Coefficients for least-squares fit of the subcadmium activation.

nth-order exponential integral.

Single-resonance self-shielding function.

Correction factor for epicadmium absorption by the cadmium covers.

Thermal self-shielding function.

Weight-correction function for the epicadmium component of the foil activation.

Weight-correction function for the thermal component of the bare foil activation.

Foil thickness.

Nominal foil thickness.

Intermediate thickness, between $t_{0}$ and $t$.

Thermal transmission factor for cadmium covèrs.

Gamma self-absorption function:

Weight-correction factor for epithermal activation.

Weight-correction factor for thermal aclivalion.

Macroscopic absorption cross section.

$\mathrm{t} \Sigma_{\mathrm{a}}$, the "blackness" of the foil to neutrons.

Value of $\dot{r}$ for a foil of thickness $t_{0}$.

Value of $T$ for a foil of thickness $t_{i}$.

Value of $\tau$ as calculated from the spectrum-averaged thermal absorption cross section.

Neutron flux.

Neutron flux averaged over the volume of the foil.

Unperturbed neutron flux at the location of the foil. 


\title{
THICKNESS CORRECTIONS F.OR NEUTRON-ACTIVATED GOLD FOILS
}

by

George S. Stanford and James H. Seckinger

\begin{abstract}
Curves for determining thickness-correction factors for treating counting data for sets of neutron-activated, unmatched gold foils have been determined experimentally, by using the first derivative of the curve of activation versus thickness. This was done for both epithermal and thermal activation of gold foils irradiated in a near-isotropic flux in a void in a graphite thermal column. The epithermal activation agreed well with a published theoretical calculation.

To obtain a differentiable curve from the activation data, a computer code was written to perform a least-squares fitting process to obtain the coefficients $C_{i}$ for the equation

$$
A(t)=C_{1}+C_{2} f(t)+C_{3} f^{2}(t)+C_{4} f^{3}(t)
$$

where $A(t)$ is the specific activation of a foil of thickness $t$, and $f(t)$ is a differentiable function with a theoretical basis for being at least an approximate fit to the data. For the epithermal data, the calculated self-shielding function for a single-resonance approximation was used for $f(t)$. For the thermal case; $f(t)$ was taken to be the standard thermal selfshielding function. One advantage of this approach over fitting to an arbitrary function, such as a polynomial or sum of exponentials, is that we can extrapolate to zero thickness with greater assurance.
\end{abstract}

\section{INTRODUCTION}

Low-power critical experiments are widely used to check calculational methods for designing high-power reactors, and in such experiments measurements of neutron-flux distributions are needed. Flux distributions are conveniently measured with sets of foils of various materials that have suitable neutron-activation characteristics. Foils are used because they . are small, easily handled, and relatively nonperturbing to the neutron flux or the core components. From the relative activations, one can deduce 
information about the neutron spectrum and the power distribution. The former is needed for reactivity calculations; the latter is used in formulating cooling requirements and detailed core design.

When many foils are used in a single experiment, it is usually not practical to match them perfectly in thickness. For foils that are "thin". (in the sense that $t \Sigma_{a}$, the product of the thickness $t$ and the macroscopic absorption cross section $\Sigma_{a}$, is small), adequate thickness correction can usually be made by dividing the observed activation by the weight of the foil (assuming that each foil has the same area). If, however, the foils are thick enough so that the inner layers are appreciably shielded from neutrons by the outer layers, or that the radiation from the activated atoms is appreciably affected by the surrounding foil material, correcting for thickness variations becomes more complicated.

Such is the case for gold foils of practical thickness. Gold is chemically stable and has a suitable half-life and a conveniently large activation cross section that cause it to be extensively used in activation experiments. The cross section of gold has a very different energy dependence in the thermal and epithermal regions: In the thermal region, the absorption cross section is inversely proportional to the neutron velocity, with the value $98.8 \mathrm{~b}$ at $0.025 \mathrm{eV}$; in the epithermal region, there is a large absorption resonance at $4.9 \mathrm{eV}$, with a peak value of some 37,000 b. Because of this, to make accurate thickness corrections to a set of gold foils, the epithermal and thermal components of the activation must be corrected individually.

Cadmium foil covers are frequently used for separating the thermal and epithermal components. Cadmium has a very large absorption cross section for neutrons of energy less than $\sim 0.5 \mathrm{eV}$ ("subcadmium" neutrons), but a very small one for neutrons of higher energy ("epicadmium" neutrons), so that a suitably thick cadmium cover (20-40 mils) will shield a foil from thermal neutrons. (The terms "epicadmium" and "subcadmium" are approximately interchangeable with "epithermal" and "thermal, "respectively.)

The principal aim of this report is to present a means for routinely applying thickness corrections to activation data from sets of gold foils. Also reported are measurements of self-shielding factors for reducing the observed activation of a gold foil of known thickness to the activation that would have been observed for an infinitely thin foil. The latter will be compared with some published theoretical work and also with some other reported measurements. 


\section{THEORY}

A. Weight-correcting Unmatched Foils

The correction factors for a set of unmatched foils will be denoted by the quantities $\delta_{\text {epi }}$ and $\delta_{\text {th }}$. The quantity $\delta_{\text {epi }}$ will be defined such that for gamma counts,

$$
A_{e p i}\left(t_{0}\right) \cdot=\delta_{\text {epi }} \cdot A_{e p i}(t)
$$

where $t$ is the foil thickness which differs from the nominal thickness $t_{0}$, and $A_{e p i}$ is the cadmium-covered activity per unit mass, corrected for gamma self-absorption, epicadmium absorption by the cadmium, and subcadmium transmission by the cadmium. In other words, $A_{e p i}$ is the epicadmium activation: a bare foil would have received. (Throughout this report, all activations are per unit mass.)

The quantity $\delta_{\text {th }}$ will be defined such that for gamma counts

$$
A_{\text {bare }}\left(t_{0}\right)=\delta_{t h} A_{t h}(t)+\delta_{e p i} A_{e p i}(t)
$$

where Abare is the bare-foil activity corrected for gamma self-absorption. We observe that, in general, $\delta_{\text {epi }}$ and $\delta_{\text {th }}$ are functions of both $t_{0}$ and $t$. Since the cadmium ratio is defined as

$$
\operatorname{CdR}(t)=\frac{A_{\text {bare }}(t)}{A_{\text {epi }}(t)}
$$

and

$$
A_{t h}(t)=A_{b a r e}(t)-A_{e p i}(t)
$$

we can write

$$
A_{t h}(t)=A_{b a r e}(t)[(1-1 / \operatorname{CdR}(t)]
$$

Substituting Eqs. 3 and 4 into Eq. 2 gives

$$
A_{\text {bare }}\left(t_{0}\right)=\delta_{t h}\left[1-\frac{1}{C d R(t)}\right] A_{\text {bare }}(t)+\delta_{\text {epi }} x \frac{1}{C d R(t)} A_{\text {bare }}(t) \text {, }
$$

which can be written as

$$
A_{\text {bare }}\left(t_{0}\right)=A_{\text {bare }}(t)\left[\delta_{t h}+\frac{\delta_{\text {epi }}-\delta_{t h}}{C d R(t)}\right]
$$


For foils of practical thickness, $\delta_{\text {th }}$ is approximately unity and $\delta_{\text {epi }}$ will rarely differ from $\delta_{\text {th }}$ by more than $20 \%$. Hence Eq. 5 is not sensitive to an error in the value assumed for CdR; therefore, for weight corrections, $\mathrm{CdR}$ need not be known with high accuracy. below.

The method for finding $\delta_{\mathrm{epi}}$ and $\delta_{\mathrm{th}}$ will be developed in Section D

\section{B. Thermal H-function}

The slope of the activation-versus-thickness curve can be used to deduce, from the observed activation of a foil thickness $t$, the activation that would have been observed had the foil been of nominal thickness $t_{0}$.

The quantity $H(\tau)$, related to the slope of the activation versus thickness curve, will be defined as ${ }^{1}$.

$$
\mathrm{H}(\tau) \equiv-\frac{\tau}{\mathrm{A}} \frac{\mathrm{dA}}{\mathrm{d} \tau}
$$

where $A$ is the activation rate in the foil per unit mass and is proportional to the average flux throughout the foil, and $\tau$ represents the macroscopic thermal absorption cross section $\Sigma_{a}$ of the foil times its thickness $t$. Thus $\mathrm{H}$, a dimensionless number, is the fractional change in activity for a small fractional change in $T$.

In the presence of thermal self-shielding and flux depression, the ratio of the average thermal flux $\bar{\phi}$ throughout the volume of the foil to the unperturbed flux $\phi_{0}$ will be denoted by the function $G(\tau)$, which is given by ${ }^{2,3}$

$$
G(\tau)=\frac{\bar{\phi}}{\phi_{0}}=\frac{\left[\frac{1}{2}-E_{3}(\tau)\right] / \tau}{1+\left[\frac{1}{2}-E_{3}(\tau)\right] g}
$$

where $E_{3}(\tau)$ is the third-order exponential integral

$$
\int_{1}^{\infty}\left(e^{-x \tau / x^{3}}\right) d x
$$

and $g$ is a parameter that depends on the foil radius and the nature of the medium in which the foil is being irradiated. ${ }^{4}$ The numerator on the right side of Eq. 7 corresponds to the self-shielding of the foil, and the denominator to the flux depression in the surrounding medium. In this experiment, the foils were irradiated in a void in a graphite medium, where the flux depression is negligible and the value of the parameter $g$ is zero. Thus, for 
the purposes of this experiment, the ratio of the average flux throughout the volume of the foil to the unperturbed flux is given by

$$
G(\tau)=\frac{\bar{\phi}}{\phi_{0}}=\frac{\frac{1}{2}-E_{3}(\tau)}{\tau} .
$$

Remembering that for any given foil the activity is proportional to $\bar{\phi}$, differentiating Eq. 8, and substituting it into Eq. 6, we get

$$
\mathrm{H}_{\mathrm{th}}(\tau)=\frac{\tau}{\mathrm{G}\left(\tau_{\mathrm{th}}\right)} \frac{\mathrm{dG}\left(\tau_{\mathrm{th}}\right)}{\mathrm{d} \tau_{\mathrm{th}}}=1-\frac{\tau \mathrm{E}_{2}(\tau)}{\frac{1}{2}-\mathrm{E}_{3}(\tau)}
$$

This is the theoretical value of $\mathrm{H}_{\mathrm{th}}(\tau)$, which will be compared with measurements in Section V.G.

C. Resonance H-function

For the case of a single large Breit-Wigner level and isotropic neutron flux, the resonance self-shielding in a foil is given by

$$
f(\tau)=\frac{\bar{\phi}}{\phi_{0}}=\frac{\tau}{2} \int_{\tau / / 2}^{\infty} \mathrm{y}^{-2} \mathrm{e}^{-\mathrm{y}}\left[\dot{\mathrm{I}}_{0}(\mathrm{y})+\mathrm{I}_{1}(\mathrm{y})\right] \mathrm{dy}
$$

where $I_{0}$ and $I_{1}$ are the zeroth and first orders, respectively, of the modified Bessel functions of the first kind, and $\tau$ is the value of $t \Sigma_{a}$ at the peak of the resonance. We are neglecting flux depression, the effect of which is small. for resonance neutrons, even when the foil is not in a void.

Since for any given foil the activity is proportional to $\bar{\phi}$, differentiating Eq. 10 and substituting it into Eq. 6 give (see Section IV.C for differentiation)

$$
\mathrm{H}_{\mathrm{epi}}(\tau)=-\frac{\tau}{\mathrm{f}(\tau)} \frac{\mathrm{df}(\tau)}{\mathrm{d} \tau}=\frac{1}{\mathrm{f}(\tau)} \mathrm{e}^{-\tau / 2}\left[\mathrm{I}_{0}(\tau / 2)+\mathrm{I}_{1}(\tau / 2)\right]-1
$$

This is the single-resonance approximation for $\mathrm{H}_{\mathrm{epi}}$ and will be compared with experiment in Section V.D.

D. Formula for the Weight-correction Factors

Let $A_{0}$ and $A$ be (respectively) the activation rates per milligram for a foil of nominal thickness $t_{0}$, and for a foil whose thickness $t$ may differ from $t_{0}$. Then

$$
A_{0}=A+\left.\left(\tau_{0}-\tau\right) \frac{d A}{d \tau}\right|_{\tau_{i}}
$$


where $\mathrm{dA} / \mathrm{d} \tau$ is evaluated at some $\tau_{i}$ lying between $\tau_{0}$ and $\tau$, the subscript $i$ denoting "intermediate." (According to the Mean Value Theorem, there is always a $\tau_{i}$ that makes Eq. 12 exact.) Since Eq. 6 can be written

$$
\left.\frac{\mathrm{dA}}{\mathrm{d} \tau}\right|_{\tau_{\mathrm{i}}}=-\frac{\mathrm{A}_{\mathrm{i}}}{\tau_{\mathrm{i}}} \mathrm{H}\left(\tau_{\mathrm{i}}\right),
$$

then

$$
\mathrm{A}_{0}-\mathrm{A}=\mathrm{A}_{\mathrm{i}} \frac{\tau-\tau_{0}}{\tau_{\mathrm{i}}} \mathrm{H}\left(\tau_{\mathrm{i}}\right)
$$

If we make the approximations

$$
A_{i} \approx\left(A_{0}+A\right) / 2 \text {, }
$$

and

$$
\tau_{\mathbf{i}} \approx\left(\tau_{0}+\tau\right) / 2
$$

and if we let the fractional deviation $D$ of the foil thickness from nominal be defined by

$$
\mathrm{D} \equiv 2 \frac{\tau-\tau_{0}}{\tau+\tau_{0}}=2 \frac{\mathrm{t}-\mathrm{t}_{0}}{\mathrm{t}+\mathrm{t}_{0}}
$$

then Eq. 14 can be written

$$
A_{0}-A=\frac{1}{2}\left(A_{0}+A\right) H\left(\tau_{i}\right) D,
$$

and by simple arrangement Eq. 18 becomes

$$
\frac{\mathrm{A}_{0}}{\mathrm{~A}}=\frac{2+\mathrm{DH}\left(\tau_{i}\right)}{2-\mathrm{DH}\left(\tau_{i}\right)} \text {. }
$$

Equation 19, the weight-correction formula, applies equally well to thermal and resonance activation; it is only necessary to use the appropriate values of $\mathrm{H}$ and $\mathrm{t} \Sigma_{\mathrm{a}}$. The thermal cross section to use is the spectrum-averaged thermal absorption cross section, which for a Maxwellian spectrum is $\sqrt{\pi} / 2$ times the $2200-\mathrm{m} / \mathrm{sec}$ cross section. The resonance cross section used in the calculations for this experiment was the peak cross section of $37,000 \mathrm{~b}$.

Thus the weight-correction factors $\delta_{\text {epi }}$ and $\delta_{\text {th }}$ used in Eqs. 1 and 5 are found by using the equations

$$
\delta_{e p i}=\frac{2+D H_{e p i}\left(t_{i}\right)}{2-D H_{e p i}\left(t_{i}\right)}
$$


and

$$
\delta_{t h}=\frac{2+D H_{t h}\left(t_{i}\right)}{2-D H_{t h}\left(t_{i}\right)}
$$

In most cases, it is sufficiently accurate, and much easier, to let $t_{i}$ equal $t_{0}$ in Eqs. 20 and 21 ; rather than determine a distinct value of $H$ for each individual foil. Thus,

$$
\delta_{\text {epi }}=\frac{2+\mathrm{DH}_{\mathrm{epi}}\left(\mathrm{t}_{0}\right)}{2-\overline{\mathrm{DH}}_{\mathrm{epi}}\left(\mathrm{t}_{0}\right)},
$$

and

$$
\delta_{t h}=\frac{2+D H_{t h}\left(t_{0}\right)}{2-D H_{t h}\left(t_{0}\right)} .
$$

Graphs for determining $\mathrm{H}$ are presented in Chapter $\mathrm{V}$. 


\section{EXPERIMENTAL TECHNIQUES}

A. Foil Preparation

The gold foils used in this experiment were $1-\mathrm{cm}$ square. For thicknesses greater than $1.2 \mathrm{mg} / \mathrm{cm}^{2}$, the foils were punched from rolled sheets with a high-precision punch-and-die set, and their thicknesses were determined by weighing on an analytical balance. For weights less than $10 \mathrm{mg}$, a six-place microbalance was used, and each foil was weighed at three separate times ( 8 a.m., 3 p.m., and 8 p.m.), for an accuracy of $\pm 10 \mu \mathrm{g}$. A five-place balance, with an accuracy of $\pm 50 \mu \mathrm{g}$, was used for the thicker foils.

The foils thinner than $1.2 \mathrm{mg} / \mathrm{cm}^{2}$ were prepared by evaporation onto a 5-mil Mylar backing. A mask of 30-mil aluminum, as shown in

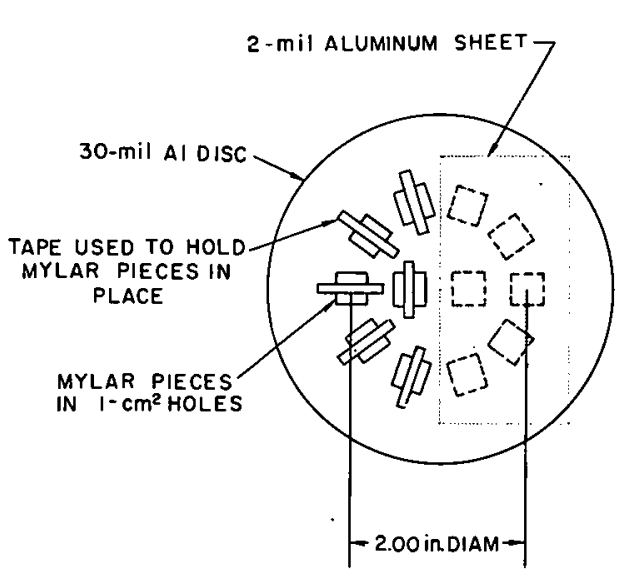

$112-8127$

Fig. 1. Top View of Mask Arrangement for Preparing Evaporated Gold Foils Fig. 1, was used. All the holes in the mask were within a 6-cm-diam circle, which, for the evaporation geometry used, was calculated to provide deposits that were the same to $\pm 1 \%$.

It was thought at first that a Mylar sheet ( $1.5 \times 3$ in.) could be placed on the mask and the $1-\mathrm{sq}-\mathrm{cm}$ foils cut out of the sheet after the evaporation. It turned out to be practically impossible to cut out the $1-\mathrm{cm}$ square accurately, without damaging the gold plated on the Mylar. To meet the demands of an accurate area of $1 \mathrm{~cm}^{2}$, the Mylar foils were punched before being coated, using the precision punch-and-die set. The punched Mylar foils were placed in the square holes on the left side of the mask by means of thin strips of tape (see Fig. l). With care, the tape could be removed from the Mylar backing without disturbing the gold film.

The thickness of the evaporated gold foils was determined by weighing, as follows: The gold was evaporated onto 2 -mil aluminum sheet ( $3 \times 1.5$ in., positioned behind the mask as shown in Fig. 1) and onto the l-sq-cm Mylar foils simultaneously. Although the uniformity of the deposited film was not experimentally checked, no effect comes to mind that could cause appreciable asymmetry between the two halves of the mask. The aluminum was weighed before and after the evaporation, on the sixplace microbalance, with an accuracy of $\pm 10 \mu \mathrm{g}$, as outlined above. The weight difference could be determined within 1 to $3 \%$, depending on the foil weight. 
Mylar was selected for the evaporation backing, after several materials were tried, because the deposited layer of gold adhered well enough to permit the subsequent handling. On the other hand, Mylar could not be used as the backing for the weight determinations, because its weight would vary from one weighing to the next--probably because of changes in moisture content. Aluminum was satisfactory for that purpose, since only minimal handling was required.

\section{B. Irradiation}

The irradiation took place in the graphite thermal column of the Argonne Thermal Source Reactor (ATSR). The ATSR is a highly enriched $\left(93.2 \%{ }^{235} \mathrm{U}\right)$, light-water-moderated reactor. The core tank, which contains. the fuel elements, water moderator, and reflector, is located inside a large shield tank. The core is fastened to the center of one side of the shield tank, called the "front face." This leakage face is next to the graphite pile (as shown in Fig. 2).

The foils used in this experiment were placed in 0.020-in.-thick cadmium and.aluminum covers. (The thermal-transmission and epicadmiumabsorption correction factors for the cadmium covers are discussed in Section IV.C.) The foils were taped to an 11 -in.-diam aluminum wheel, near the periphery, alternately cadmium and aluminum covered. The wheel was attached to an assembly (as shown in Fig. 2) which rotated the wheel at a constant rate throughout the irradiation, to ensure that all foils were exposed to the same flux. The wheel assembly was located in a foot-square cavity, with 8 in. of graphite between it and the reactor face. The wheel face was parallel to the reactor face.

Because of the large range of foil weights, two separate irradiations were made. To ensure reproducibility, the reactor geometry was not changed between the irradiations, and graphite stringers and blocks were placed on top of the graphite pile in such a way that the wheel assembly could be placed in a reproducible position for both runs. The first irradiation, foils numbered 1 through 32, was for. $2 \mathrm{hr}$ at approximately $1 \mathrm{~kW}$. The second irradiation, foils numbered $21^{\prime}$ through $32^{\prime}$ and 33 through 48 , was for $30 \mathrm{~min}$ at approximately $250 \mathrm{~W}$. For normalization purposes, there was a 12 -foil overlap (six bare and six cadmium covered). The overlapping foils (21 through 32,21 'through 32') were matched in weight to within $1 \%$. (The weights are listed in Appendix B.)

C. Counting

The activated foils were counted automatically in sample changers of the type shown in Fig. 3. There are two detectors $(2 \times 2-$ in. NaI: T l crystals) per sample changer, with the amplifier for each detector feeding two (South Counting Room) or three (North Counting Room) single-channel analyzers and scalers. The use of two detectors located above and below the 


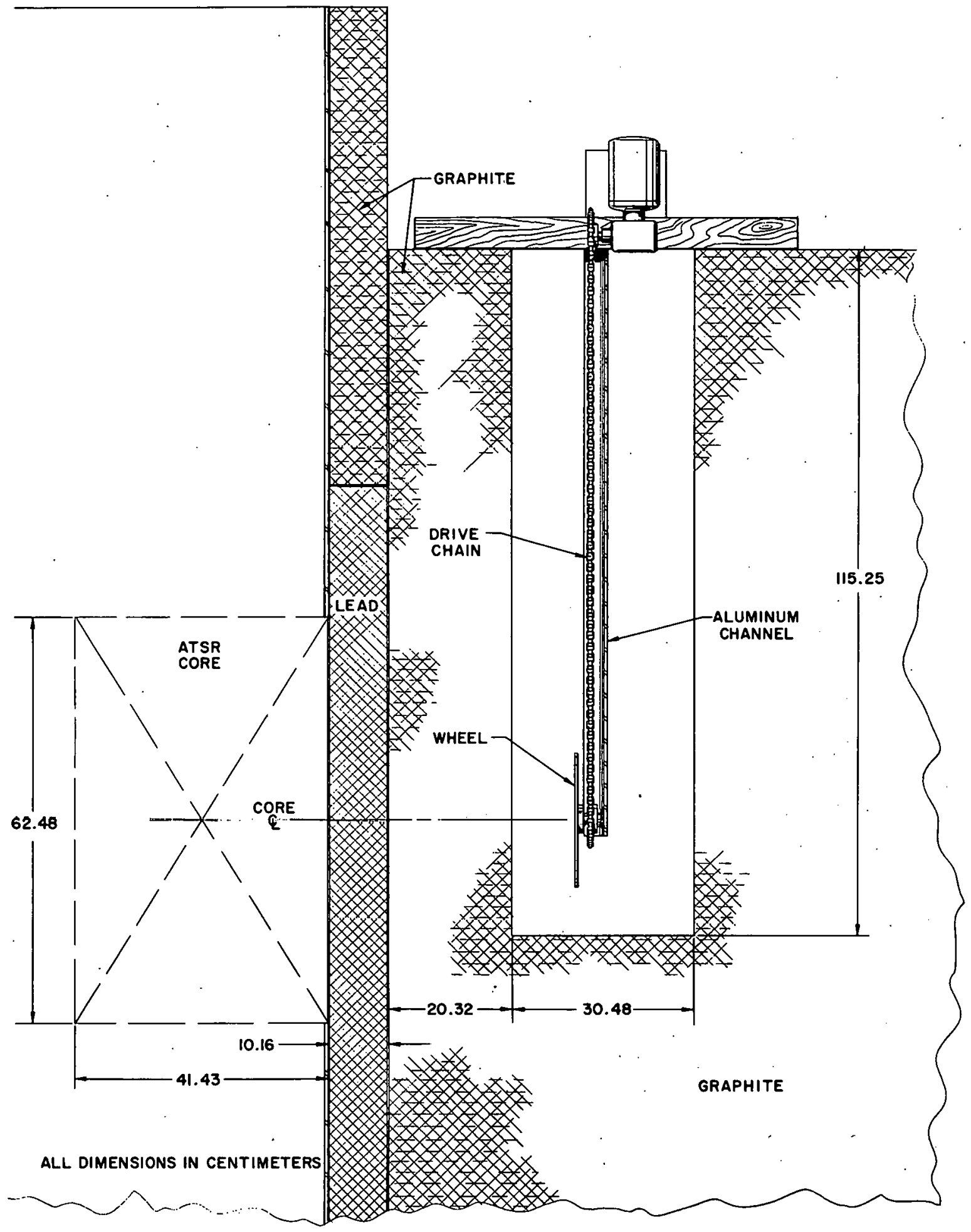

$112-7816$

Fig. 2. ATSR Facility, Showing Location of Wheel Assembly 


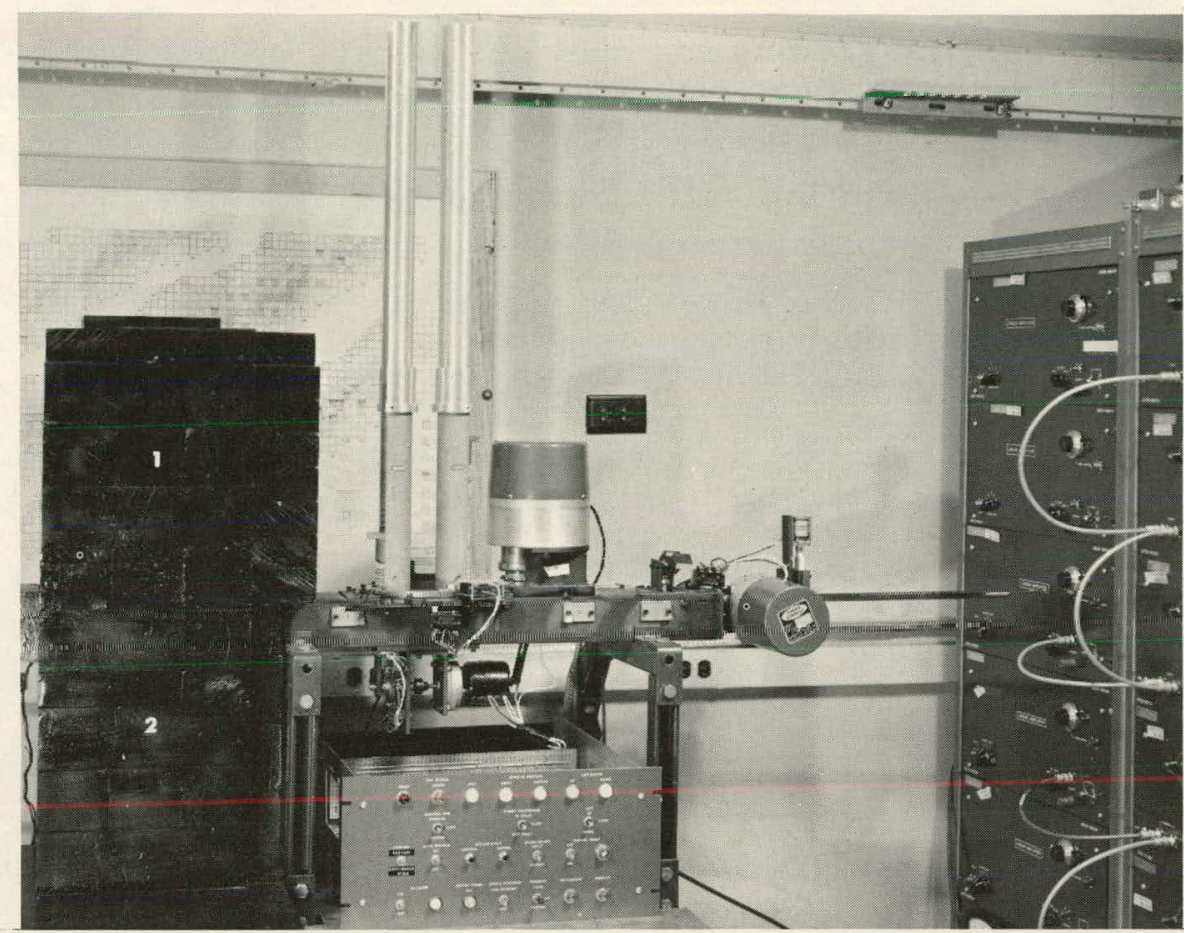

$112-6655$

Fig. 3. Automatic Foil-counting Facility

foil permitted first-order cancelation of the effects of small vertical displacements in the foil positions, and the redundancy in the subsequent circuitry was useful insurance against possible loss of data due to malfunction of one of the electronic romponents.

In the use of the automatic foil changers, the foils on their planchets were initially loaded in one of the two stacks; after each foil was counted, it would automatically be inserted at the bottom of the other stack. The foils were cycled repetitively; between cycles they were restacked so that each cycle started with the first foil. The two detectors inside the lead column at the left in Fig. 3 were well removed from the stacks to permit adequate shielding for gamma counting, a slide being used to transport the planchet to its counting position between the detectors.

The pulses were processed by conventional amplifiers, singlechannel analyzers, and scalers, the data being punched automatically on IBM cards. All the foils were counted in each of two counting rooms: North and South, Building 316. The two sets of counting equipment were used to determine if the minor variations in counting geometry and electronics had an appreciable effect on the shape of the activation-versus-thickness curves, and to provide a general check on the reproducibility of the counting data.

The performance of the equipment was satisfactory: The scatter in successive counts of the same foil was usually commensurate with the 
counting statistics. Indications are that positioning errors between cycles, and random drifts in the electronic circuits, lead to errors considerably less than $0.1 \%$. There are systematic differences, from foil to foil in a stack, in the relative counting rates in the top and bottom detectors. Such differences, amounting in some cases to $1 \%$ or more, can be due to unavoidable differences in the vertical positioning of the foils. Consequently, the results for the top and bottom detectors were averaged--a process that provides good cancelation of these systematic differences.

To achieve satisfactory statistics, the counting time was preset so that at least 15,000 counts would be accumulated, and one of the scalers was preset to stop at 80,000 counts. This gave a statistical-error range of 0.4 to $0.8 \%$ and a reasonable counting time. At least seven traverses through the stack were obtained during an overnight run, thus reducing the statisticalerror range to 0.1 to $0.3 \%$.

The foils were counted at two integral bias settings: "low" (approximately $60 \mathrm{keV}$ ) and "high" (including the $41 \mathrm{ll} \mathrm{keV}$ gold peak and above). The program COMBO (described in Section IV.B) was used to compute the ratio of the low-bias to high-bias results, and the effect observed is discussed in Section V.B.

In general, the largest source of counting error has to do with deadtime corrections. The resolving times were approximately 4 or $5 \mu \mathrm{sec}$, but the exact value depends on such counting conditions as bias setting and foil material and varies from one counting channel to the next. A computer code ${ }^{6}$ was used in the routine determination of the deadtime by the double-source method, but even then the results are not believed to be much better than $\pm 1 \mu \mathrm{sec}$. To minimize the uncertainty due to deadtime, the counting rates were kept well below 5000 counts/sec.

Immediately after the first irradiation, the counting rates ranged from 100 to 50,000 counts/sec. To meet the requirement that counting rates be less than 5000 counts/sec, the foils from the first irradiation were counted in two groups. The foils in Group 1 were those foils with a counting rate of 5000 counts/sec or less immediately after the irradiation (bare foils 1 through 11 and cadmium-covered foils 2 through $24 *$ ). The rest of the foils from the first irradiation (bare foils 13 through 31 and cadmium-covered foils 26 through 32 ) were allowed to decay for 10 days ( 3.7 half-lives). For normalization purposes, ten of the most active foils from Group 1 were counted again with Group 2. Thus Group 2 contained bare foils 3 through 31 and cadmium-covered foils 16 through 32. Reference to Section III.B and to Table II in Appendix B will help to clarify the foil-numbering system.

Immediately after the second irradiation (foils $21^{\prime}$ through $32^{\prime}$ and 33 through 48 ), the counting rates ranged from 1000 to 74,000 counts/sec.

\footnotetext{
* The odd-numbered foils were bare, and the even-numbered cadmium covered.
} 
To keep the counting rates below 5000 counts/sec, the foils from the second irradiation were counted in three groups (Groups 3, 4, and 5). The foils in Group 3 were those with a counting rate of 5000 counts/sec or less immediately after the irradiation. The foils in Group 4 were allowed to decay for eight days (three half-lives), and the two most active bare foils were allowed to decay for ten days ( 3.7 half-lives). For normalization purposes, ten of the foils in Group 3 were recounted in Group 4, and five of the foils in Group 4 were included in Group 5. Thus Group 3 contained bare foils $21^{\prime}$ through. 29', 31, and 33 and cadmium-covered foils $22^{\prime}$ through $32^{\prime}$ and 34 through 42; Group 4 included bare foils $25^{\prime}$ through 29', 35 through 43, and cadmium-covered foils 34 through 48: and Group 5 consisted of bare foils 35 through 47 .

Before each group was counted, the deadtime correction for that group was determined by the paired-source method, using the two hottest foils in the group. The TWOSORCE $E^{6,8}$ computer program was used to calculate the deadtime, and the resulting value was used in the dataprocessing code RP- 202 . 


\section{DATA ANALYSIS}

A. $\underline{R P}-202$

The first stage of data processing was done with RP $-202,{ }^{7}$ a standard ANL computer code for processing foil-counting data. As input, this code uses the counting-data cards produced by the automatic foil-counting systems. It corrects for counter efficiency, background, deadtime, foil weight, and decay since the time of irradiation, and computes the saturated specific activity on the basis of the input irradiation time. These results are printed numerically and graphically, along with the statistical errors. Then for each foil the average of all the determinations of saturated activity is calculated, both unweighted and weighted according to the counting statistics. The results are printed out, together. with the statistical error in the weighted average and the standard deviation in the unweighted average. In addition, the program produces punched cards containing the weighted averages for use in subsequent processing by the COMBO code.

\section{B. COMBO}

The data for the five groups of foils were combined and normalized by the COMBO computer program. ${ }^{8}$. For the COMBO program, the principal input consists of the weighted-average specific activity for each foil and each scaler, as punched out on IBM cards by RP-202.

Processing proceeds in two stages. In the first stage, for each group of foils the data for all the scalers are averaged foil by foil, and the results are stored for subsequent use and printed out. In the second stage, all the groups of foils are combined into one. By matching foil identifiers, which are included in the output from RP-202, the program locates the foils that are common to the first and second groups, and from the relative activities of the common foils, it determines the multiplier to be applied to the foils of the second group. After the multiplication is performed, the two groups are combined into one, and then this new group is similarly combined with the third group, and so on, until five groups are combined into one. When the process has been completed, the results are normalized to the most active foil and printed out.

The program COMBO combined five groups of data and normalized the results for the four different sets: North High Bias; North Low Bias; South High Bias; South Low Bias.

\section{STANSECO}

STANSECO, a computer code for the CDC-3600; was written during this work. The principal input for the program is the relative specific activities (from COMBO), weighting factors, and the foil weights. The 
program's main function is to apply corrected activity to the appropriate theoretical function, and to calculate the self-shielding and thicknesscorrection factors. The FORTRAN listings are given in Appendix C.

\section{Cadmium-covered Foils}

The observed cadmium-covered foil activity must be corrected for gamma self-absorption, and for epicadmium absorption and subcadmium transmission of neutrons by the cadmium cover. The corrected activity is then the epicadmium activity that the foil would have if covered by an "ideal" filter, an ideal filter being one that changes sharply from black to transparent at the cadmium cutoff energy. The observed cadmium-covered foil activity $A_{\text {épi }}^{\prime}$ can be separated into two components, subcadmium and epicadmium:

$$
A_{\text {épi }}^{\prime}=A_{\text {sub }}^{\prime}+\frac{A_{\text {epi }}}{F_{t} \dot{\gamma}(t)}
$$

where $t$ is the thickness of the foil, $\gamma(t)$ is the gamma self-absorption function (discussed in Section V.A), $F_{t}$ is the epicadmium absorption factor for $20-$ mil cadmium, ${ }^{9}$ epi is the corrected epicadmium activation, and $A_{s u b}^{\prime}$ is the subcadmium component of the observed activity of a cadmium-covered. foil.

\section{Rewriting Eq. 24, we obtain}

$$
A_{e p i}=F_{t} \gamma(t)\left(A_{\text {epi }}^{\prime}-A_{s u b}^{\prime}\right)
$$

The subcadmium component, $A_{s}^{\prime} u b$, is defined as

$$
A_{\text {sub }}^{\prime}=\frac{\alpha A_{t h}}{\gamma(t)}
$$

where $A_{\text {th }}$ is the subcadmium activity that a bare foil would have, and $\alpha$ is the thermal-transmission factor as determined from Fig. 1 of Ref. 10.

The corrected cadmium ratio is defined as

$$
C_{d R}=\frac{A_{\text {bare }}}{A_{\text {epi }}}=\frac{A_{\text {th }}+A_{\text {epi }}}{\cdots A_{\text {epi }}}=\frac{A_{\text {th }}}{A_{\text {epi }}}+1
$$

Equation 27 can be written as

$$
A_{t h}=A_{\text {epi }}(C d R-1)
$$


By substituting Eqs. 28 and 26 into Eq. 25, one gets

$$
A_{\text {epi }}=F_{t} \gamma(t)\left[A_{\text {epi }}^{\prime}-\frac{\alpha A_{e p i}(C d R-1)}{\gamma(t)}\right] \text {. }
$$

Thus the corrected epicadmium activation is

$$
A_{\text {epi }}=\frac{A_{\text {epi }}^{\prime} \gamma(t)}{1 / F_{t}+\alpha(C d R-1)}
$$

Observe that since $F_{t}$ and $\gamma(t)$ are close to unity, and since $\alpha$ is small (of the order of $10^{-3}$ ), even a crude estimate of $\mathrm{CdR}$ is adequate for this correction, unless $\mathrm{CdR}$ is very large.

In the processing by STANSECO, the corrected experimental epicadmium activation $A_{\text {epi }}$ was fitted by the method of least squares to the equation

$$
A_{\text {epi }}(\tau)=C_{1}+C_{2} f(\tau)+C_{3} f^{2}(\tau)+C_{4} f^{3}(\tau)+\ldots
$$

where $f(\tau)$ is the single-resonance self-shielding function described by Trubey, Blosser, and Estabrook, ${ }^{5}$ given in Eq. 10. The program uses Eqs. 29 and 10 in Eq. 30 to find the $\mathrm{C}_{i}$; the integral in Eq. 10 being determined by numerical integration. Since

$$
\lim _{\tau \rightarrow \infty} f(\tau)=0
$$

and physical reality requires $\mathrm{A}_{\text {epi }}(\tau)$ to approach zero as $\tau$ approaches infinity, the first coefficient, $C_{j}$, was constrained to be approximately zero. This was done by using the artificial datum point

$$
f(\tau)=0, A_{e p i}(\tau)=0
$$

with a very large weighting factor.

For the rest of the points, the weighting factors were determined from the estimated experimental errors. The counting statistics were approximately the same for all foils: For the light foils, the weighing uncertainties were the chief source of error, but for the heavier foils, the weighing errors were less important than the deadtime uncertainties. The error in the weights of the foils (ranging from 3\% in the thinnest foils to $0.1 \%$ in the thickest) was determined by the accuracy of the balance. Deadtime uncertainties contributed an error of approximately $0.3 \%$. The weighting factors used in the least-squares fit subroutine were calculated according to 
weighting factor $=\frac{1}{\text { error }}$

and ranged from 0.33 to 10 .

The $C_{i}$ as calculated by the least-squares subroutine define the fitted epicadmium activity as

$$
A_{e p i-f i t}(\tau) \equiv C_{1}+C_{2} f(\tau)+C_{3} f^{2}(\tau)+C_{4} f^{3}(\tau)+\ldots
$$

Note that

$$
A_{\text {epi-fit }}(0)=\sum_{i} C_{i}
$$

since

$$
\lim _{\tau \rightarrow 0} f(\tau)=1
$$

Thus the sum of the coefficients of the least-squares fit gives the extrapolated value of the activity at zero thickness. The experimental values $\mathrm{A}_{\text {epi }}(\tau)$, and the fitted values $A_{\text {epi-fit }}(\tau)$, of the epicadmium activity were normalized by dividing by $A_{e p i-f i t}(0)$. Graphs of these normalized values, along with a theoretical function, are given in Chapter $V$.

The $\mathrm{H}$-function for the epicadmium activity is defined (see

Eq. 6) as

$$
\mathrm{H}_{\text {epi }}(\tau)=\frac{-\tau}{\mathrm{A}_{\text {epi-norm }}(\tau)} \frac{\mathrm{d}}{\mathrm{d} \tau}\left[\mathrm{A}_{\text {epi-norm }}(\tau)\right]
$$

where $A_{\text {epi-norm }}(\tau)$ is the normalized fitted epicadmium activity,

$$
A_{\text {epi-norm }}(\tau)=\frac{A_{\text {epi-fit }}(\tau)}{A_{\text {epi-fit }}(0)}
$$

Thus

$$
\frac{\mathrm{d}}{\mathrm{d} \tau}\left[\mathrm{A}_{\text {epi-norm }}(\tau)\right]=\frac{\mathrm{l}}{\mathrm{A}_{\text {epi-fit }}(0)} \frac{\mathrm{d}}{\mathrm{d} \tau}\left[\mathrm{A}_{\text {epi-fit }}(\tau)\right]
$$

Differentiating Eq. 3.2 and substituting into Eq. 34 give

$$
\frac{\mathrm{d}}{\mathrm{d} \tau}\left[\mathrm{A}_{\text {epi-norm }}(\tau)\right]=\frac{1}{\mathrm{~A}_{\text {epi-fit }}(0)} \frac{\mathrm{df}(\tau)}{\mathrm{d} \tau}\left[\mathrm{C}_{2}+2 \mathrm{C}_{3} \mathrm{f}(\tau)+3 \mathrm{C}_{4} \mathrm{f}^{2}(\tau)+\ldots\right]
$$


To find $\operatorname{df}(\tau) / d \tau$, we note the identity.

$$
\int_{a}^{b} F^{\prime}(x) d x:=F(b)-F(a)
$$

from which

$$
\frac{d}{d a} \int_{a}^{b} F^{\prime}(x) d x=-F^{\prime}(a)
$$

Recalling Eq. 10 that

$$
f(\tau)=\frac{\tau}{2} \int_{\tau / 2}^{\infty} y^{-2} e^{-y}\left[I_{0}(y)+I_{1}(y)\right] d y,
$$

and using Eq. 37, we get

$$
\frac{d f(\tau)}{d(\tau / 2)}=\frac{\tau}{2}\left[-F^{\prime}(\tau / 2)\right]+\int_{\tau / 2}^{\infty} F^{\prime}(y) \cdot d y
$$

where we have denoted the integrand in Eq. 38 by $F^{\prime}(y)$. Thus,

$$
\frac{\mathrm{df}(\tau)}{\mathrm{d} \tau}=\frac{\mathrm{f}(\tau)}{\tau}-\frac{\mathrm{e}^{-T / 2}}{\tau}\left[\mathrm{I}_{0}(\tau / 2)+\mathrm{I}_{1}(\tau / 2)\right]
$$

By substituting Eqs. 35 and 3.9 into Eq. 33, we get

$$
\begin{aligned}
\mathrm{H}_{\text {epi }}(\tau)= & \frac{-1}{\mathrm{~A}_{\text {epi-norm }}(\tau)} \frac{\mathrm{C}_{2}+2 \mathrm{C}_{3} \mathrm{f}(\tau)+3 \mathrm{C}_{4} \mathrm{f}^{2}(\tau)+\ldots}{\mathrm{A}_{\text {epi-fit }}(0)} \\
& :\left\{\mathrm{f}(\tau)-\mathrm{e}^{\left.-\tau / 2\left[\mathrm{I}_{0}(\tau / 2)+\mathrm{I}_{1}(\tau / 2)\right]\right\}}, \cdots\right.
\end{aligned}
$$

which is plotted as the experimental H-function in Section V.G.

\section{Bare Foils}

The observed activity of the bare foils must be corrected for gamma self-absorption. The corrected bare-foil activity: is defined by

$$
A_{\text {bare }}(t)=A_{\text {bare }}(t) \cdot \gamma(t)
$$

where $t$ is the thickness of the foil, $\gamma(t)$ is the gamma self-absorption function (see Section V.A), and $A_{b a r e}^{\prime}$ is the observed bare-foil activity. 
The bare-foil activity is composed of subcadmium and epicadmium components, and may be written

$$
A_{\text {bare }}(t)=A_{t h}(t)+A_{e p i-f i t}(t)
$$

where $\dot{A}_{\text {epi-fit }}(t)$ is calculated using the coefficients $C_{i}$ (Eq. 32 ) at the foil thicknesses t. Thus we can write

$$
A_{\text {th }}(\tau)=A_{\text {bare }}(\tau)-A_{\text {epi-fit }}(\tau)
$$

The "experimental" subcadmium activation, $A_{t h}(\tau)$, waș fitted by the method of least squares to the equation

$$
A_{t h}(\tau)=D_{1}+D_{2} G(\tau)+D_{3} G^{2}(\tau)+D_{4} G^{3}(\tau)+\ldots
$$

where $G(\tau)$ is the function given in Eq. 8. The computer program used Eqs. 43 and 8 in Eq. 44 to find the $D_{i}$. Since

$$
\lim _{\tau \rightarrow \infty} G(\tau)=0,
$$

and physical reality requires $A_{t h}(\tau)$ to approach zero for large $\tau$, the first coefficient was constrained to be very small, as in the epicadmium case. The weighting factors used for the data points were again calculated according to Eq. 31. The $D_{i}$ calculated by the least-squares subroutine define the fitted subcadmium activity,

$$
A_{\text {th-fit }}(\tau) \equiv D_{1}+D_{2} G(\tau)+D_{3} G^{2}(\tau)+D_{4} G^{3}(\tau)+\ldots
$$

Note that

$$
A_{\text {th-fit }}(0)=\sum_{i} D_{i}
$$

since

$$
\lim _{\tau \rightarrow 0} G(\tau)=1
$$

Thus the sum of the coefficients of the least-squares fit gives the extrapolated value of the activity at zero thickness.: The experimental values, $A_{\text {th }}(\tau)$, and the fitted values, $A_{\text {th-fit }}(\tau)$, of the subcadmium activity were normalized by dividing by $A_{\text {th-fit }}(0)$. These normalized values will be presented, along with the theoretical function $G(\tau)$, in Chapter V.

Eq. 6) as

The $\mathrm{H}$-function for the subcadmium activity is defined (see

$$
\mathrm{H}_{\mathrm{th}}(\tau)=\frac{-\tau}{\mathrm{A}_{\mathrm{th}-\operatorname{norm}}(\tau)} \frac{\mathrm{d}}{\mathrm{d} \tau}\left[\mathrm{A}_{\mathrm{th}-\operatorname{norm}}(\tau)\right]
$$


where $A_{\text {th-norm }}(\tau)$ is the normalized fitted subcadmium activity,

$$
A_{\text {th-norm }}(\tau)=\frac{A_{\text {th-fit }}(\tau)}{A_{\text {th-fit }}(0)}
$$

The derivative of $A_{\text {th-norm }}(\tau)$ is

$$
\frac{\mathrm{d}}{\mathrm{d} \tau}\left[\mathrm{A}_{\mathrm{th}-\operatorname{norm}}(\tau)\right]=\frac{1}{\mathrm{~A}_{\mathrm{th}-\mathrm{fit}}(0)} \cdot \frac{\mathrm{d}}{\mathrm{d} \tau}\left[\mathrm{A}_{\mathrm{th}-\mathrm{fit}}(\tau)\right]
$$

Differentiating Eq. 45 and substituting into Eq. 47 give

$\frac{\mathrm{d}}{\mathrm{d} \tau}\left[\mathrm{A}_{\mathrm{th}-\operatorname{norm}}(\tau)\right]=\frac{1}{\mathrm{~A}_{\mathrm{th}-\mathrm{fit}}(0)}: \frac{\mathrm{dG}(\tau)}{\mathrm{d} \tau}\left[\mathrm{D}_{2}+2 \mathrm{D}_{3} \mathrm{G}(\tau)+3 \mathrm{D}_{4} \mathrm{G}^{2}(\tau)+\ldots\right]$.

Recalling (Eq. 8) that

$$
G(\tau)=\frac{\frac{1}{2}-E_{3}(\tau)}{\tau}
$$

and noting that

$$
\frac{d}{d x}\left[E_{n}(x)\right]=-E_{n-1}(x)
$$

we obtain

$$
\frac{\mathrm{d}}{\mathrm{d} \tau} \mathrm{G}(\tau)=\frac{\mathrm{E}_{2}(\tau)}{\tau}-\frac{\frac{1}{2}-\mathrm{E}_{3}(\tau)}{\tau^{2}}
$$

By substituting Eq. 49 into Eq. 51, we get

$$
\frac{\mathrm{d}}{\mathrm{d} \tau} \mathrm{G}(\tau)=\frac{1}{\tau}\left[\mathrm{E}_{2}(\tau)-\mathrm{G}(\tau)\right]
$$

By substituting Eqs. 48 and 52 into.Eq. 46, we get

$$
\mathrm{H}_{\mathrm{th}}(\tau)=\frac{-1}{A_{\text {th-norm }}(\tau)}\left[\frac{D_{2}+2 \mathrm{D}_{3} \mathrm{G}(\tau)+3 \mathrm{D}_{4} \mathrm{G}^{2}(\tau)}{\because A_{\mathrm{th}-\mathrm{fit}}(0)}\right]\left[\mathrm{E}_{2}(\tau)-\mathrm{G}(\tau)\right],
$$

which is plotted as the experimental H-function in Section V.G.

D. Graph Plotting

Most of the graphs in this report were plotted by a CalComp-565 plotting machine in conjunction. with the ANL Reactor Physics Laboratory's DDP-24 computer, using a FORTRAN program written for the purpose. 


\section{EXPERIMENTAL RESULTS}

A. Correction Factor for Gamma Scattering and Self-absorption

To determine the correction factor for self-absorption and scattering of gamma rays during counting, a stack of thin foils was used to approximate a thick foil. To eliminate edge effects due to uneven stacking, the entire stack was punched at once. After the stacks were punched in this manner with the gold dry, the stack could not be separated without damaging the individual layers. Therefore the foils were dipped in silicone oil before being stacked for punching. The stacks used in this experiment were $0.5,1$, 3 , and 7 mils thick.

The 0.5-mil foil was punched from a stack of five layers of 0.1 -mil gold, the 1-mil foil from a stack of ten layers of 0.1-mil gold, the 3-mil foil from a stack of ten layers of $0.3-\mathrm{mil}$ gold, and the 7-mil foil from a stack of seven layers of 1 -mil gold. These stacks were counted intact, and then taken apart for the individual layers to be counted separately. The separation was accomplished by placing the stack on a flat clean eraser and applying pressure to the top of the stack with a pencil eraser to slide the layers apart.

For each thickness, the self-absorption correction factor was calculated from the ratio of the sum of the counts of the individual layers to the counts of the stack. The counts of the individual layers of the 0.5-, 1-, and 3-mil stacks were summed without applying a correction, assuming that

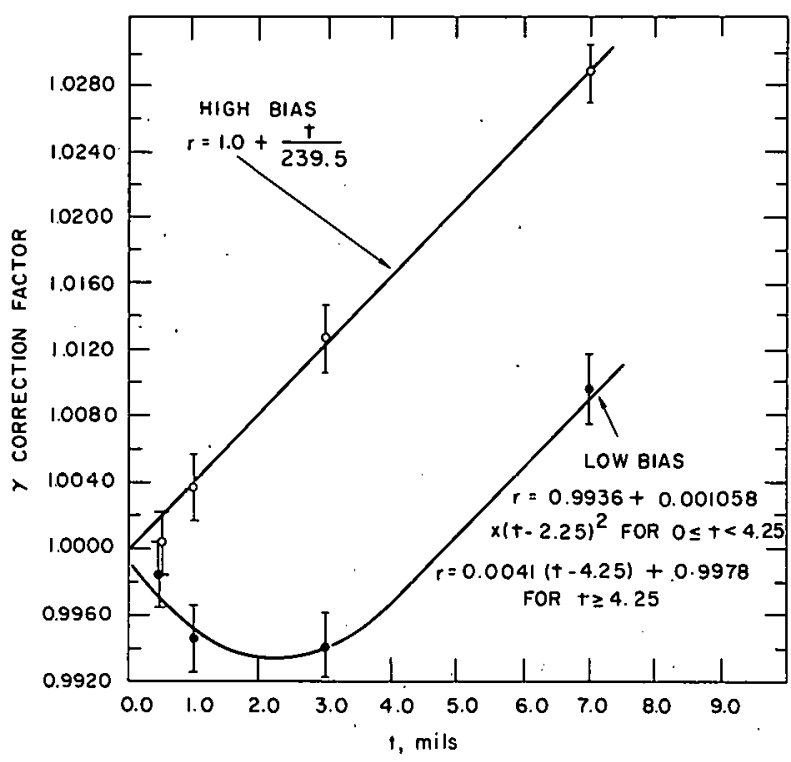

$112-8128$ Rev. 1

Fig. 4. Correction Factor for Gamma Scattering and Self-absorption in a Gold Foil as a Function of Foil Thickness there is a negligible self-absorption in foils of thickness 0.1 and $0.3 \mathrm{mil}$. However, the counts of the individual layers (each layer was 1 mil thick) of the 7-mil stack were corrected for gamma self-absorption. The counts of the individual layers were multiplied by the correction factor obtained from the 1-mil stack, before being summed.

Figure 4 shows the correction as a function of thickness for a high and a low bias setting.

The behavior of the selfabsorption correction function for the low bias setting was at first somewhat surprising. However, the initial negative slope, with a minimum near a thickness of 2 mils, can 
be ascribed to the detection of gamma rays with degraded energy due to Compton scattering in the foil, and of $X$ rays due to photo-events in the foil. These effects would lead to increased detection of low-energy pulses, since such interactions would occur with highest probability for those gammas with long paths in the foil, which therefore were not originally directed toward one of the detectors. Supplementing that geometrical consideration is the increased efficiency of the NaI crystal for low-energy radiations. As the foil thickness increases still further, the increase in self-absorption overcomes the increased Compton scattering and X-ray production in the foil. These conclusions are further supported by the observations reported in Section B below. Since the correction factor for gamma self-absorption depends to some extent on the counting geometry, for highest accuracy the çorrection must be determined separately for each system--particularly if a low counting bias is used.

The curves and equations shown in Fig. 4 are approximate fits to the data. In the STANSECO processing, the first equation shown for the lowbias case was used over the entire range of thicknesses. That approximation would lead to an error of approximately $1 \%$ in the last datum point; the others would be unaffected.

To get the data for Fig. 4, the foil stacks were irradiated in ATSR in the rabbit facility, which happened to be cadmium lined. The resulting correction curves were assumed to be applicable to both bare and cadmiumcovered foils; therefore the data for the thickness-correction experiment were processed on that basis. It has turned out, however, that that assumption was not valid. This will be discussed more fully in Appendix $F$.

\section{B. Ratio of Low - to High-bias Counts as a Function of Thickness}

The ratio of the low - to high-bias activities as a function of foil thickness was initially expected to be constant. The computer program COMBO was used to calculate the ratios for the different foil thicknesses, and the ratios were effectively constant (minor scatter) in the region of thin foils (less than $0.2 \mathrm{mil}$ ). However, as $t$ increased above $0.2 \mathrm{mil}$, the ratios steadily.increased.

Multichannel pulse-height spectra were obtained for a 6 -mil foil. and a $0.2-\mathrm{mil}$ foil. The $\mathrm{X}$-ray peak near $70 \mathrm{keV}$ (due to both mercury and gold $X$ rays) was observed to be about $50 \%$ more intense for the thicker foil, relative to the photopeak intensity. The low-energy portion of the Compton spectrum was also more intense (by about 20\%). These differences were compatible with the observed integral count-rate ratio differences.

The gold $X$ rays contribute much more to the $X$-ray peak than do the mercury $X$ rays. In fact, the gold $X$ rays increase as $t$ increases, while the mercury $X$ rays decrease as $t$ increases, as can be seen by a detailed 
look at the decay schemes. Consider the decay of the first excited state of

${ }^{198} \mathrm{Hg}$. Three percent of these decays are by internal conversion, with the emission of an oribital electron and an ensuing mercury $X$ ray. In the other $97 \%$ of the decays, a $412-\mathrm{keV}$ gamma ray leaves the mercury atom. This gamma ray has some probability $X$ of interacting with an electron in one of the surrounding gold atoms, leading to the emission of a gold $X$ ray. Thus a fraction $(1-X)$ of the emitted gamma rays escape from the foil. Some of them interact with one of the detector crystals and are counted; others are absorbed in surrounding material, such as the lead shield, causing more $\mathrm{X}$ rays.

Of the internal-conversion $\mathrm{X}$ rays, some fraction $\mathrm{Y}$ will be absorbed in the surrounding gold, and more gold $X$ rays will result. Some of the remaining mercury $X$ rays will reach the detector crystals.

Therefore as the foil thickness increases, the number of gold $X$ rays increases ( $X$ increases because there are more gold atoms present for the gamma ray to interact with) and the number of unscattered gamma rays counted decreases $[(1-X)$ goes down]. Thus the high-bias (specific) activity, where the $X$ rays and Compton-scattered $X$ rays are not counted, decreases, as the foil thickness increases, more rapidly than the low-bias activity. The effect is mainly due to gold $X$ rays. (and Compton scattering) rather than mercury $X$ rays, because as the foil thickness increases, the probability of the mercury $X$ rays escaping from the foil and being counted decreases (1-Y decreases). Thus as the foil thickness increases, a greater percentage of mercury $X$ rays will be transformed into gold $X$ rays by interaction with the surrounding gold atoms.

C. Flux Isotropy

The isotropy of the flux was determined by irradiating a group of $1-$ mil foils on the wheel assembly located in the graphite the rmal column of ATSR (described in Section III.B). Twelve l-mil foils were taped to the aluminum wheel near its periphery, alternately in the plane of the wheel and perpendicular to the wheel. Three of the foils in the plane of the wheel and three of the ones perpendicular to the wheel were cadmium covered, and the rest were aluminum covered. The foils were counted in the automatic system described in Section III.C, and the data were processed by RP- 202 . The average specific activity of the bare foils in the plane of the wheel was $1 \%$ higher than for the bare foils perpendicular to the wheel; the average specific activity of the cadmium-covered foils in the plane of the wheel was $6 \%$ higher than for the cadmium-covered foils perpendicular to the wheel. This difference is reasonably consistent with the cadmium ratio for a l-mil foil $(\sim 5)$, since the much higher self-shielding for epicadmium neutrons causes the epicadmium activation to be a more sensitive indicator of flux anisotropy. Thus the effective epicadmium flux seen by the rotating foils was observably nonisotropic, presumably because the foot-square void in 
which the irradiation was performed was open at the top. Anisotropy had no observable effect on the subcadmium activation of the 1 -mil foils. The experiment was not repeated with thicker foils.

As will be shown in Section D below, there was generally good agreement between the observed epicadmium self-shielding for this slightly nonisotropic flux and the theory for isotropic flux.

D. Epicadmium Self-shielding

Figures 5-9 are curves showing the epicadmium activation as a function of foil thickness. The first six data points are for the evaporated foils. As mentioned in Section III.C above, the foils were counted in two independent (but similar) counting systems, in each case at two bias settings. Figures 5 and 6 show the North Counting Room low-bias data, fitted to Eq. 30 using three and four coefficients, respectively. Including the fourth (cubic) term leads to a somewhat better fit to the data, and also to better agreement with the calculations of Baumann. ${ }^{11}$ Those calculations included factors for the nine strongest resonances, the epicadmium $1 / \mathrm{v}$ component, and the effect of Doppler broadening. Considering the slight flux anisotropy referred to in Section $\mathrm{C}$ above, the agreement between theory and measurement is regarded as satisfactory.

Also plotted in Figs. 5 and 6 is the single-resonance function of Trubey, Blosser, and Estabrook. ${ }^{5}$ This curve has the shape that would be provided by a two-coefficient fitting of the data to Eq. 30. Clearly, high accuracy requires more than a single-resonance treatment.

Curves for three- and four-coefficient fits are plotted in Fig. 7, where the difference between them can more clearly be seen.

As can be seen from Fig. 8, the agreement between the high-bias (photopeak and above) and low-bias ( $\mathrm{X}$ rays and above) results is very close, which confirms that the gamma-ray self-absorption correction curves of Fig. 4 are reasonably correct, for epicadmium activation.

In three of the four cases, the results from the two counting rooms were indistinguishable, indicating that the counting statistics obtained were more than adequate, and that any effects of the minor differences in counting geometry were undetectable. Figure 9 shows the kind of agreement obtained. The one exception was in the case of the low-bias, subcadmium activity, where there was a rather marked difference in the curves for the two counting systems. In this case, the biases may not have been the same in the two systems, and this would have led to differences in the effects of gamma-ray scattering and self-absorption (as discussed in Section $\mathrm{E}$ below). 


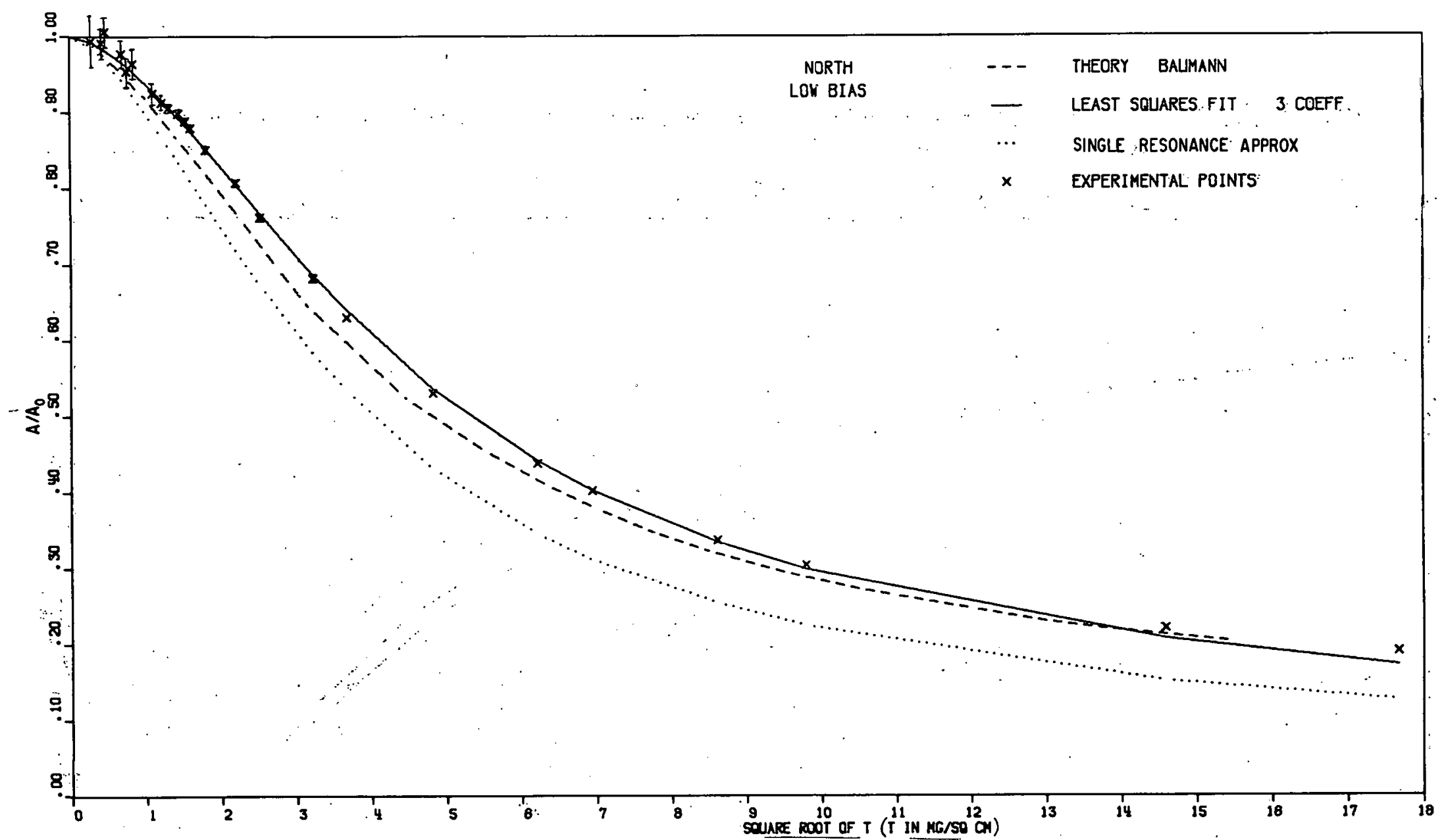

$112-8139$

Fig. 5. Experimental and Theoretical Epicadmium Activaticn as a Function of Foil Thickness, with a Three-coefficient Fit to the Data 


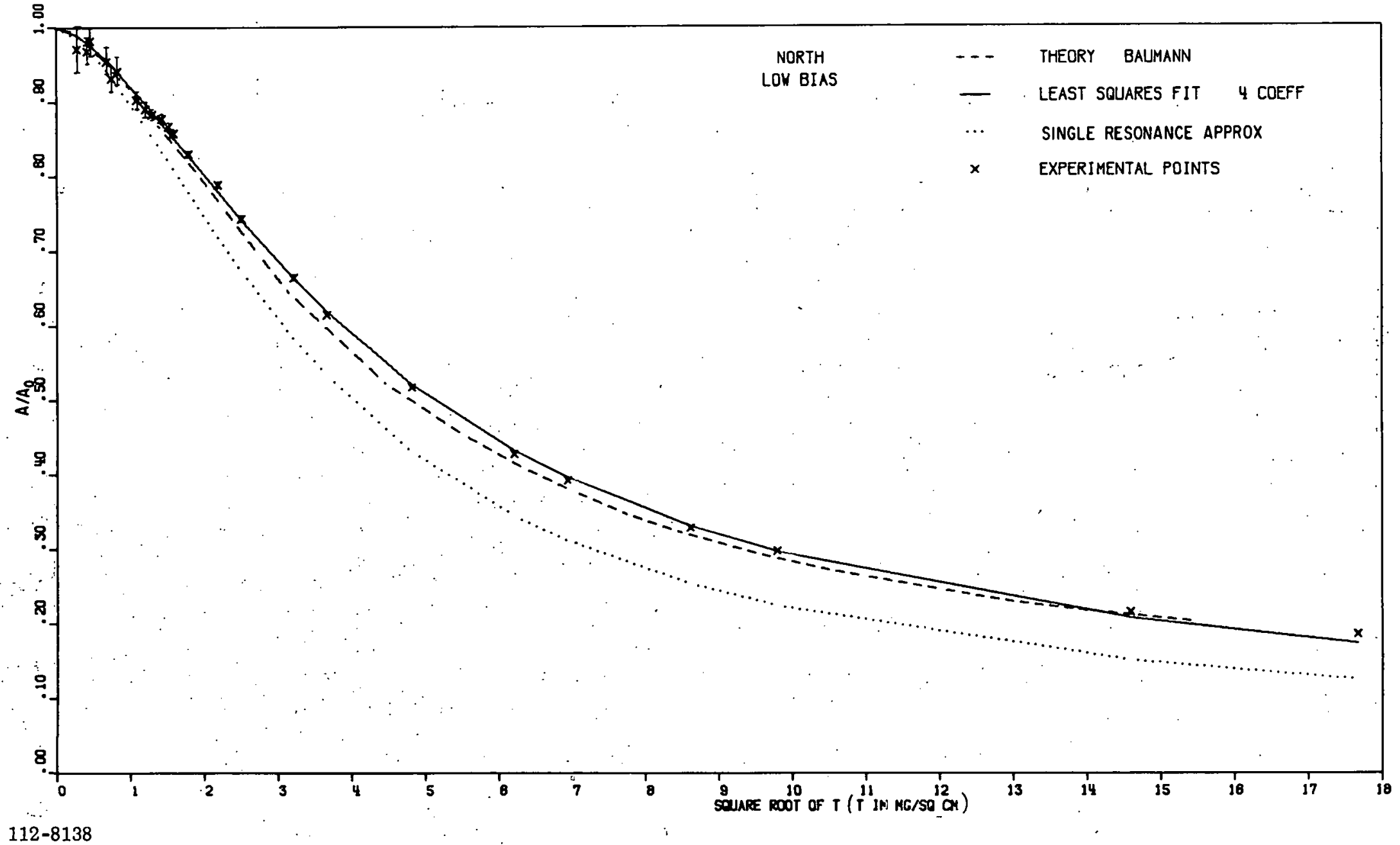
112-8138

Fig. 6. Experimental and Theoretical Epicadmium Activation as a Function of Foil Thickness, with a Four-coefficient Fit to the Data 


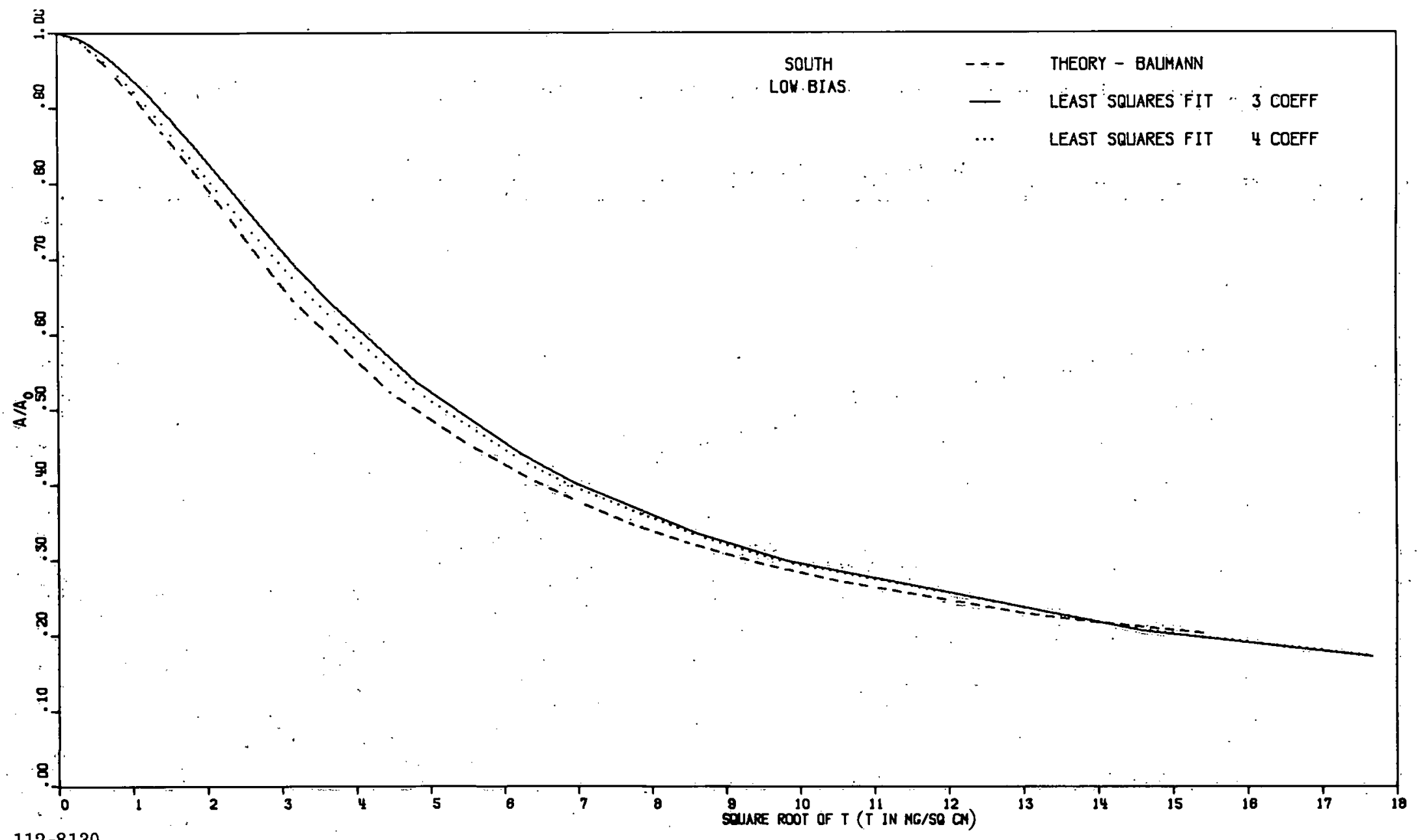

$112-8130$

Fig. 7. Comparison of Experimental Epicadmium Self-shielding Curve for a Three-coefficient Fit with That for a Four-coefficient Fit 


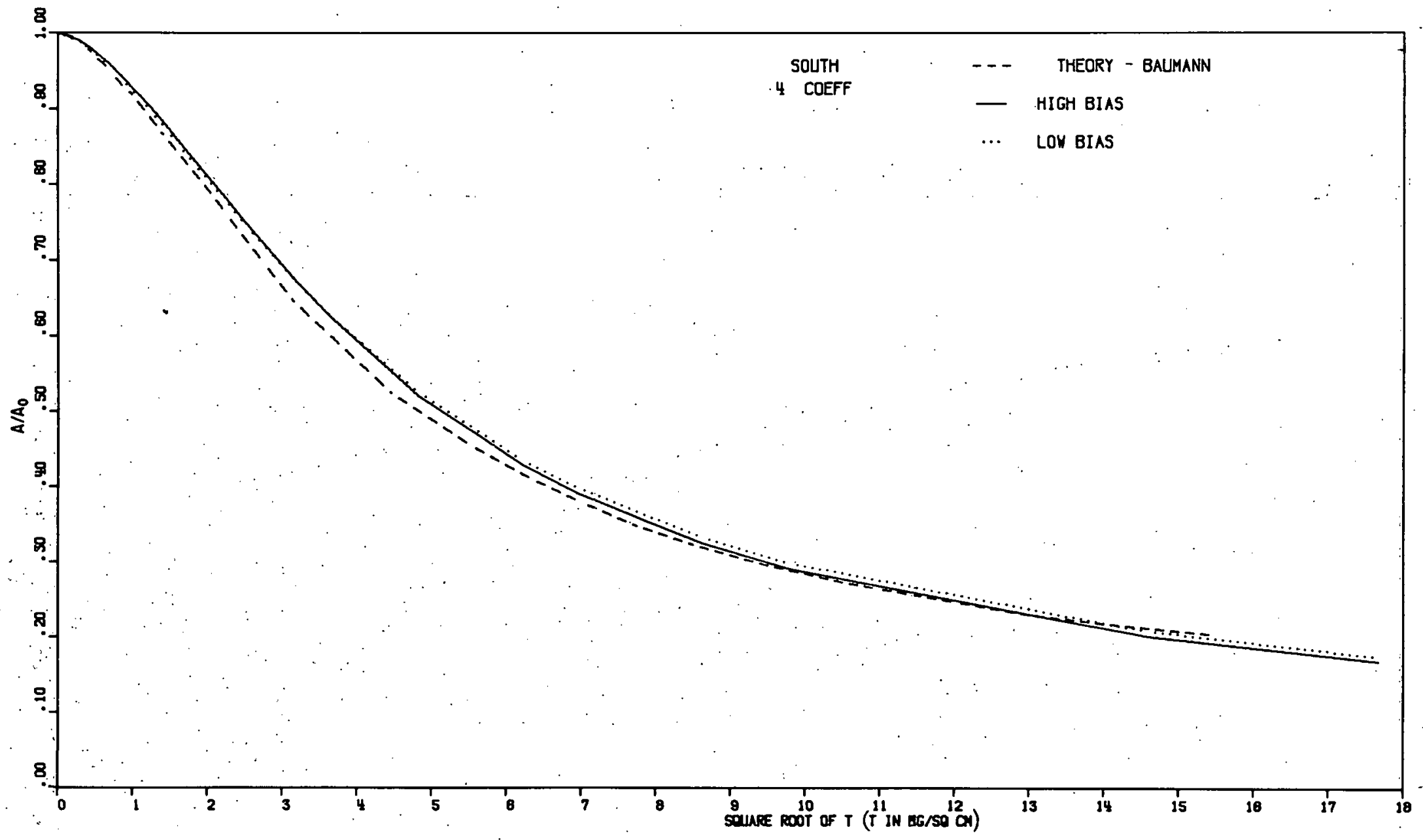

$112-8131$

Fig. 8. Comparison of Experimental Epicadmium Self-shielding Curve for High-bias Counting with That for Low-bias Counting 


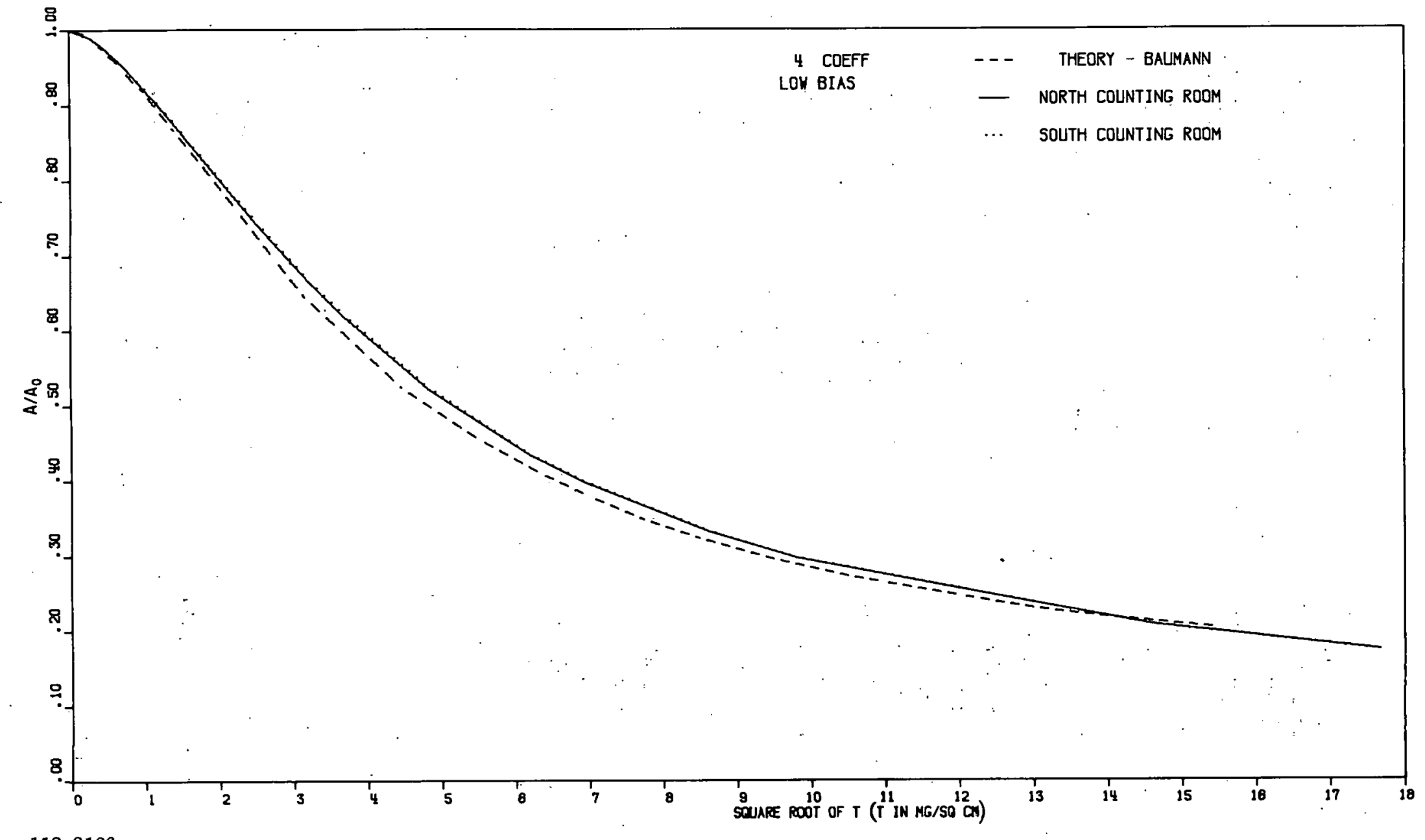

$112-8136$

Fig. 9. Comparison of Experimental Epicadmium Self-shielding Curve for the North Counting Room with That for the South Counting Room 
E. Thermal Self-shielding

The subcadmium activation data for the North Counting Room are presented in Figs. 10 and 11 , where again the first six points are for evaporated foils. The ordinates for the plotted points were calculated according to Eqs. 41 and 43, using for the gamma self-absorption correction $\gamma(t)$ the functions as determined from cadmium-covered foils (see Section V.A). The divergence between the high-bias and low-bias results is evident in Fig. 12.

As mentioned in Section A above, we first assumed that $\gamma(t)$ would be the same for both bare and cadmium-covered foils. However, in Appendix $F$ we show that that is not the case, with indications that at least the difference between the high-and low-bias results can be explained on that basis. The question of whether the discrepancy between the high-bias curve and the theoretical one (Eq. 8) is also due to this cause has not been settled experimentally. However, for purposes of making corrections for weight differences of the order of $10 \%$, this discrepancy is small (note the suppressed zero in Figs. 10-13), as will be shown more fully in Section G below.

The low-bias subcadmium results for the two counting rooms are plotted together in Fig. 13. As mentioned in Section D above, this is the only case in which there was an appreciable difference in the results for the two counting systems.

In counting activated gold foils, one should set the bias so as to reject pulses below and including the Compton counts from the $41 \mathrm{l}-\mathrm{keV}$ gamma ray. Alternatively, highest precision requires a separate determination of $\gamma(t)$ for each bias setting and each counting system, and also independently for subcadmium and epicadmium activation.

The bare-foil, low-bias data were corrected using the (insufficient) low-bias function from Fig. 4. Without this correction, the initial slope of the subcadmium activation curves would have been positive. Zobel, ${ }^{12}$ in the course of somewhat similar measurements, observed such an anomaly.

F. Cadmium Ratios

Jacks ${ }^{13}$ has reported cadmium ratios for a range of gold-foil thicknesses. The foils were irradiated in voids in graphite assemblies; hence, Jacks' results are convenient for comparison with the results of the present work. To use Jacks' cadmium ratios, we had to adjust them for the difference in cadmium thickness (30 mils instead of 20), and then apply a normalizing factor. 


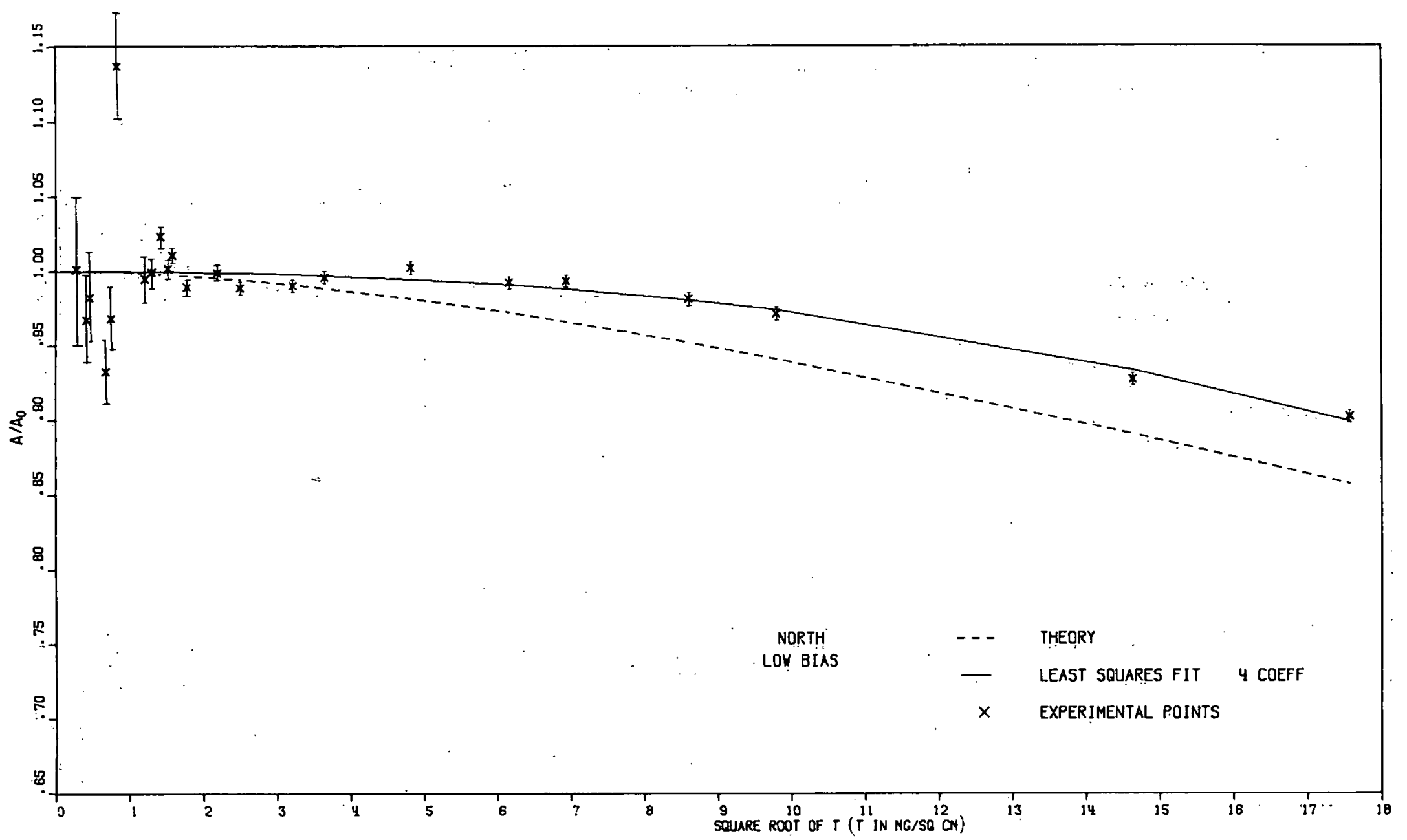

$112-8133$

Fig. 10. Experimentally Determined Subcadmium Activation as a Function of Foil Thickness for a Four-coefficient Fit to the Data, Compared with Theory; Low-bias Counting 


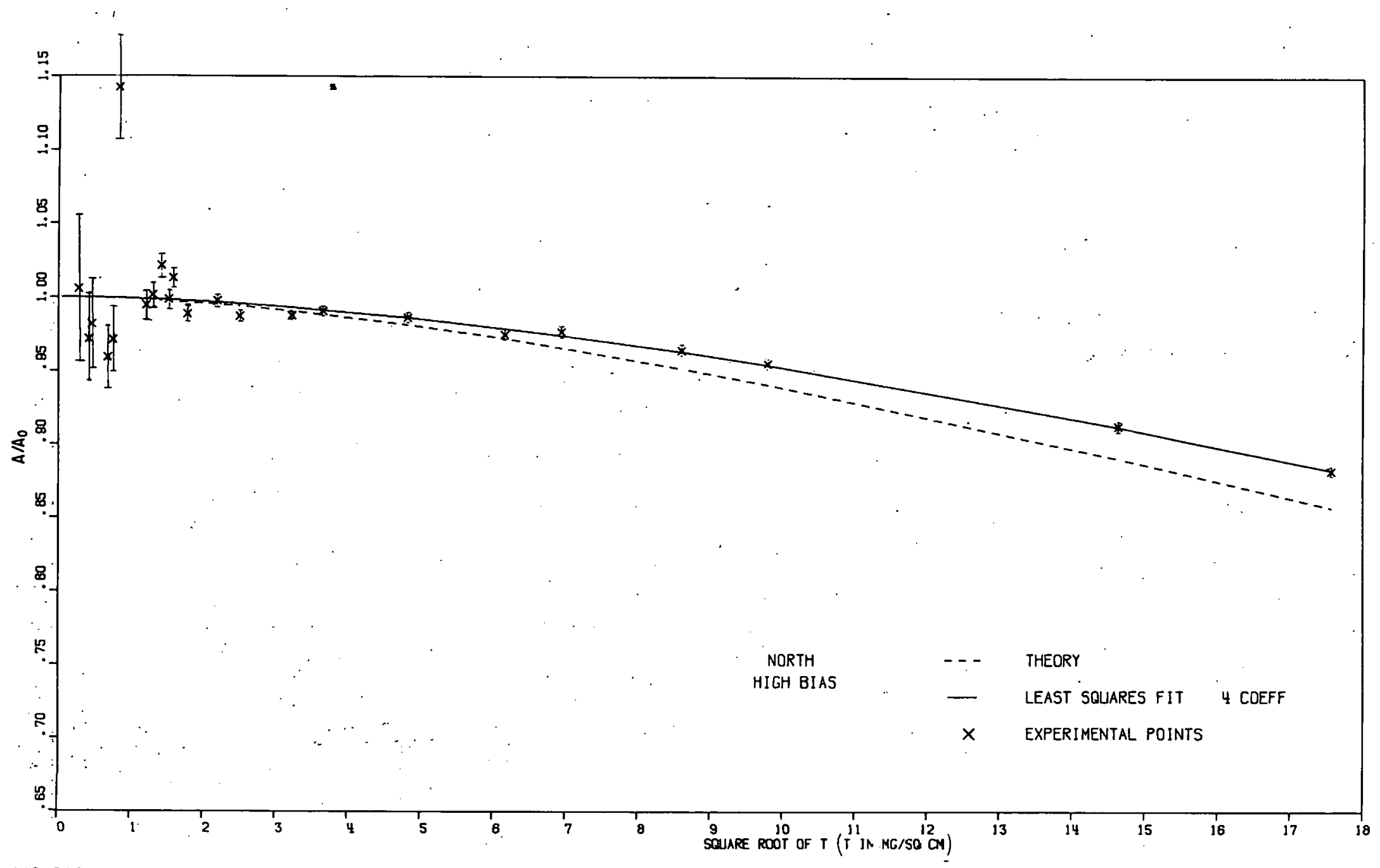

112-8132

Fig. 11. Experimentally Determined Subcadmium Activation as a Fuzction of Foil Thickness for a Four-coefficient Fit to the Data, Compared with Theory; High-bias Counting 


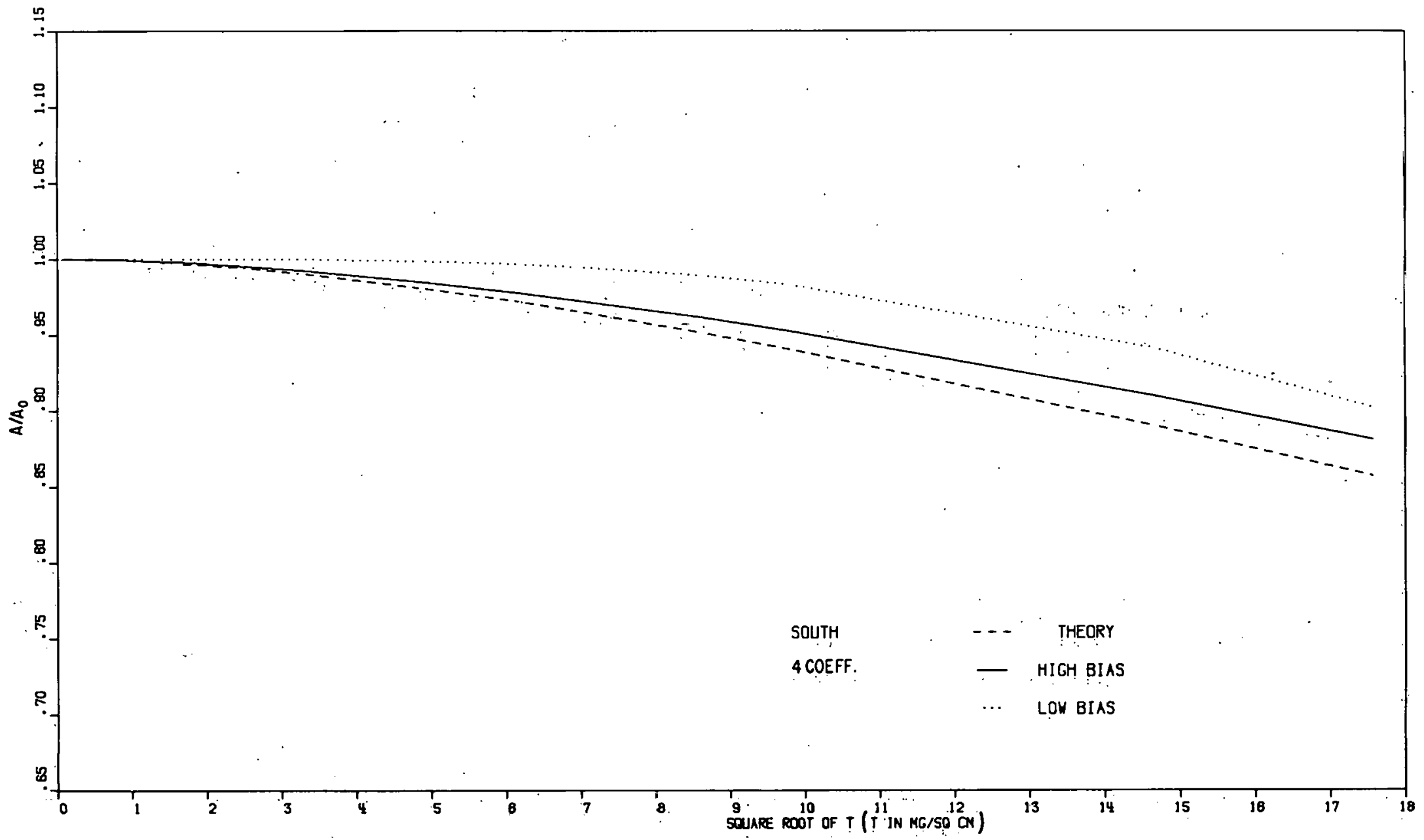

112-8134

Fig. 12. Comparison of Experimental Subcadmium Self-shielding Factor for a High Bias with That for a Low Bias 


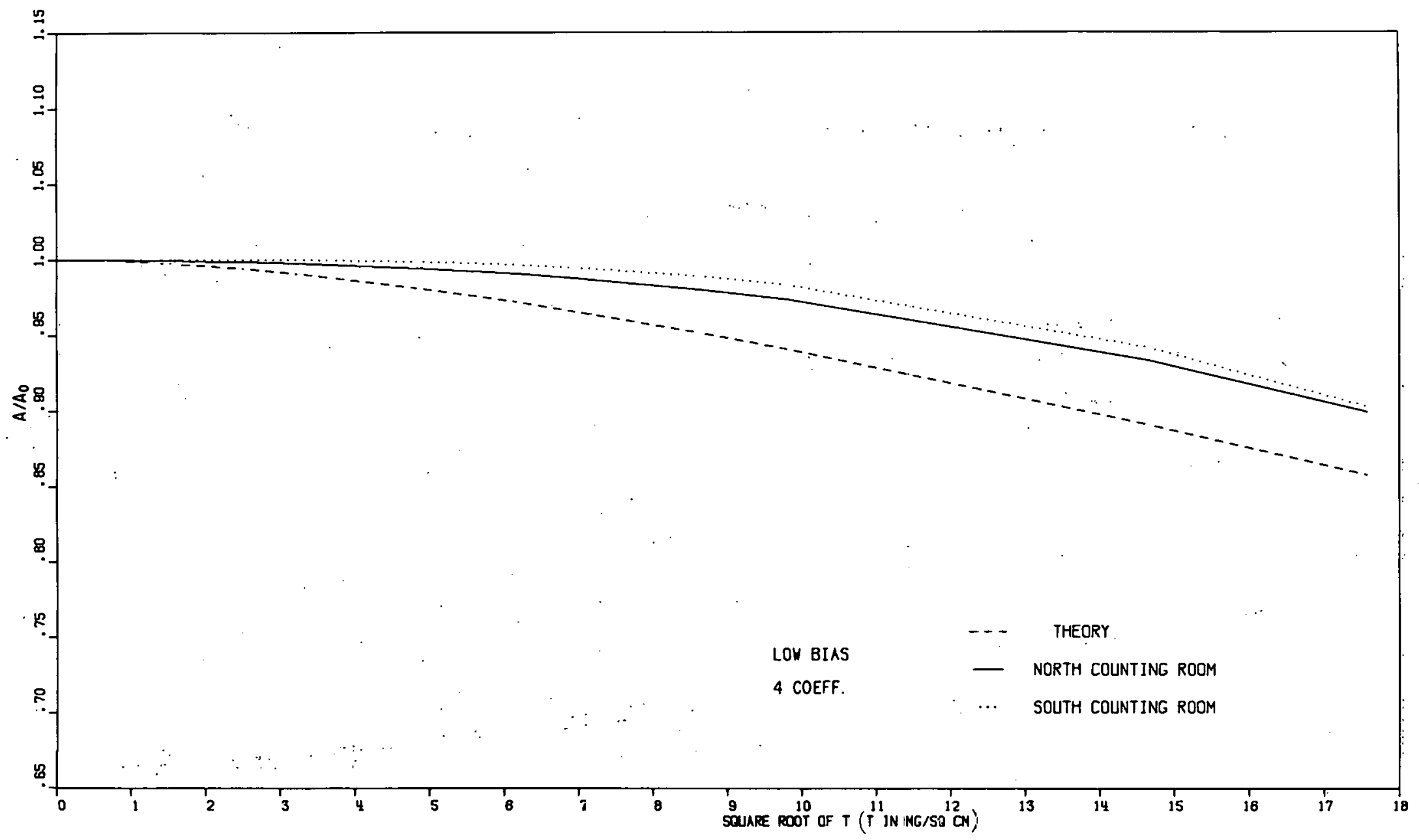

112-8129

Fig. 13. Comparison of Experimental Subcadmium Self-shielding Factor for North Counting Room with That for South Counting Room; Low-bias Counting 
The adjusted.cadmium ratio $\mathrm{CdR}_{\mathrm{J}}$ is given by

$$
\mathrm{CdR}_{\mathrm{J}}(\mathrm{t})=\frac{\mathrm{F}_{\mathrm{Cd}}(20)}{F_{\mathrm{Cd}}(30)} \mathrm{CdR}_{\mathrm{J}}(\mathrm{t}) \frac{1}{\mathrm{~F}_{\mathrm{t}}}
$$

where $F_{C d}$ and $F_{t}$ are cadmium correction factors, as defined in Ref. 9. The normalizing factor $\mathrm{N}_{J}$ was determined from

$$
N_{J}=\frac{1}{n} \sum_{j=1}^{n} \frac{C d R_{S}\left(t_{j}\right)-1}{C d R_{J}\left(t_{j}\right)-1}
$$

where $n$ is the number of different thicknesses $t_{j}$ used by Jacks, and the $\mathrm{CdR}_{S}\left(t_{j}\right)$ are caliculated from the fitted curves for the present set of measurements.

The results of the comparison are shown in Figs. 14 and 15, where the data points attributed to Jacks are the normalized values

$$
\mathrm{N}_{\mathrm{J}}\left[\mathrm{CdR} J\left(\mathrm{t}_{\mathrm{j}}\right)-1\right]
$$

Both.the three- and four-coefficient curves are plotted, although the four-. coefficient results were better fits to the data. There is good agreement between the two experiments for gold thicknesses. less than approximately 4 mils. The disagreement for the thickest foil is not understood.

G. Weight-correction Curves

The formulas for making weight corrections to gold-foil activations were derived in Chapter II: for cadmium-covered foils, Eqs: I and 20, and and for bare foils, Eqs. 5 and.21. To apply these formulas, one must know the appropriate values of $\mathrm{H}_{\mathrm{epi}}$ and $\mathrm{H}_{\text {th }}$. The STANSECO program calculated those functions from the curves fitted to the experimental points, using Eqs. 40 and 53, and also from the theoretical functions. The results are presented in Figs: 16 and 17. For comparison, Fig. 16 includes the calculations based on the three-coefficient fits. However, it will be remembered that the data were better fitted.by using four coefficients.

Figure 1.7, which is for the subcadmium component, used only the high-bias results. As discussed in Section A above, good correction factors were not available for correcting the low-bias, bare-foil data for gamma-ray scattering and self-absorption. Figures 11 and 12 showed that the highbias data. for the bare foils, as corrected with the available gamma selfabsorption correction function, deviated somewhat from the theoretical predictions. Figure 17 shows the effect of this deviation upon the $\mathrm{H}_{\text {th }}$ function. It will shortly be shown that for normal weight-correction purposes, the difference is negligible. 


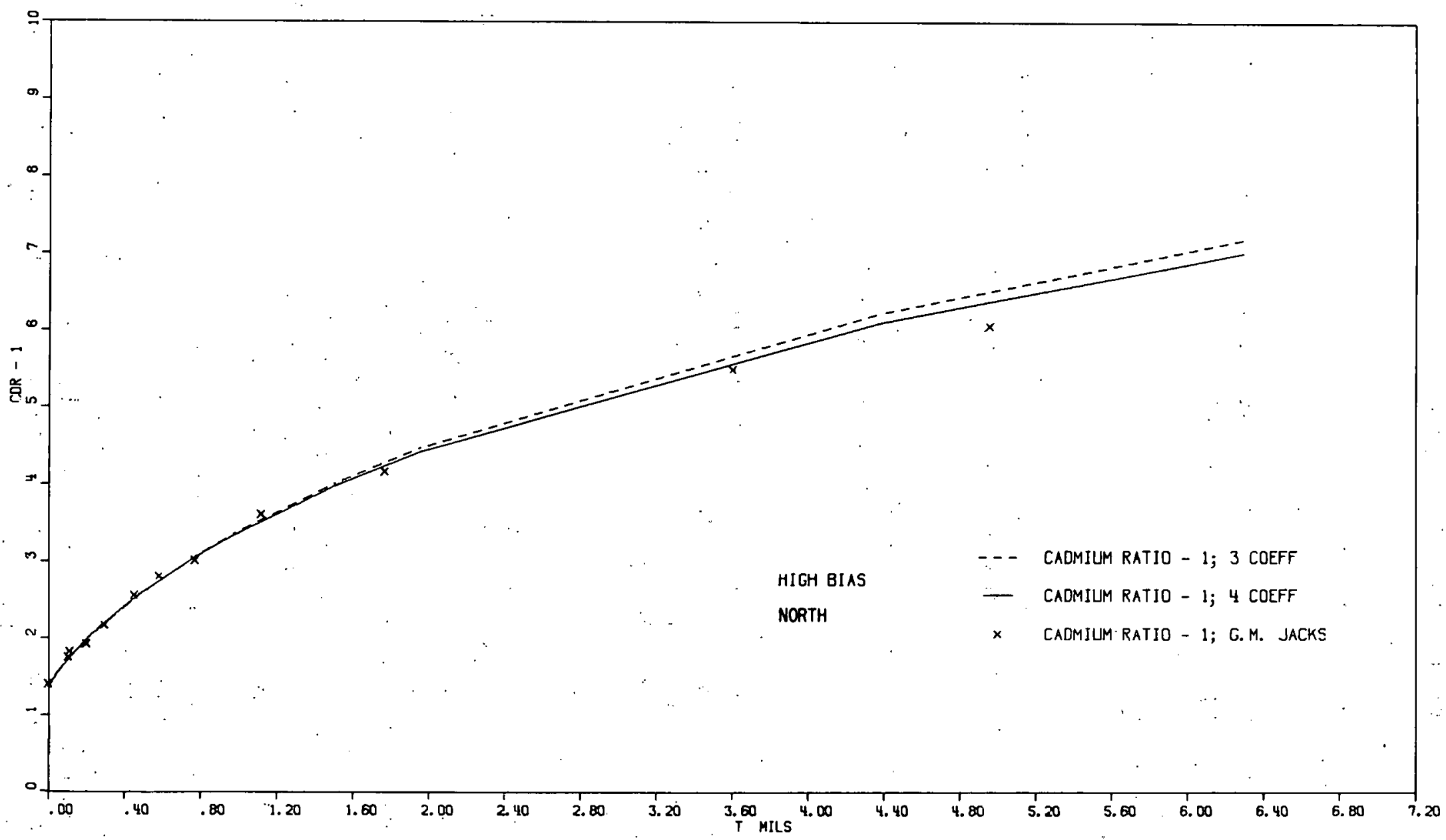

$112-8137$

Fig. 14. Comparison of Experimental Cadmium Ratio from Present Work with Cadmium Ratic Determined by Jacks; High-bias Counting 


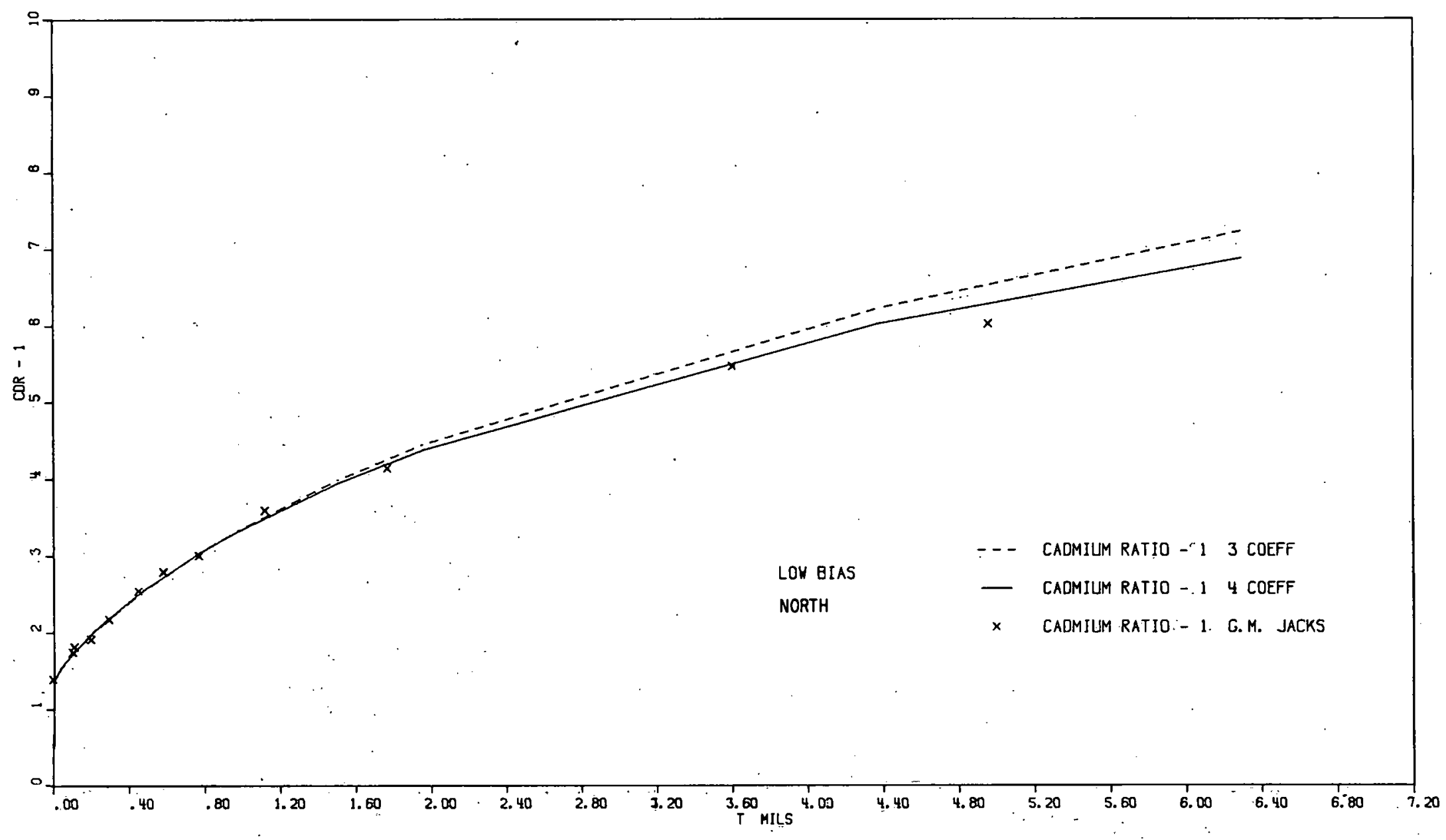

112-8135

Fig. 15. Comparison of Experimental Cadmium Ratio from Fresent Work with Cadmium Ratio Determined by Jacks; Low-bias Counting 


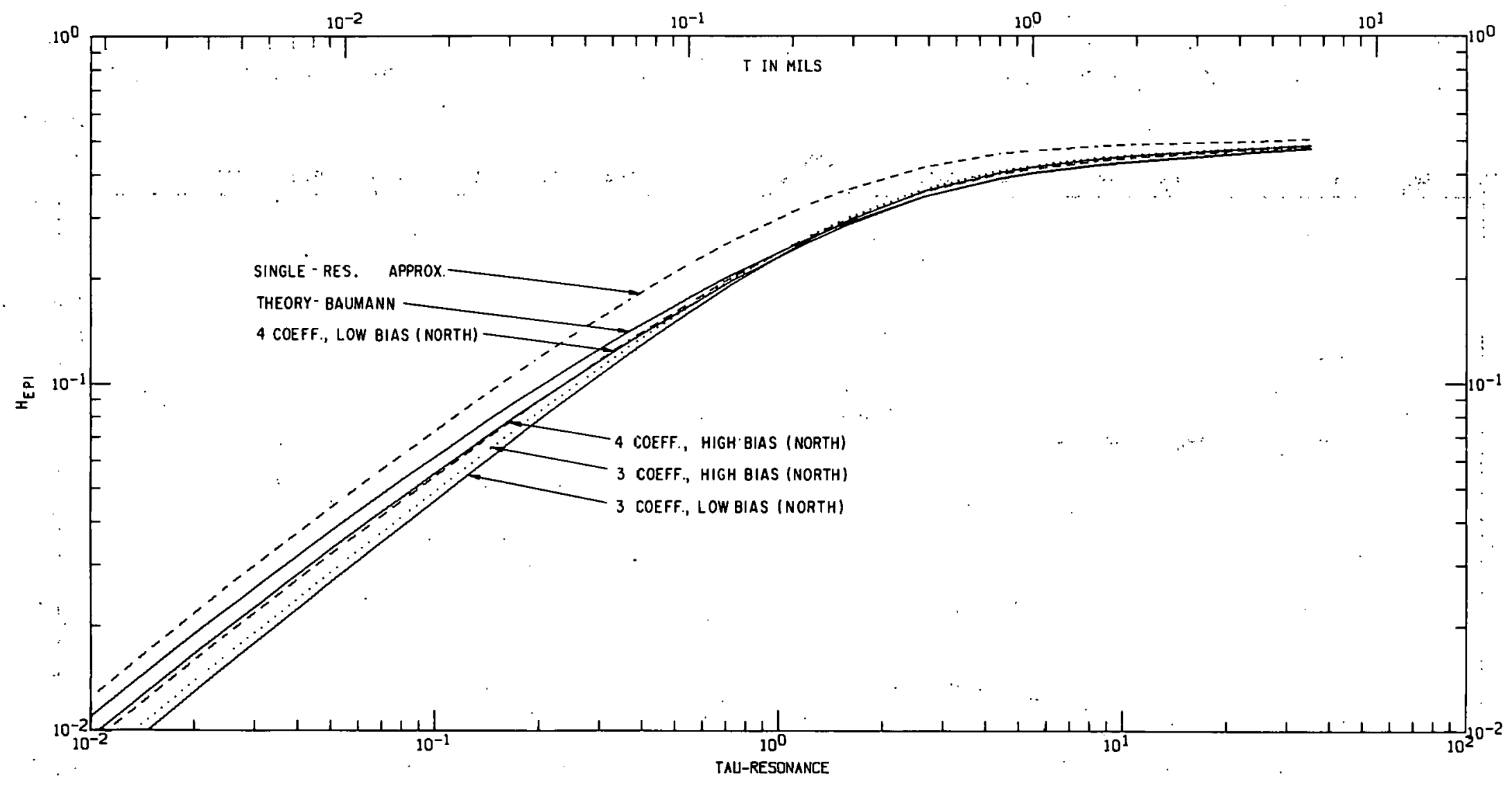

$112-8141$

Fig. 16. Thickness-correction Function for Resonance Activation of Gold Foils 


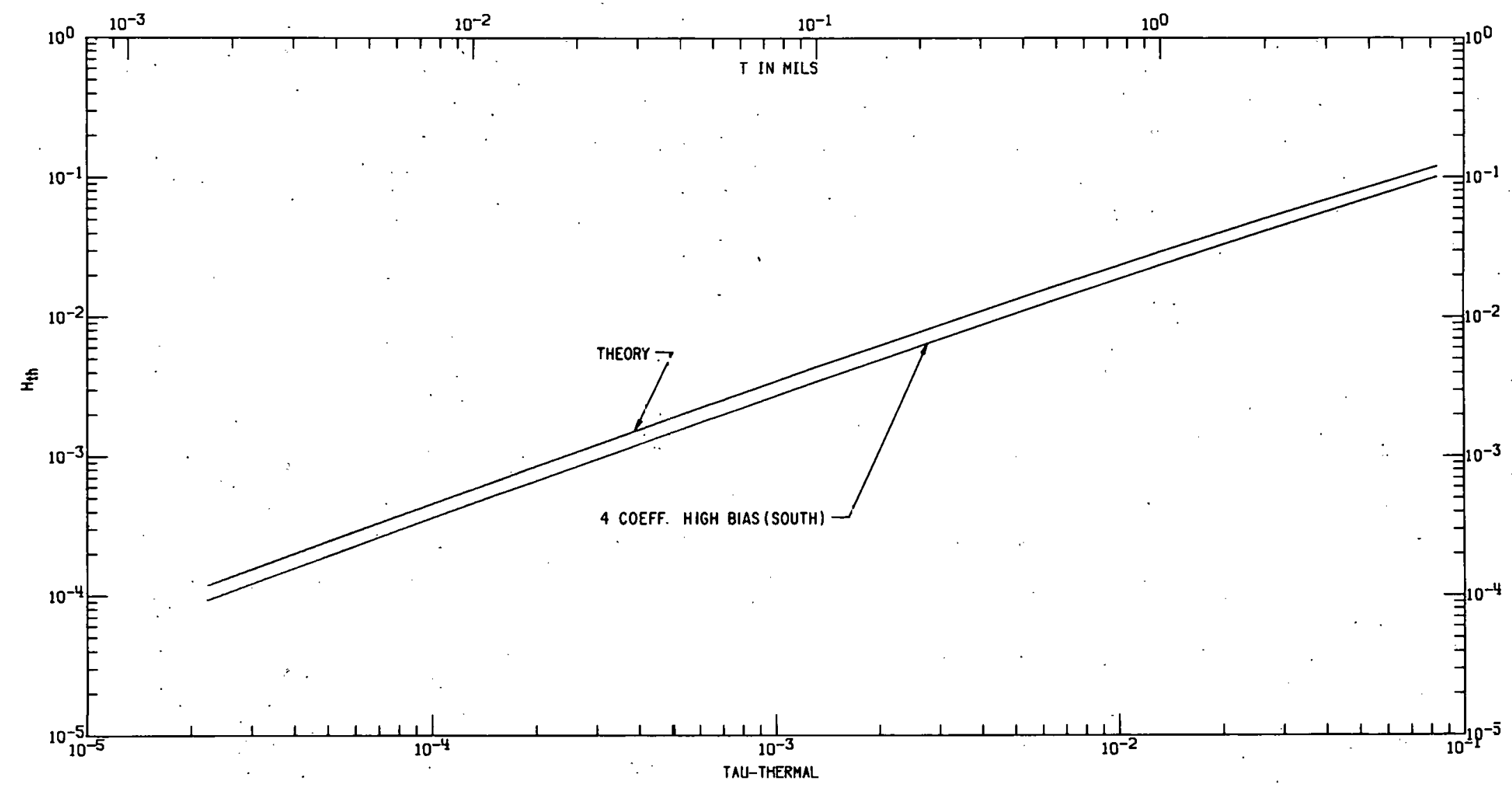

$112-8140$

Fig. 17. Thickness-correction Function for Thermal Activation of Gold Foils 
In the epicadmium case (Fig. 16), there is good agreement between the $\mathrm{H}$-functions calculated for the present experimental data and the one calculated for Baumann's theoretical values in the region above $0.1 \mathrm{mil}$. The deviation in $\mathrm{H}_{\mathrm{epi}}$ that exists in this region does not appreciably affect the weight-correction factor. For example, at $1 \mathrm{mil}$ an error of $7 \%$ in

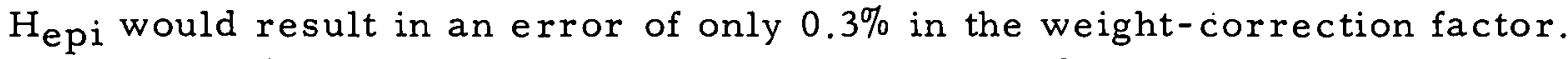
The larger deviation between the experimental and theoretical $\mathrm{H}$-function in the region below $0.1 \mathrm{mil}$ is not critical because the correction factor $\delta$ (see Eqs. 1, 5, 20, and 21) for normal weight differences is small in that region. This is demonstrated by the following calculations:

1. At $0.1 \mathrm{mil}$, the re is a spread of approximately $7.3 \%$ in the values of $\mathrm{H}_{\text {epi }}$, but this corresponds to a range of only $0.1 \%$ in the weightcorrection factor, $\delta_{\text {res }}$.

2. At $0.1 \mathrm{mil}$, an increase of $40 \%$ in $\mathrm{H}_{\text {epi }}$ again results in a change of only $0.1 \%$ in $\delta_{\text {epi }}$.

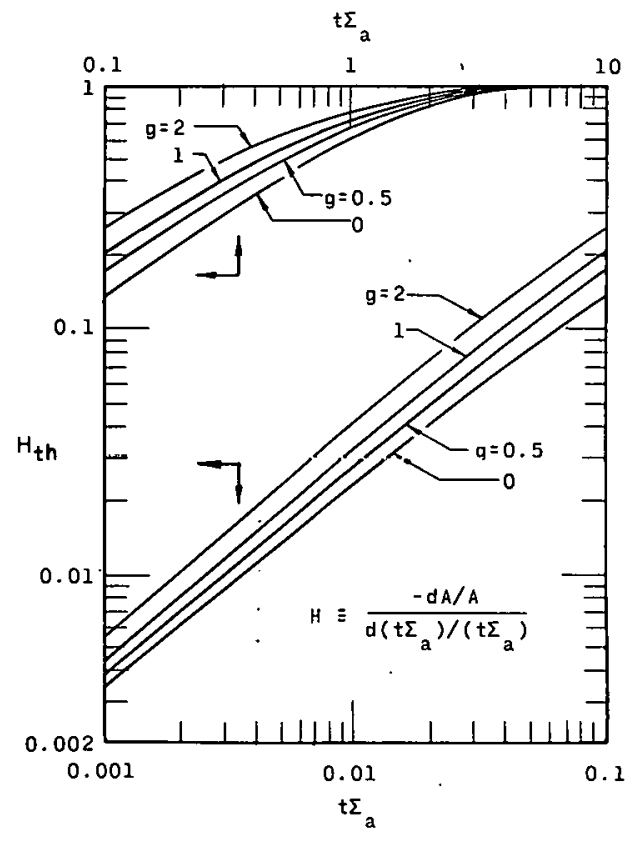

112-1724 Rev. 1

Fig. 18. Calculated Thickness-correction Function for Thermal Activation of Gold Foils (from Ref. 1)
3. Similarly, for the thermal case, decreasing $\mathrm{H}_{\text {th }}$ by $35 \%$ leads to changes in $\delta_{\text {th }}$ of only $0.1,0.02$, and $0.002 \%$ at thicknesses of $1,0.1$, and $0.01 \mathrm{mil}$, respectively.

Thus one can choose any value of $\mathrm{H}$ within the bands of values presented in Figs. 16 and 17 and still have good accuracy in the calculation of the weight-correction factor.

For irradiations other than in a void, the factor $\mathrm{g}$ in Eq. 7 will in general be nonzero. Figure 18 (from Ref. 1) shows the calculated values of $\mathrm{H}_{\text {th }}$ for several values of $\mathrm{g}$, and also for thicker foils than are included in Fig. 17. In comparing Figs. 16 and 18 , note that $H_{\text {th }}$ approaches unity for very thick foils, while $\mathrm{H}_{\text {epi }}$ levels off at about half that value. The reason for the difference is that, unlike the thermal-absorption cross section, the epithermal cross section varies

over a very large range, so that foils that are heavily self-shielded for resonance-energy neutrons can still be relatively transparent to neutrons of other energies. 


\section{VI。ACCURACY}

\section{A. Approximations}

Starting with Eqs. 20 and 21, we can make a series of approximations, each one resulting in simpler expressions, along with some loss of accuracy. Approximations appropriate for $25-\mu(1-\mathrm{mil})$ gold foils are considered in this section, with some illustrative calculations.

\section{Accurate Formulas}

In principle, the only approximation involved in Eqs. 20 and 31 is the one expressed by Eqs. 15 and 16--namely, that the specific activation $A$ is a linear function of the foil thickness in the interval between $\tau_{0}$ and $\tau_{1}$. This is a good assumption for thickness variations $\leqslant \pm 10 \%$. However, as was remarked in Section II.D, evaluating the $\mathrm{H}$-function separately for each individual foil is not convenient, and Eqs. 22 and 23 use the values of $\mathrm{H}_{\text {epi }}$ and $H_{\text {th }}$ for the nominal thickness $t_{0}$. Fortunately, this is an excellent approximation for all gold foils that are not unreasonably thick: $H_{\text {th }}$ is small $(<0.1)$ for foils thinner than about 5 mils (Fig. 17), so that thickness corrections are insensitive to errors in it (see Section V.G); $\mathrm{H}_{\text {epi }}$ is always less than 0.5 or so and changes most slowly where it has the largest values.

Thus, the most accurate thickness-correction formulas that are convenient to use are Eqs. 22 and 23, in conjunction with Eqs. 1 and 5. For convenicnce, $\delta_{\text {th }}$ all $\delta_{\text {epi }}$ can be eliminated from these equations to give the following accurate formulas for thickness-correcting cadmium-covered and bare gold foils:

\section{Cadmium-covered}

$$
A_{e p i}\left(t_{0}\right)=A_{e p i}(t)\left[\frac{2+D H_{e p i}\left(t_{0}\right)}{2-D H_{e p i}\left(t_{0}\right)}\right]
$$

\section{Bare}

$A_{\text {bare }}\left(t_{0}\right)=\frac{A_{\text {bare }}(t)}{C d R(t)}\left\{\frac{2+D H_{t h}\left(t_{0}\right)}{2-D H_{t h}\left(t_{0}\right)}[-C d R(t)-1]+\frac{2+D H_{\text {epi }}\left(t_{0}\right)}{2-D H_{e p i}\left(t_{0}^{\prime}\right)}\right\}$.

For definitions of the terms used, see the nomenclature at the front of this report. In particular, note that $A_{e p i}(t)$ is assumed to have been corrected for perturbations due to the cadmium cover, that is, for absorption of epicadmium neutrons by the cover and transmission of subcadmium neutrons. This topic has been partially treated in the literature $e^{9,10}$ and is 
not covered in this report. Another assumption is that adequate correction has been made for self-absorption of the gamma (or beta) radiation during counting. (See Section IV.C.1.)

\section{Effect of Error in CdR(t)}

The cadmium ratio in Eq. 57 is for the thickness $t$ of the bare foil, rather than for $t_{0}$. Since this is not always easy to evaluate accurately a priori, one should know how accurate an estimate needs to be. In Section II.A, the qualitative statement was made that $\mathrm{CdR}(\mathrm{t})$ need not be known with high accuracy. Quantitative support can be given to that statement.

In most uses of the cadmium ratio, the quantity CdR - 1 (the ratio of subcadmium to epicadmium activation) is of interest. By differentiating Eq. 5 with respect to $C d R(t)-1$, and making the approximations $\delta_{\text {th }} \approx 1$ and $\delta_{\text {epi }} \approx 1+\mathrm{DH}_{\text {epi }}$, one can show that for a given percentage error in $C d R(t)$ - 1 , the maximum fractional error in $A_{\text {bare }}\left(t_{0}\right)$ occurs for $\mathrm{CdR}(t) \approx 2$. The magnitude of this fractional error is approximately $\triangle \mathrm{C} \cdot \mathrm{DH}_{\text {epi }} / 4$, where $\Delta \mathrm{C}$ is the fractional error in $\mathrm{CdR}(\mathrm{t})-1$. Using, for example, $\mathrm{D}=0.1$ and $\mathrm{H}_{\text {epi }}=0.4$, a $50 \%$ error in $\mathrm{CdR}(\mathrm{t})-1$ leads to an error of only $0.5 \%$ in Abare $\left(t_{0}\right)$, and less if $C d R(t)$ is appreciably different from 2 .

\section{Further Approximations}

In a computer code, there is no reason not to use Eqs. 56 and 57 as they stand, but. for routine hand calculations simpler expressions would be convenient. For a start, one can often neglect the effect of thermal self-shielding (let $\delta_{\text {th }}=1$ ) in making thickness corrections to gold foils that are not much thicker than $1 \mathrm{mil}$, even if not in correcting to zero thickness. Equation 57 then reduces to

$$
A_{\text {bare }}\left(t_{0}\right) \approx A_{\text {bare }}(t)\left[1+\frac{1}{C d R(t)} \cdot \frac{2 D H_{e p i}\left(t_{0}\right)}{2-D H_{e p i}\left(t_{0}\right)}\right] \text {. }
$$

For cadmium-covered foils, one still uses Eq. 56.

Next, if the product $\mathrm{DH}_{\text {epi }}$ is much smaller than 2, the bracketed term in Eq. 56 can usefully be expanded in series form. If we keep only the first two terms of the series and still neglect thermal selfshielding, Eqs. 56 and 57 for cadmium-covered and bare foils reduce to

$$
\mathrm{A}_{\text {epi }}\left(t_{0}\right) \approx \mathrm{A}_{\text {epi }}(t)\left[1+\mathrm{DH}_{\mathrm{epi}}\left(\mathrm{t}_{0}\right)\right]
$$


and

$$
A_{\text {bare }}\left(t_{0}\right) \approx A_{\text {bare }}(t)\left[1+\frac{D_{\text {epi }}\left(t_{0}\right)}{C d R(t)}\right] \text {. }
$$

4. Unmatched Foils and the Effect of Approximations

The extent to which the results of the above approximations differ will be illustrated in an example. Consider two gold foils nominally 1 mil thick, but actually 0.9 and 1.1 mil thick. (In practice, no foil in a set should differ from $t_{0}$ by more than 10\%.) Suppose one of these foils is bare and one is cadmium-covered and they are irradiated in a neutron flux with a spectrum such that the bare foil becomes twice as active (per unit weight) as the cadmium-covered one, after correcting for the perturbations due to the cadmium cover. Let the subscripts $b$ and $c$ refer to the bare- and cadmium-covered foils.

An estimate of $\mathrm{CdR}\left(\mathrm{t}_{\mathrm{b}}\right)$ is required. In view of Section 2 above, using 2.00, the ratio of bare-to-cadmium-covered specific activation before thickness corrections, would be an adequate approximation. However, for this illustrative example, a more accurate estimate will be made. With the knowledge that the areal density of 1 - mil gold is $49.1 \mathrm{mg} / \mathrm{cm}^{2}$, one can determine from Fig. 8 that the epicadmium specific activity of 0.9 -mil gold is about $7.5 \%$ greater than for $1.1-$ mil gold. Thus, $\operatorname{CdR}\left(t_{b}\right) \approx 2.000 /$ $1.075=1.86$.

We now have the following input values:

$$
\begin{aligned}
& \mathrm{t}_{\mathrm{b}}=0.9 \mathrm{mil} \\
& D_{b}=-0.1053(E q .17), \\
& t_{c}=1.1 \mathrm{mil} \text {, } \\
& D_{c}=+0.0952 \text {, } \\
& A_{\text {bare }}\left(t_{b}\right)=2.00, \\
& \mathrm{H}_{\text {epi }}=0.42 \\
& \text { (Fig. 16), } \\
& A_{\text {epi }}\left(t_{c}\right)=1.00 \text {, } \\
& \text { and } \\
& \operatorname{CdR}\left(t_{b}\right)=1.86, \\
& \mathrm{H}_{\mathrm{th}}=0.03 . \quad \text { (Fig. 17). }
\end{aligned}
$$

When these numbers are used in Eqs. 56-60, the results are as given' in Table I. One should not assume that the values in the first row of the table are exactly what would have been observed for a pair of 1.000-mil-thick matched foils, since the linear approximations (Eqs. 15 and 16) are implicit, and there is some experimental uncertainty in $\mathrm{H}_{\text {epi }}$ and $H_{t h}$. The tabulation verifies the insensitivity of gold-foil thickness corrections to thermal self-shielding, at least for foils not thicker than 
about $1 \mathrm{mil}$, and for thicknesses that are not more than $10 \%$ or so from nominal. It also indicates that the simplified forms (Eqs. 59 and 60) are likely to be'accurate enough for all but the most exacting experiments.

TABLE I. Effects of Approximations

\begin{tabular}{|c|c|c|c|c|c|c|c|c|}
\hline \multirow[b]{3}{*}{ Equations } & \multirow{2}{*}{\multicolumn{2}{|c|}{$A_{e p i}\left(t_{0}\right)$}} & \multirow{2}{*}{\multicolumn{2}{|c|}{$A_{\text {bare }}\left(t_{0}\right)$}} & \multirow{2}{*}{\multicolumn{2}{|c|}{$A_{t h}\left(t_{0}\right)$}} & \multicolumn{2}{|c|}{$\operatorname{CdR}\left(t_{0}\right)$} \\
\hline & & & & & & & & Erro \\
\hline & Value & $\underset{\%}{\operatorname{Error}}$ & Value & $\underset{\%}{\operatorname{Error}}$ & Value & $\underset{\%}{\operatorname{Error}}$ & Value & $\underset{\%}{\operatorname{CdR}\left(t_{0}\right)-1}$ \\
\hline 56 and 57 & 1.0408 & - & 1.9565 & $\begin{array}{l}- \\
-\end{array}$ & 0.9157 & - & 1.8798 & - \\
\hline 56 and 58 & 1.0408 & - & 1.9536 & 0.15 & 0.9128 & 0.32 & 1.8770 & 0.32 \\
\hline 59 and 60 & 1.0400 & 0.08 & 1.9524 & 0.21 & 0.9124 & 0.36 & 1.8773 & 0.28 \\
\hline a & 1.0000 & 3.9 & 2.0000 & 2.2 & 1.0000 & 9.2 & 2.0000 & 13.7 \\
\hline
\end{tabular}

a The last row shows the results of neglecting self-shielding in making thickness corrections to gold foils.

B. Nonuniform Foils

Until now we have assumed that each foil has a uniform thickness. We will now show that foil nonuniformity, within reason, is not important as a source of error.

\section{Thick Foil}

As an extreme example, consider a nominal 1 -mil gold foil with two thickness regions, such that half the area is $20 \%$ greater than nominal, and half is $20 \%$ less. The cross section of such a foil is shown here.

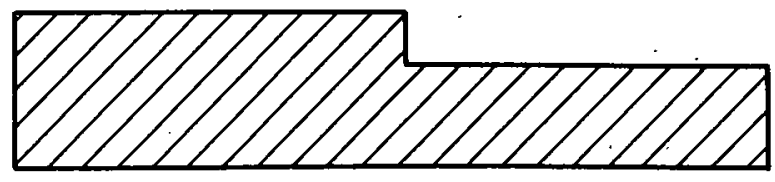

If the thickness of the foil illustrated is computed from its weight and area, it will be exactly $t_{0}$, which is 1 mil. We wish to discover how close the observed activation will be to the activation that would have been observed for a truly uniform 1 -mil gold foil. The calculation will be made for epicadmium activation, since this will be more serious than for thermal activation.

Let the subscripts 1 and 2 denote the thicker and thinner regions, respectively; then $m_{1}=3 \mathrm{~m} / 5$ and $m_{2}=2 \mathrm{~m} / 5$, where $m$ is the mass of the foil. The fractional thickness deviations from nominal are (from Eq. 17) $\mathrm{D}_{1}=+0.182$, and $\mathrm{D}_{2} \doteq-0.222$. Using Eq. 56 , we can calculate the activities (per gram) for the two regions of the foil:

$$
A_{\text {epi }}\left(t_{1}\right)=0.9264 \mathrm{~A}_{\text {epi }}\left(t_{0}\right)
$$


and

$$
A_{e p i}\left(t_{2}\right)=i .0978 A_{e p i}\left(t_{0}\right)
$$

The observed specific activity $A_{\text {obs }}$ of the whole foil will be given by

$$
\mathrm{A}_{\text {obs }}=\frac{3}{5} \mathrm{~A}_{\text {epi }}\left(t_{1}\right)+\frac{2}{5} \mathrm{~A}_{\text {epi }}\left(t_{2}\right) \text {. }
$$

which works out to be $0.9950 \mathrm{~A}_{\text {epi }}\left(t_{0}\right)$.

Thus, the (very large) step-function $\pm 20 \%$ variation in thickness results in an error of only about $0.5 \%$ in the observed epicadmium activation, leading to the perhaps surprising conclusion that foil uniformity is not very important.

\section{Thin Foil with Voids}

A similar situation arises in the case of a thin foil with defects. Consider a nominal $0.1-\mathrm{mil}$, cadmium-covered foil, with $5 \%$ of its area: void. (This situation is equivalent to a $5 \%$. overestimate of the area of the foil. The mass of the foil is assumed to be accurately known.) We now have

$$
\begin{aligned}
t_{0} & =0.1 \mathrm{mil} \\
t & =0.10526 \mathrm{mil} \\
D & =0.05128(\text { Eq. 17) }
\end{aligned}
$$

and

$$
\mathrm{H}_{\mathrm{epi}} \approx 0.17 \text { (Fig. 16) }
$$

Using these values of $\mathrm{D}$ and $\mathrm{H}_{\mathrm{epi}}$ in Eq. 56, we calculate

$$
A_{e p i}(t)=0.9913 A_{e p i}\left(t_{0}\right)
$$

That is, for 0.1 -mil gold foils, a $5 \%$ void leads to an error of somewhat less than $1 \%$ in the resonance activation, due to the resulting underestimation of the foil thickness.

The accurate formula (Eq. 56) has been used in the above calculations. However, it can be seen from Eq. 59 that the fractional error in the corrected specific activation is equal to $\mathrm{DH}$, if $\mathrm{DH}$ is small, where $\mathrm{D}$ is to be calculated with $t$ and $t_{0}$ as the true and assumed foil thicknesses, respectively. 


\section{SUMMARY AND CONCLUSIONS}

To make accurate weight corrections to a set of neutron-activated gold foils, the components of the activation that are due to thermal and epithermal neutrons must be treated separately. For a cadmium-covered foil (and for the epicadmium component of bare-foil activation),

$$
A_{e p i}\left(t_{0}\right)=A_{e p i}(t) \frac{2+D H_{e p i}\left(t_{0}\right)}{2-D H_{e p i}\left(t_{0}\right)}
$$

where $t$ and $t_{0}$ a.re the actual and nominal foil thicknesses, respectively, and $A_{e p i}(t)$ has been corrected.for cadmium-cover effects and for gammaray scattering and self-absorption. For a bare foil,

$A_{\text {bare }}\left(t_{0}\right)=\frac{A_{\text {bare }^{(t)}}}{C d R(t)}\left\{\frac{2+D H_{t h}\left(t_{0}\right)}{2-D H_{t h}\left(t_{0}\right)}[C d R(t)-1]+\frac{2+D H_{e p i}\left(t_{0}\right)}{2-D H_{e p i}\left(t_{0}\right)}\right\}$.

The value of $\mathrm{H}_{e \mathrm{i}}\left(\mathrm{t}_{0}\right)$ can be determined from Fig. 16, and $\mathrm{H}_{\text {th }}$ from Fig. 17 or 18:" The fractional thickness deviation from nominal, D, is calculated according to Eq. 17 ,

$$
D=2 \frac{t-t_{0}}{t+t_{0}}
$$

The following approximate forms of Eqs. 56 and 57, which neglect thermal self-shielding and flux depression, are accurate enough for most purposes:

$$
\mathrm{A}_{\text {epi }}\left(t_{0}\right) \approx \mathrm{A}_{\text {epi }}(t)\left[1+\mathrm{DH}_{\mathrm{epi}}\left(t_{0}\right)\right]
$$

and

$$
A_{\text {bare }}\left(t_{0}\right) \approx A_{\text {bare }}(t)\left[1+\frac{D H_{e p i}}{C d R(t)}\right]
$$

Theoretical and experimental $\mathrm{H}$-functions were in reasonable agreement. The latter were determined by measuring specific activation as a function of foil thickness. The data, after correction for cadmiumcover effects' and gamma-ray scattering and self-absorption, were fitted

- by least squares to the differentiable function

$$
A(t)=C_{2} f(t)+C_{3} f^{2}(t)+C_{4} f^{3}(t)
$$


where $f(t)$ is a differentiable function that fits the data at least approximately. This approach offers an advantage over fitting to an arbitrary function such as a polynomial or sum of exponentials, in that extrapolation beyond the range of the measurements, particularly to zero thickness, can be done with more confidence. For epicadmium activation, the singleresonance approximation was used for $f(t)$, and a good fit to the data was obtained when the three terms shown were used. The subcadmium results were well fitted by the same number of terms, where $f(t)$ was the standard thermal self-shielding function (Eq. 8).

To determine zero-thickness specific activation from measurements with a gold foil of finite thickness, one can use Figs. 8 and 12 . In using Fig. 12 to reduce the thermal component of the activation to zero thickness, one must remember that neither the theoretical function nor the experimental data include any effects of outer flux depression, the experimental measurements having been made in a void in graphite. Consequently, if a gold foil is closely surrounded by some material during irradiation, the observed thermal part of the activation must be multiplied by $1+\left[\frac{1}{2}-E_{3}(\tau)\right] \mathrm{g}$ before applying the correction determined from Fig. 12. (See Section II.B.)

Alternatively, particularly when the cadmium ratio $C d R\left(t_{0}\right)$ has been determined, reduction to zero thickness can be done with the help of the curves published by Jacks ${ }^{14}$ and Baumann; ${ }^{11}$ the present work has yielded results that are in reasonable agreement with theirs. Again, however, thermal outer flux depression was not present, so that one must multiply $C d R\left(t_{0}\right)-1$ by $1+\left[\frac{1}{3}-E_{3}(\tau)\right]$ \& hefnre using the curvoo.

Regarding foil uniformity, a calculation (described in Section VI.B) indicates that the measured epicadmium activation of a gold foil will be quite insensitive to nonuniformity in the thickness of the foil.

Accurate interpretation of gold-foil counting results requires careful attention to the effect of gamma-ray scattering and self-absorption, which is a function of foil thickness. As a side result of this investigation, we discovered that the nature of this function depends on the counting bias (Section V.A), and that, if the bias is low, the function is different for subcadmium and epicadmiurr activation (Appendix F). Complications due to both effects can be avoided by setting the counting threshold so as to reject all pulses below the $41 \mathrm{l}-\mathrm{keV}$ photopeak. 


\section{APPENDIX A}

Error Analysis

\section{Foil-weight Error}

The weight of the evaporated foils was determined by evapor ating $6 \mathrm{~cm}^{2}$ of gold on the aluminum sheet (Fig. 1), and then dividing by six to determine the amount of gold per square $\mathrm{cm}$ on the Mylar. The amount of gold weighed was significant enough for an accuracy of $\pm 3 \%$ for the thinnest foil. Since the aluminum sheet was weighed with an accuracy of $\pm 10 \mu \mathrm{g}$ before and after the evaporation, the weight difference was known with an accuracy of $\pm 14 \mu \mathrm{g}$. The error for the evaporated foils ranged from 1 to $3 \%$. The error in the weight of the punched foils was determined by the accuracy of the two balances used. The balance accuracy was $\pm 10 \mu \mathrm{g}$ for foils weighing $1-10 \mathrm{mg} / \mathrm{cm}^{2}$, and $\pm 50 \mu \mathrm{g}$ for foils weighing $10-300 \mathrm{mg} / \mathrm{cm}^{2}$. The error range for the punched foils was 0.1 to $0.8 \%$. This accuracy was confirmed by weighing each foil on three different occasions.

\section{Foil-area Error}

\section{a. Evaporated Foils}

The area plated depends on the evaporation mask. The holes in the mask for the $1-\mathrm{cm}^{2}$ Mylar foils were made larger than $1 \mathrm{~cm}^{2}$ to prevent shadowing effects; the holes in the portion of the mask covered by the aluminum sheet were $1.00 \mathrm{~cm}^{2}$. (See Fig. l.) Because of the finite thickness of the mask (30 mils) and the Mylar ( 5 mils), two effects should be considered: reduction of the exposed area of the aluminum sheet due to shadowing, and gold plating on the edge of the Mylar foils. The uncertainty due to the shadowing on the aluminum sheet was estimated to be approximately $1 \%$, based on the geometry of the evaporation apparatus. The slots in the evaporation mask for the Mylar foils were arranged so that gold plating could occur on only one edge of the Mylar foil. Since the Mylar was 5 mils thick, the area of one edge would be $0.0125 \mathrm{~cm}^{2}$. Thus, the maximum error due to gold plating on the edge of the Mylar foil would be $1.25 \%$. Combining the errors of 1 and $1.25 \%$, the total error in the area of the evaporated foils is approximately $1: 5 \%$.

\section{b. Punched Foils}

The punched foils, produced by a precision punch-and-die set, were examined under a microscope at a magnification of $50 \mathrm{X}$. The error due to jagged edges was judged to be negligible. 
3. Deadtime Error*

The results of a deadtime: determination by the double-source method are not believable to much better than \pm l $\mu$ sec. Since the counting rates were restricted to 2000 to 4000 counts/sec, the deadtime error range was 0.2 to $0.4 \%$. An error of $0.3 \%$ was assumed for all the foils.

4. Counting Errors

The counting statistics were approximately: the same for all foils; the statistical error was approximately 0.2\%. (See Section III.C for a fuller discussion.)

\section{Total Error}

The total percentage error $\mathrm{R}$ for the cadmium-covered and barefoil activity was calculated by

$$
R=\left(R_{\text {weight }}^{2}+R_{\text {foil area }}^{2}+R_{\text {deadtime }}^{2}+R_{\text {counting }}^{2}\right)^{1 / 2} .
$$

The error ranged from 0.4 to $3.4 \%$.

The subcadmium data points were calculated from the epicadmium curve and the bare-foil data points according to Eq. 43. The absolute error in a subcadmium data point is given by

$$
E_{\text {sub }}=\left(E_{\text {bare }}^{2}+E_{\text {epi }}^{2}\right)^{1 / 2}
$$

where the absolute error $E$ is the product of the relative error $R$ and the activity. Thus, Eq. A.2 can be written

$$
E_{\text {sub }}=\left[\left(R_{\text {bare }} A_{\text {bare }}\right)^{2}+\left(R_{e p i} A_{e p i}\right)^{2}\right]^{1 / 2} \text {. }
$$

By use of the cadmium ratio and Eq. 43, the subcadmium activity can be written as

$$
A_{\text {sub }}=A_{\text {epi }}(C d R-1) .
$$

Dividing Eq. A.3 by Eq. A.4 and using the cadmium ratio, we get

$$
R_{\text {sub }}=\frac{E_{\text {sub }}}{A_{\text {sub }}}=\frac{\left[\left(R_{\text {bare }} C d R\right)^{2}+R_{\text {epi }}^{2}\right]^{1 / 2}}{C d R-1}
$$

\footnotetext{
*See Section III.C for additional discussion of the deadtime.
} 
Note that the epicadmium-activity points used in calculating the subcadmium activity are not data points, but rather points that have been read from a fitted curve. The process of fitting the data points to a curve decreases the relative error $R_{\text {epi }}$, calculated by Eq. A.1., by an estimated factor of three. Thus, $R_{e p i}$ in Eq. A.5 can. be effectively ignored, and Eq. A.5 becomes

$$
R_{\text {sub }}=\frac{R_{\text {bare }} C d R}{C d R-1}
$$

The total error for the subcadmium activity, as calculated by Eq. A.6, ranged from 6 to $0.5 \%$.

In both the subcadmium and epicadmium cases, the weighing uncertainties were the chief source of error for the light foils, but for the heavier foils, the deadtime-correction uncertainties predominated. 


\section{APPENDIX B}

Foil Weights

Table II lists the gold foils: and their weights. Chapter III contains a description of how the foils were prepared, irradiated, and counted.

TABLE II: Foil Weights

\begin{tabular}{lc|lc}
\hline $\begin{array}{c}\text { Foil } \\
\text { No. }\end{array}$ & $\begin{array}{l}\text { Weight, } \\
\mathrm{mg} / \mathrm{cm}^{2}\end{array}$ & $\begin{array}{l}\text { Foil } \\
\text { No: }\end{array}$ & $\begin{array}{c}\text { Weight, } \\
\mathrm{mg} / \mathrm{cm}^{2}\end{array}$ \\
\hline 1 & $0.0830 \pm 0.0025$ & 26 & $3.245 \pm 0.010$ \\
2 & $0.0830 \pm 0.0025$ & $26^{\prime}$ & $3.244 \pm 0.010$ \\
3 & $0.1858 \pm 0.0025$ & 27 & $4.833 \pm 0.010$ \\
4 & $0.1858 \pm 0.0025$ & 27 & $4.826 \pm 0.010$ \\
5 & $0.2197 \pm 0.0025$ & 28 & $4.851 \pm 0.010$ \\
6 & $0.2197 \pm 0.0025$ & 28 & $4.852 \pm 0.010$ \\
7 & $0.4715 \pm 0.0025$ & 29 & $6.281 \pm 0.010$ \\
8 & $0.4715 \pm 0.0025$ & 291 & $6.281 \pm 0.010$ \\
9 & $0.5797 \pm 0.0025$ & 30 & $6.363 \pm 0.010$ \\
10 & $0.5797 \pm 0.0025$ & 30 & $6.358 \pm 0.010$ \\
11 & $0.7090 \pm 0.0025$ & 31 & $10.451 \pm 0.050$ \\
12 & $0.7090 \pm 0.0025$ & 31 & $10.453 \pm 0.050$ \\
13 & $1.167 \pm 0.010$ & 32 & $10.463 \pm 0.050$ \\
14 & $1.216 \pm 0.010$ & 32 & $10.460 \pm 0.050$ \\
15 & $1.484 \pm 0.010$ & 33 & $13.41 \pm 0.05$ \\
16 & $1.489 \pm 0.010$ & 34 & $13.52 \pm 0.05$ \\
17 & $1.708 \pm 0.010$ & 35 & $23.32 \pm 0.05$ \\
18 & $1.712 \pm 0.010$ & 36 & $23.34 \pm 0.05$ \\
19 & $2.032 \pm 0.010$ & 37 & $38.04 \pm 0.05$ \\
20 & $2.069 \pm 0.010$ & 38 & $38.71 \pm 0.05$ \\
21 & $2.355 \pm 0.010$ & 39 & $48.27 \pm 0.05$ \\
$211^{\prime}$ & $2.331 \pm 0.010$ & 40 & $48.27 \pm 0.05$ \\
22 & $2.327 \pm 0.010$ & 41 & $74.05 \pm 0.05$ \\
221 & $2.332 \pm 0.010$ & 42 & $74.24 \pm 0.05$ \\
23 & $2.523 \pm 0.010$ & 43 & $95.95 \pm 0.05$ \\
231 & $2.526 \pm 0.010$ & 44 & $95.95 \pm 0.05$ \\
24 & $2.548 \pm 0.010$ & 45 & $214.28 \pm 0.05$ \\
24 & $2.574 \pm 0.010$ & 46 & $212.93 \pm 0.05$ \\
25 & $3.216 \pm 0.010$ & 47 & $308.71 \pm 0.05$ \\
251 & $3.197 \pm 0.010$ & 48 & $312.29 \pm 0.05$ \\
\hline & & &
\end{tabular}

Odd-numbered foils were aluminum-covered, evennumbered cadmium-covered. Foils l-12 were deposited on Mylar by evaporation. 


\section{APPENDIX C \\ FORTRAN Listings for Program STANSECO}

This appendix contains the F.ORTRAN listings of the STANSECO program. including some of the subroutines called by the main program. The subroutine EONE, which evaluates the first-order exponential integral $E_{1}(x)$, is a standard ANL routine (ANL C305) written by Gerald J. Duffy. The rest of the routines listed were written during the present investigation.

Three of the subroutines used in STANSECO are omitted from the following FORTRAN listings. The NEWPAGE routine merely prints the title, date, and page number at the top of a new output page. The leastsquares polynomial.fitting is done by the subroutine LSQPOL (ANL E206, by Burton S. Garbow). Also used is the Bessel-function subroutine BESI, a library subroutine for the CDC -3600 computer. 
PROGRAM STANSECO

DIMENSIUN $\times C(100), \times B(100), A C A D(100), A B A R E(100), W C A D(100), W B(100), G$ $X S(18)$, TAUEPI $(100), A E P I(1 \cap 0)$, TAUTH $(100)$, EPIFAC $(100), C O E F 1(10)$, NEPIC $X 100), H H(1011)$, ERMAT $(10,10)$, CUERIV $(100)$, EDERIV $(100)$, ASLBFIY $(100)$. XNGARE $(10 U)$, ANORME $(100)$, ANORMS $(100)$, SUBFAC $(100), A S U B(100), A E P 1 B(100$ $X), A E P I F I T(100), D E R I V(100), D D E R I V(100), D E R I V T H(100), H_{T H}(1 D O)$ $X, X R T C(10 U)$, SORTEPI $(1 \cap 0), X R T B(100)$, SORTAUTH(100),CDRC (100) $X$, EPIFACB $(100), A B A R C O(1 \cap 0), R E S I D(100), R E S I D B(100), \operatorname{COEF} 2(10), E R(10$. $X 10), T A U E P I B(100), A E(1,016), C D R(100), E X(10,10)$, ASUBNORM $(900)$, XAEP!NUKM(100), CADRAT $1.0(100)$, HEPIFAC $(100)$, HSUBFAC $(100)$ TYPE INTEGER GS P. TYPE REAL LGAMMAF COMMON/XYZ/DEL, FIN I , FE COMMON/PAGEBLK/NPAGE, GS

IU FORMAT ( YAE, $7 \times A 1$ )

20 FORMAT (1H $10 \times 18 A 4 / 1)$

3U FORMAT (3E12,5,413,3E6;0,13,6x,A1)

40 FORMAT $(3 E 12,5)$

50 FURMAT $(2 H U 5 X * N+15 X * W T / M G * 9 X * S O R T(W T / M G)+11 X * W T$. FACT,*12X*ACTIVIPY $X * 13 X * \operatorname{CURC}(N) * 11 H * C A D, \operatorname{COV}, *)$

6.U FURMAT (IH +BARE*)

70 FORMAT (1H $16,5 F 20,5)$

120 FORMAT (IHU34HNORMALIIATION FACTOR(AEPIFIT(N)) =E12.5/)

13 U FORMAT (2HO34HNORMALI ZATION FACTOR (ASUBFIT(M)) = E12.5/)

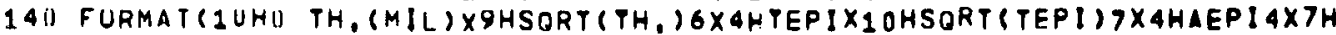
XAEP IF ITOXSHRES I D $X P H \triangle E P$ INORM5 $X 6$ HANORME $5 \times 6$ HEP IFAC6X5HDER IV5X2HHR $\left.\times 8 \times 2 H 11 /\left(E 10,3, F 10,5, E 10,3, F 11 ; 5,8 F_{11}, 5,16\right)\right)$

15U FORMAT(IUH TH, (MIL) X9HSTRT.(PH, 6 X4MTSUBXIOHSORT (TSUB) OXSHTEPIE X8X6HAGAKC $0.9 \times 5 H A E P I S 10 \times 4$ HASUB $7 \times 7 H A S U B F I T 8 \times 6 H R E S I D B 6 \times 2 H I I /(E 10.3$, $X F 10,5, t 10,3, F 11,5,(F, 14,5,(8))$

160 FURMAT (1HU3X8HTH, (NIL) 4X9HSORT (TH, ) OX4HTSUR3X1OHSORT (TSUB) X6X8HASUBNOHM $8 \times 6 H A N C R M S 8 \times 6 H S U B F A C 8 \times 6 H D D E R I V 11 \times 3 H H T H 11 \times 3 H C N R$ $X(t 12,\{, F 13,5, E 13,3, F 13,5,6 F 14,5)\}$

903U FURMAT $(12, X, A 8, X, 5 E 12,5)$

9040 FURMAT $(6 x, 15 H C A L, C C V$. EPIFAC,6x,16,6x,E12,6,16)

9050 FORMAT (6X,15H BARE EPIFAC,6X,16,6X,E12.6,16)

9045 FORMAT $(3 Y X, E 12,6,16)$

SOME STATEMENTS. IN THF FOLLOWING. LISTING LOOK LIKE LEGITIMATE INSTRUCTIONS, BUT HAVE THE CUMMENT LAREL, C. THOSE STATEMENTS WERE ORIGINALLY USED TO PRODUCE CUTPUT CARDS WHICH COULD BE READ IN FOR FUTURE CALCULATIONS, THUS SAVING CUMPUTER TIME,

$$
\begin{aligned}
& \operatorname{CADF}(x)=1,0045-x+7,0 E-5 \\
& \operatorname{CAMMAF}(x)=1.0+x / 239,5
\end{aligned}
$$

NPAGE $=U$

LGAMMAF $(x)=0.9936+0.001058 *(x-2.25) * 2$

READ SU,SIGRES,SIGTH, ATOMS, NCAD, MBARE, ICOMAX, ICOMIN, DEL,FINI,EPS,N

$X, N O P U N C H$

KEAD YU 43, ( EPIFAC $(J)$, NEPI $(J), J=1, N C A D$,

READ Y Y 45 ; (EPIFACP(J), NBARE $(J), J=1$, MRARE)

250 READ 10, (GS(I),I:1, Q),LRIAS

IF ILBIAS. EQ, IH, LBIAS = IHH

IF (EOR.,OU)A1,

GI CUNTINUE

S STOP

1 CALL NEWPAGE \& KKK = KKK • 1 
$01 / 14 / 67$

PRINTSU, SIGRES, SIGTH, ATOMS, NCAD, MBARE, ICOMAX, ICOMIN, DEL, FINI,EPS, N $X$. LBIAS

$c$
$c$
$c$

READ AND PKINT INPUT TATA PLUS MG/SO CM

PRINT SO

DO 11. $I=1, M C A D$

READ $40, X C(1), W C A D(1), A C A D(1) \quad \& \triangle C A D(1)=\operatorname{EXPF}(A C A D(1))$

$X \times C=X C(1)+2$

$\operatorname{CDRC}(1)=0,345+x(1)+2,07$

11 PRINT $70,1, \times X C, X C(1), W C A D(1), A C A D(1), C D K C(1)$

NAME $=\triangle H S Q R M G C D$ \& DO298 NO $=1.6$

c

C 2 $N P=5 \cdot(N O-1)+1$ \& $N F 4=N P+4 \&$ IF (NP4,GT, NCAD) NP4 = NCAD

98. PUNCH 9OSO, NO, NAME, (XC(I), I = NP, NP4)

PRINT OO

DO $12 \quad I=1$, MUARE

READ $40, X B(1), W B(I), A B A R E(I)$ S ABARE(I) : EXPF (ABARE(I))

$X \times B=X B(1) \div-2$

12 PRINT $70,1, X \times B, X B(1), W B(1), A B A R E(I)$

C NAME $=O H$ SORMG 8 \$ DO299 NO $=1.6$

C NP=5 $(N O-1)+1$ \$ NP4 $=N P+4$ \$ IF (NP4,$G$. MBARE) NP4 = MBARE

C 299 PUNCH 9USU, NO, NAME, (XB(I), I = NP, NP4)

DO $21=1$, NCAD

$X C(1)=X C(1) *+2 / 49.0728$ SXRTC(1) $=$ SORTF $(X C(1))$

TAUEPI $(!)=$ ATOMS $\$$ IGRES $\times C$ ( I)

2 SURTEPI $(I)=$ SQRTF (TAUEPII $(I))$

DO 3 I $=1$, MHARE

$X B(I)=X B(1) * 2 / 49,0728 \$ X R T B(1)=\operatorname{SORTF}(X B(1))$

TAUEPIB(1) = ATOMS $\$$ SIGRES $\$ B(1)$

TAUTH(I) = ATUMS * SIGTH $* X B(1)$

3 SURTALTH(I) = SORTF(TAUTH(I))

$\triangle L P H A=0,0 E=4$

DO $51=$ ICOMIN, ICCMAX

$K I=1$

$c$
$C$
$C$
$c$
$C$
$C$
$C$
$C$
$c$

CD COVEKED FOILS

DO $202 \jmath=1$, NCAD

C EPIFAC (J) CALCULATÉ ONCE PROM then ON the Values read IN

IF (KKK, GT, 1) GO TO 210

CALL EPIF UNC (TAUEPI (J), TEMP, EPS, ICOUNT, N)

PUNCH 9040, J. TEMP, ICOUNT

EPIFAC(J) = TEMP \& NEPI J) = ICOUNT

210 TX $=$ TAUEP $[(J) / 2$,

CALL UESI $(T X, 0,0,1, A E, L)$

DERIV(J) $=A E(1) \cdot A E(2)$

CUERIV(J) = (EPIFAC.(J) D DERIV(J))/TAUEPI (J)

IF (LBIAS, EO, IHL) GO TO 200

AEPI $(J)=L A M M A F(X C(J)) \cdot A C A D(J) /(1, / C A D F(X C(J))+A L P H A *(C D R C(J)-1)$, GO TO 201

200 AEPI $(J)=L G A M M A F(X C(J))+A C A D(J) /(1, / C A D F(X C(J))+A L P H A *(C D R C(J)-1)$,

201 CONTINUE

CONSTRAIN LSU FIT TO MEET PHYSICAL REQUIREMENT THAT AEPI a O WHEN 'EPIFAC $=0$. $N C I=N C A D+1$ S EPIPAC (NCI) $=0.0$ 


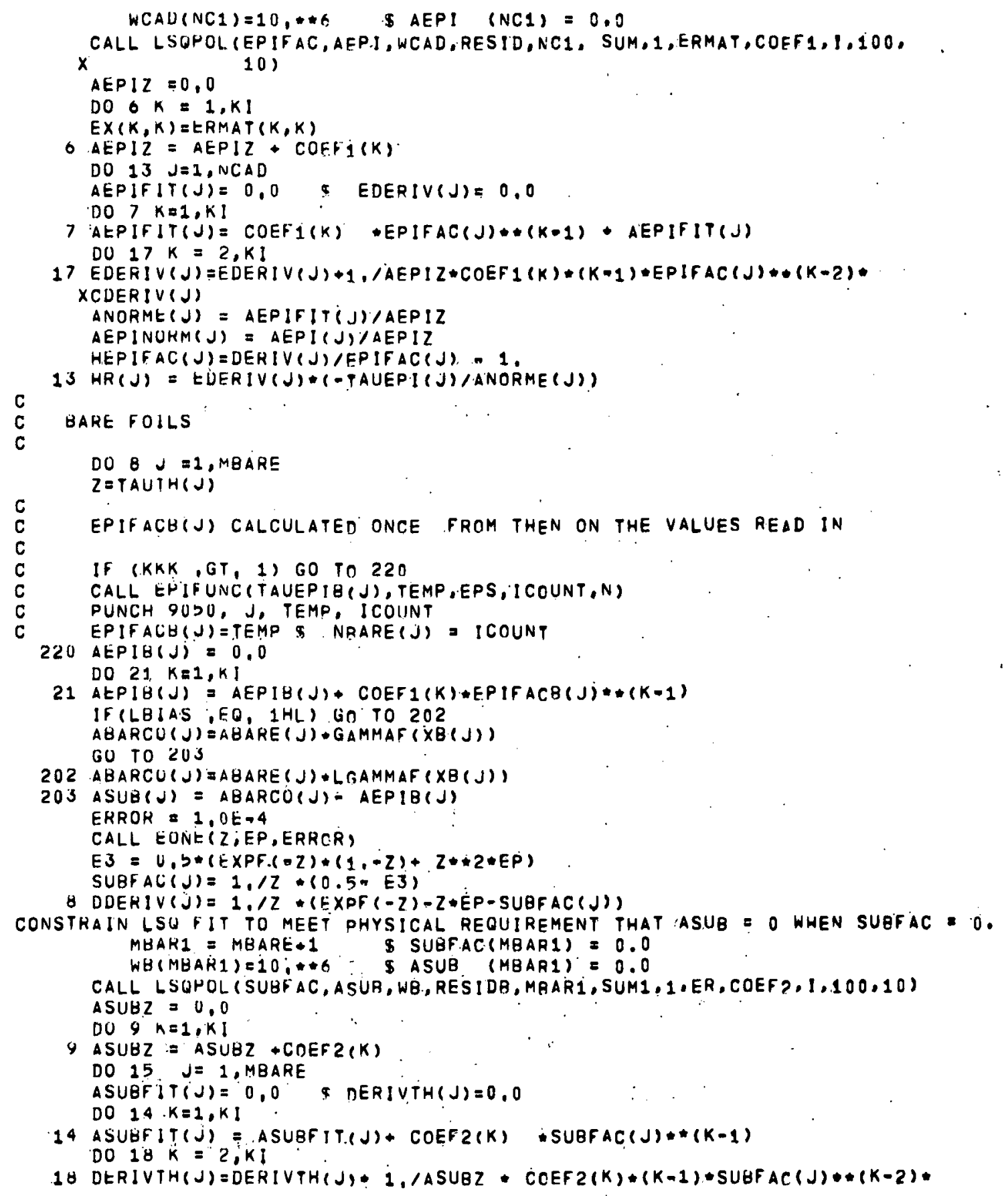




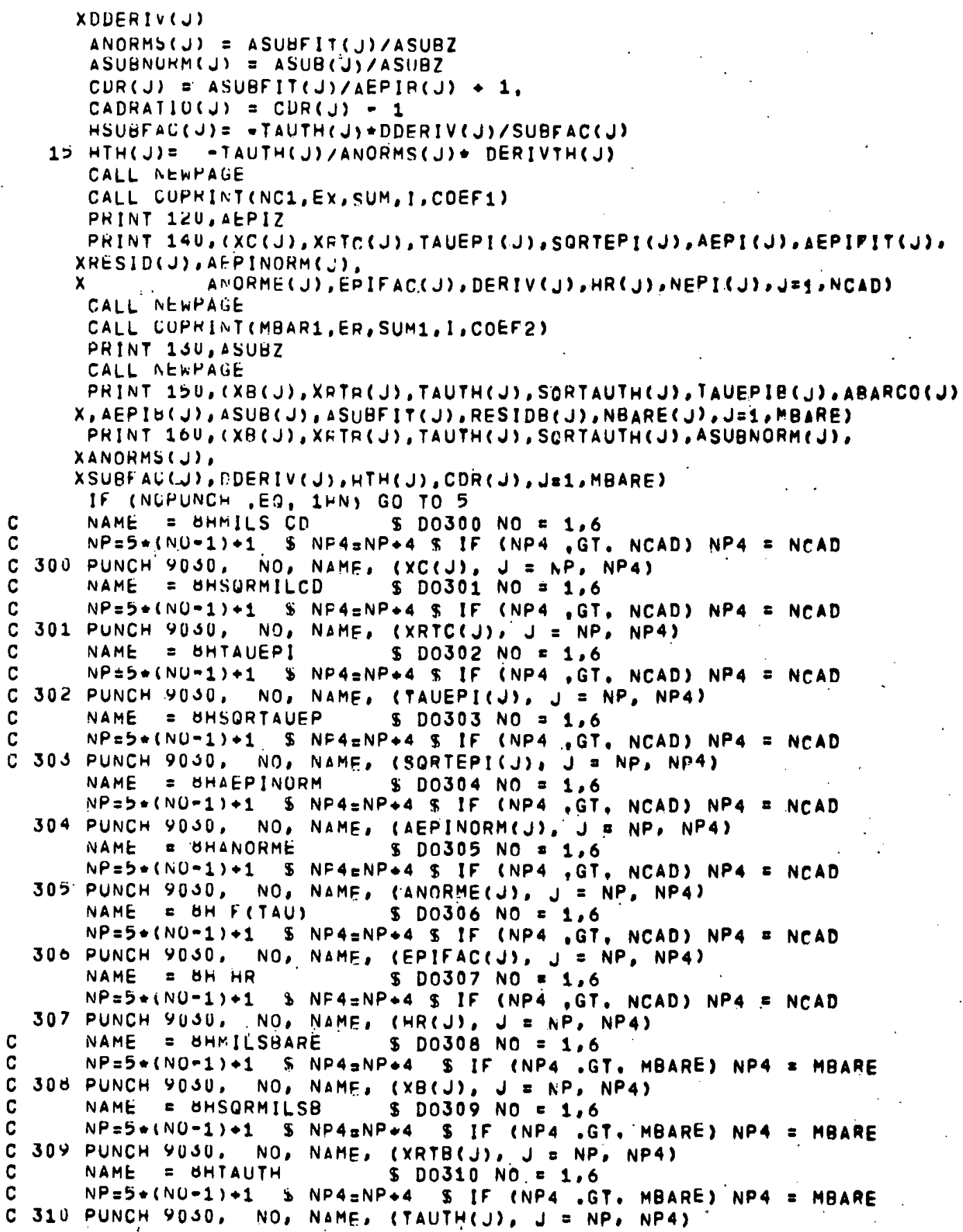




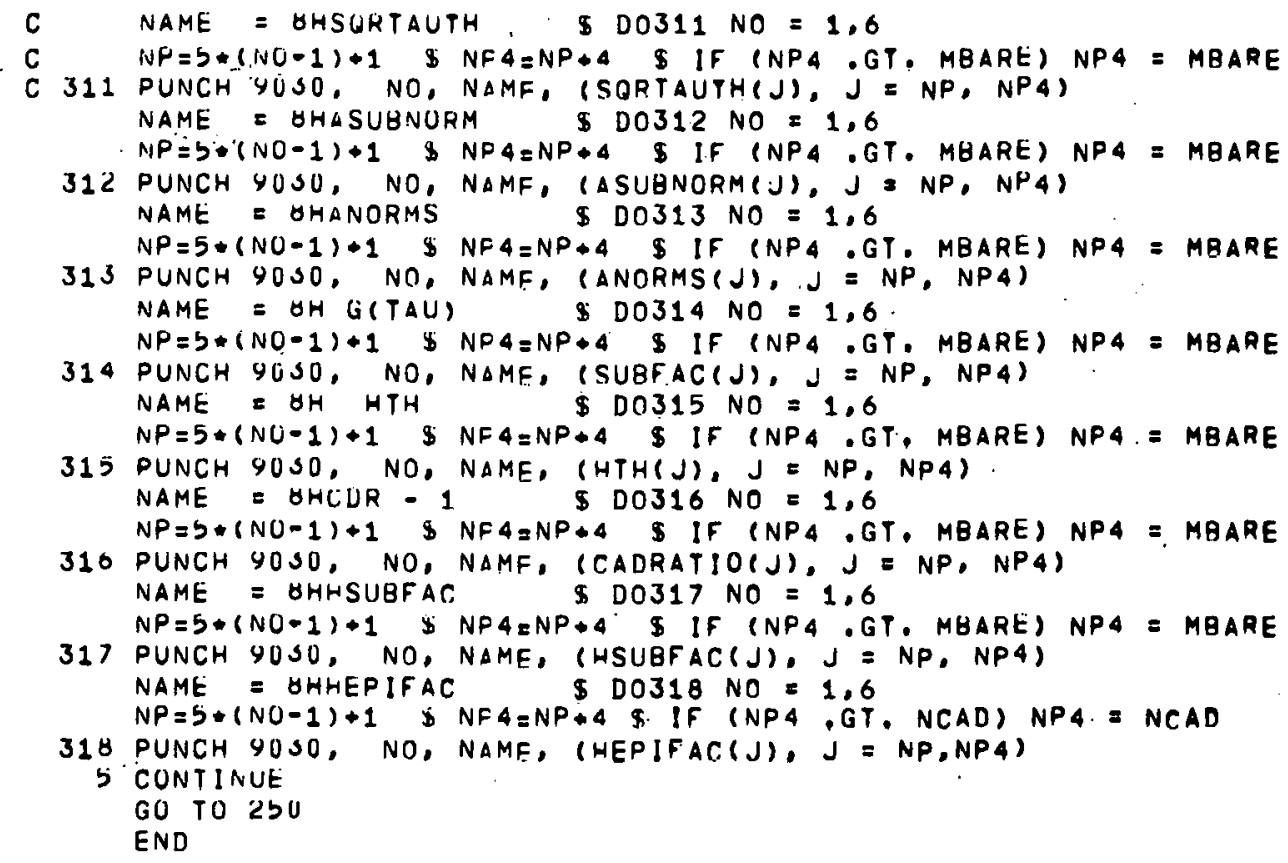


SUBROUTINE EPIFUNC (T; SUM, EPS, ICOUNT, N)

13. FORMAT (IHO ARGUMENT LIMIT EXCEEDED IN EPIFUNC SUBROUTINE*) COMMON $X Y Z / D E L, F I N], X P$

$X P=T 0,5 \quad \$ \quad X_{1}=X P \quad \$ \quad J \operatorname{COUNT}=0 \quad \$ \quad N S=1$ GO TO $(2,4)$, NS

$2 \times 2=X 1+D E L+X 1$

IF $(X 2.6 T .709$,$) GO TO 5$

TEST = RIEMAN $(X 1, \times 2, N, E P S, I$ COUNT $)$

$N S=2 \&$ SUM $=$ TEST

$4 \times 1=x_{2} \quad \$ \quad x_{2}=x_{1} \cdot D E L+X_{1}$

IF (X2,GT,709,) GO TO 5

TEST1 = HIEMAN $\left(X_{1}, \times 2, N, E P S\right.$, ICOUNT)

SUM = SUM + TEST1

IF (ICUUNT,GT,1NOOO) GO TO 9

IF(TESTI/TEST , FINI)9,9,4

IG CONTINUE

C

PRINT $1 \mathrm{~S}$

9 RETURN

END

$01 / 14 / 67$

SUBROUTINE COPRINT(N,E,S,I,C)

DIMENSION E $(10,10), C(1), J E R C O(10)$

3 FORMAT (1HO114,2E2O.7)

4 FORMAT (// 1 HO9X 5HJERCO 9X11HCDEFFICIENT11X5HERROK /)

5 FURMATI 37 WEIGHTED SUM OF SQUARED DEVIATIONS = E13.5/1)

PRINT 4

DES $=\mathrm{N}-1$

DO $1 \quad K=1,1$

$J E R C O(K)=0$

If $(E(K, K), G T, 0,0)$ :O TO?

$J E R C O(K)=1$

$2 E(K, K)=S S R T F(S+A P S F(E(K, K)) / D E G)$

1 PRINT S, JERCO $(K), C(K), E(K, K)$

PRINT $b, S$

RETURN

END 
$01 / 14 / 67$

FUNCTION. VALUE $(X, 11)$

DIMENSION A(1016)

COMMON/XYYZ/OEL,FINI, XP

II $=11 \div 1$

CALL UESI $(X, 0,0,1, A, L)$

VALUE $=1,1 X * 2+X P+(A(1)+A(2))$

RETURN

END

$01 / 14 / 67$

SUBROUTINE EONE(TAUB;ESBONE, ERROR)

C

200 IF (TAUB-1,0) 206,206,202

HASTINGS APPROXIMATION

202 ESBONE $=((()(8,57332874+T A U B)+T A U B+18,0590170)$ *

$X \quad$ TAUB $\$ 8,63476099)=$ TAUB 0.0267773734$).$

$X \quad 2,71828183 *+(-T A \cup B)) /((1(9.57332235+T A \cup B) *$

TAUB +25.6329561 ) TAUB-21.0996531)*TAUB $X \quad+3,95849692) * T A \cup B$ )

c 204 RETURN SERIES EXPANSION FCR SMALL TAUB

206 SUMS $=$ LUGF (TAUB)

210 SUMS $=00,577215665$-SUMS

212 FND $=1,0$

213 SIGN $=1,0$

214 FAC $=1,0$

215 TAUI = TAUB

216 SUMT $=$ SUMS

218 SUMS $=S U M S * S(G N \otimes T A U I /(F N D * F A C)$

220 T1=SUMS-SUMT

222 T2=ABSF $(T 1)$

224 IF (T2-EKROR-SUMS) $230,230,226$

$226 F A C=(F N D+1,0) \backsim F A C$

227 SION=(-1,U) SIGN

$228 F N D=F N D+1,0$

232 TAUIETAUI TAUB

229 GO TO 210

230 ESBONE=SUMS

231 GO TO 204

END

C3050003

c3050004

C3050005

C3050006

C3050007

c3050008

C3050009

c3050010

C3050011

c3050012

c3050013

C3050014

C3050015

C3050016

c3050017

C3050018

C3050020

c3050021

C3050022

C3050023

C3050024

C3050025

C3050026

C3050027

C3050028 
Examples of STANSECO Output

Figures 19-22 are typical samples of the printout from Program STANSECO. Figure 1.9 is a listing of the input data for the North Counting Room, high-bias case. Figure 20 gives the four-coefficient output for the cadmium-covered foils, and Figs. 21 and 22 give the four coefficients and the corresponding output for the bare foils. 
SECKINGER AU FOILS GAMMA ACT -EAST SOR FIT,HITI,CD RATIO NORTH HIGH BIAS

$3.7000000208 .75900-0231.5100000202423 \quad 4 \quad 250011.0041 .0054$

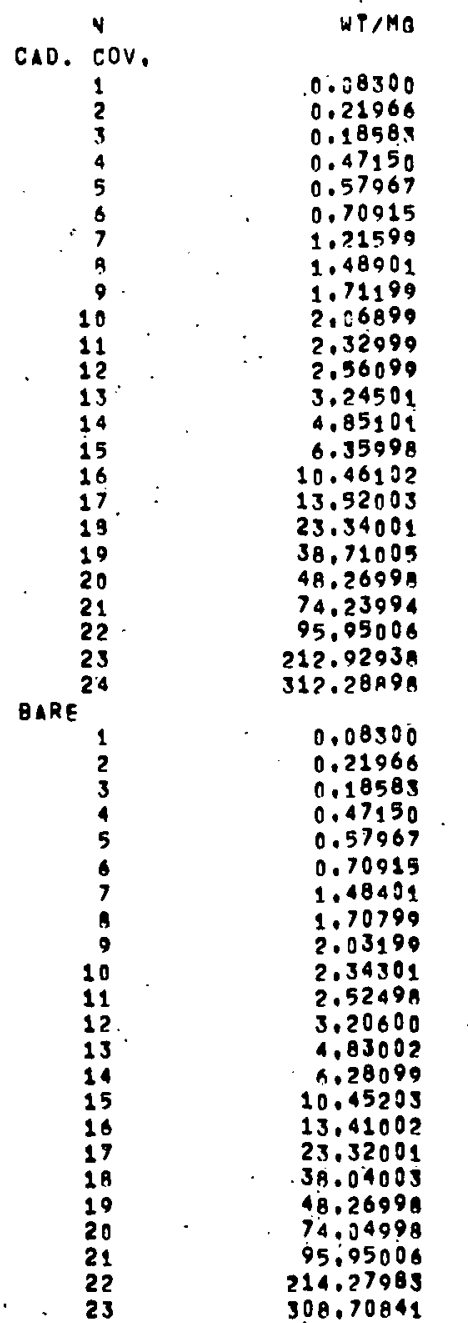

112-8145-B
SORT (WT/MG)

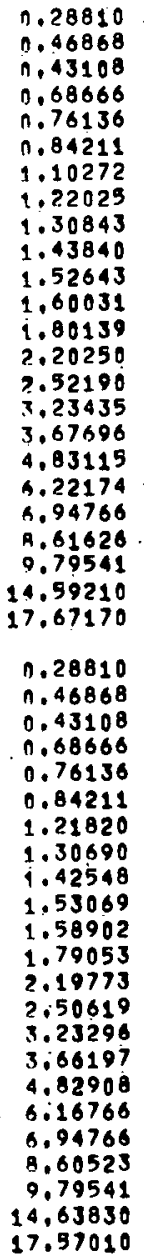

WT. FACT.

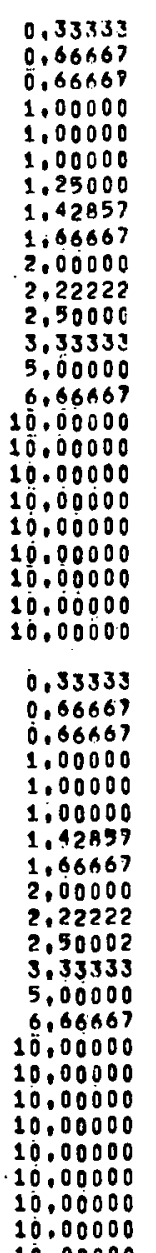

activitr

5.57410

5,63378

5.18639

5.36019

5.42149

$5,1851 \mathrm{n}$

5.08060

5.04654

4.93430

$4.7677 \mathrm{~A}$

4.26359

$4.2635 \mathrm{~A}$
3.81359

$3 . \$ 1191$

2.41140

?. 2.0030

1.82800

1.34650

$1.1735 n$
1.00000

$13.4324 n$

13.17564

12.89075

12.94218
14.21247

14.21247
$12.8376 ?$

$12,8376 ?$
12,83095
12,90313

12.05332

12.72349

12.39236

12.17360

11.87494

11.40429

$11.1707 \mathrm{~A}$

10,53823

9.93516

9.72363

Q.2286

B. 27 AR

$7.5581 A$
ednC (N)

2.16939

2.16939
2.23169
0.21872

.30690

. 33267

2.36053

2.45044

2.4909

2.52141

..

2.59662

2.62211
$? .89148$

2.69148
9.82986

2.04006

2.04006
3.18585

3.33855

3.73675

4.21650

4.46094

5.04261

9.44942
$i .10427$

7.10427
$0.166 ?^{4}$

Fig. 19. Input Data for STANSECO 


$\begin{array}{ccc}\text { JERCO } & \text { COEFFICIENT } & \text { ERROR } \\ 0 & 1.3308800 .007 & 7.5515721 .005 \\ 0 & 0.06859250000 & 1.07622150001 \\ 0 & -3.06038630000 & 3.6598981 .001 \\ 0 & 7.5522387 .001 & 2.9204298 .001\end{array}$

WEIOHTEO SUM OF SOUARED DEVIAYIONS $=1.19755 .001$

NORMALIZATION FACYORSAEPIFIT(N)) $=5.75 ? 43+000$

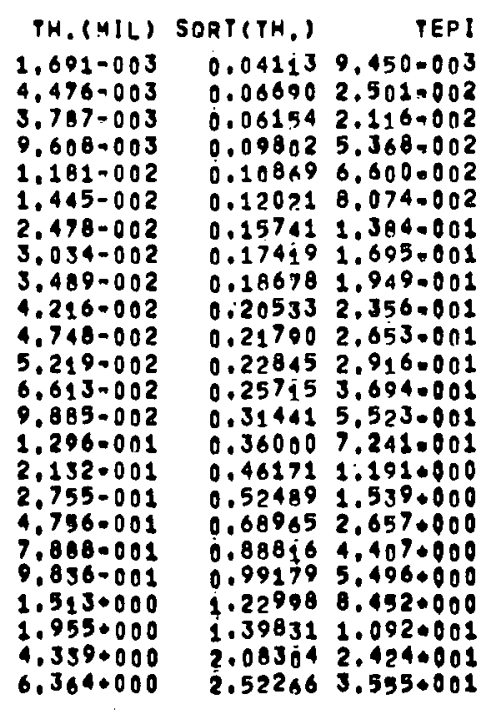

$112-8145-\mathrm{A}$

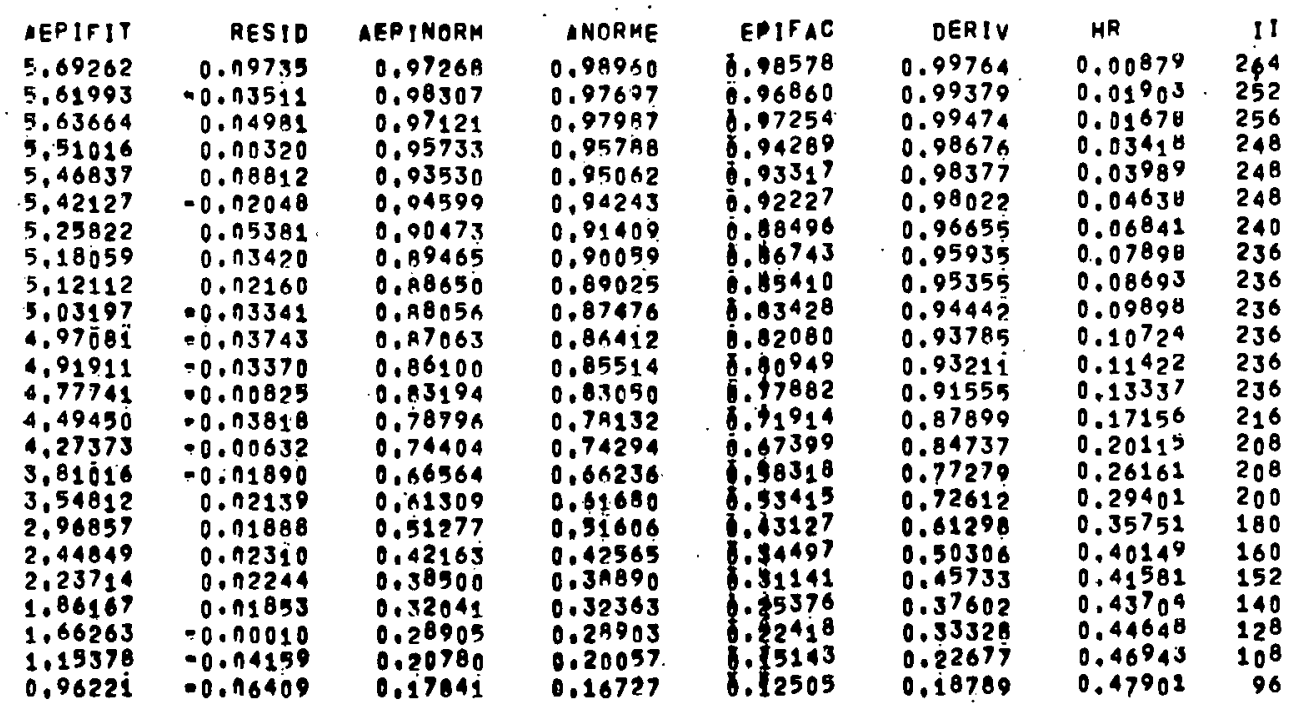

Fig. 20. Four-coefficient Output Data from STANSECO for Cadmium-covered Foils 


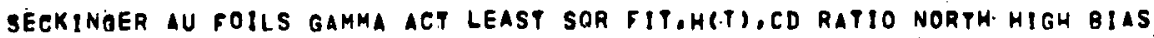

\section{. \\ COEFFICIENT \\ ERROR \\ 2.8092480 .004 \\ $6,9353254+000$ \\ $1,4495250+001$ \\ 3.52103190000 \\ $3.1116466+001$ \\ $-2,7584551+000$ \\ $1,6058.349 \cdot 002$}

$\therefore \quad-6.1488297 .091$

WEIGHTEO SUM OF SQUARED DEVIATIONS $=1.578260000$

NORMALIZATION FACTOR(ABUBPIT(M)) $7.69950+0.00$

$112-8145-C$

Fig. 21. The Four Coefficients for Bare-foil Data. [The relative size of the numbers in the ERROR column indicates that the experimental precision was such that no significance should be ascribed to the coefficients shown. Processing with two and three coefficients (results not shown) yielded smaller errors in the coefficients, indicating that the experimental data do differ significantly from the simple theoretical model. See Fig. 11.] 
SECKINGER AU FOILS GAMMA ACT LEAST SOR FIT,HETI, CD RATIO NORTH HIGA BIAS

PRECESSED 07/29/86

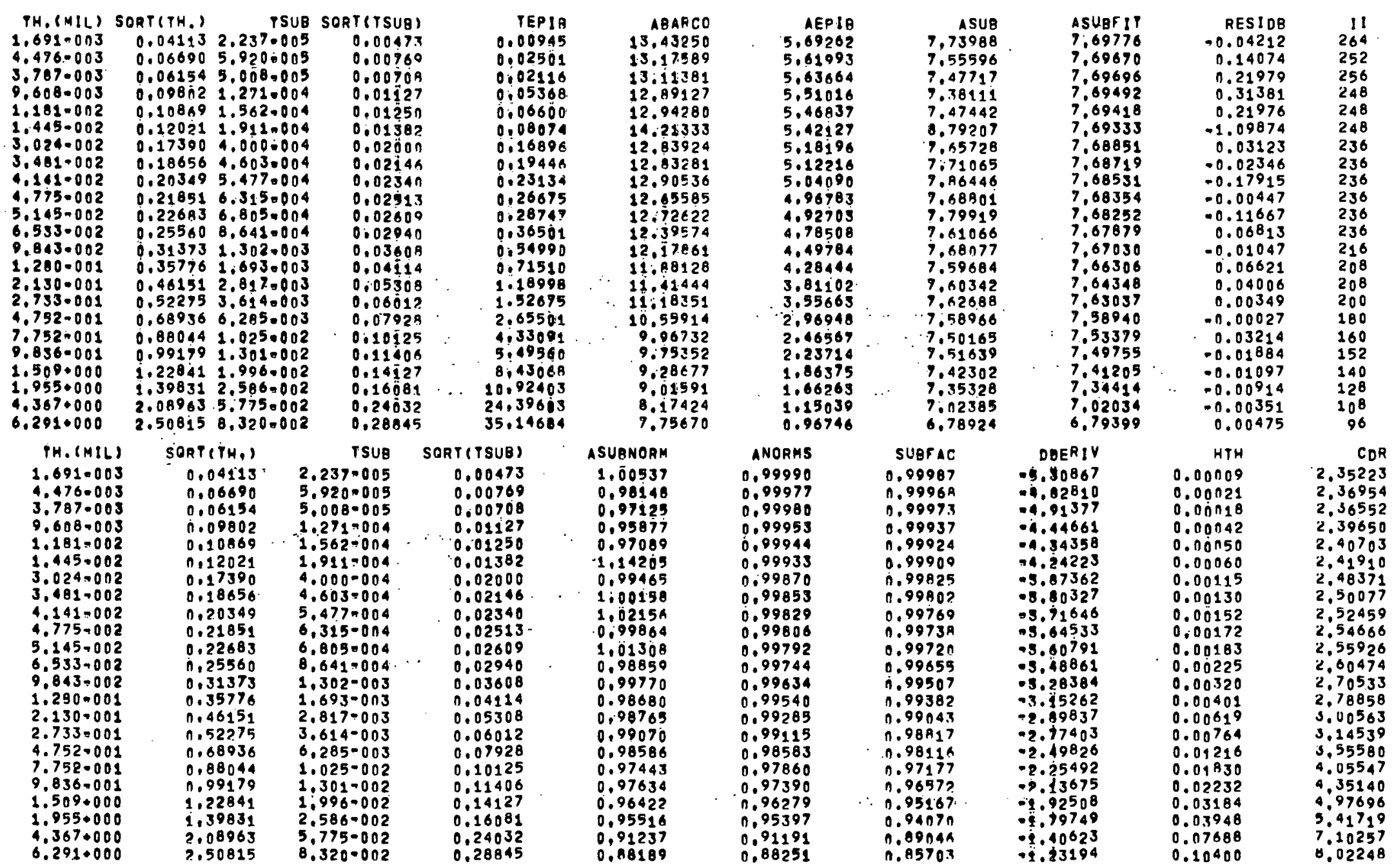

$112-8145$ 
APPENDIX E

\section{Least-squares Coefficients}

Table III contains a complete listing of the coefficients as determined by STANSECO, for the three - and four-coefficient calculations. In examining the last column, containing the extrapolated values, keep in mind that there were four independently normalized sets of input data, so that the only meaningful comparisons to be made in this column are between the three- and four-coefficient results for the same set of data.

TABLE III. Coefficients for the Least-squares fits As Determined by STANSECO

\begin{tabular}{|c|c|c|c|c|c|c|c|c|c|c|c|c|}
\hline \multirow{2}{*}{$\begin{array}{l}\text { Epi } \\
\text { or } \\
\text { Sub }\end{array}$} & \multirow{2}{*}{$\begin{array}{l}\text { No. of } \\
\text { Coefficients }\end{array}$} & \multirow{2}{*}{$\begin{array}{c}\text { Counting } \\
\text { Bias }\end{array}$} & \multicolumn{8}{|c|}{ Coefficients } & \multirow{2}{*}{$\begin{array}{l}\text { Weighted } \\
\text { Sum of } \\
\text { Squared } \\
\text { Residuals }\end{array}$} & \multirow{2}{*}{$\begin{array}{c}\text { Extrapolate } \\
\text { Activity } \\
\text { at } t=0\end{array}$} \\
\hline & & & First & Error & Second & Error & Third & Error & Fourth & Error & & \\
\hline \multicolumn{13}{|c|}{ South Counting Room } \\
\hline \multirow[t]{2}{*}{ Epi } & 3 & $\begin{array}{l}\text { Low } \\
\text { High }\end{array}$ & $\begin{array}{l}1.15 \times 10^{-6} \\
7.13 \times 10^{-7}\end{array}$ & $\begin{array}{l}1.01 \times 10^{-4} \\
8.14 \times 10^{-5}\end{array}$ & $\begin{array}{l}7.631 \\
7.890\end{array}$ & $\begin{array}{l}0.062 \\
0.050\end{array}$ & $\begin{array}{r}2.286 \\
-2.163\end{array}$ & $\begin{array}{l}0.088 \\
0.070\end{array}$ & - & - & $\begin{array}{l}0.227 \\
0.146\end{array}$ & $\begin{array}{l}5.345 \\
5.727\end{array}$ \\
\hline & 4 & $\begin{array}{l}\text { Low } \\
\text { High }\end{array}$ & $\begin{array}{l}4.67 \times 10^{-7} \\
4.44 \times 10^{-7}\end{array}$ & $\begin{array}{l}8.12 \times 10^{-5} \\
7.94 \times 10^{-5}\end{array}$ & $\begin{array}{l}8.014 \\
8.039\end{array}$ & $\begin{array}{l}0.115 \\
0.113\end{array}$ & $\begin{array}{l}-3.700 \\
-2.717\end{array}$ & $\begin{array}{l}0.393 \\
0.384\end{array}$ & $\begin{array}{l}1.147 \\
0.450\end{array}$ & $\begin{array}{l}0.314 \\
0.307\end{array}$ & $\begin{array}{l}0.139 \\
0.132\end{array}$ & $\begin{array}{l}5.461 \\
5.772\end{array}$ \\
\hline \multirow[t]{3}{*}{ Sub } & .3 & $\begin{array}{l}\text { Low } \\
\text { High }\end{array}$ & $\begin{array}{l}-1.33 \times 10^{-8} \\
-9.17 \times 10^{-10}\end{array}$ & $\begin{array}{l}3.27 \times 10^{-4} \\
2.95 \times 10^{-4}\end{array}$ & $\begin{array}{c}10.74 \\
9.462\end{array}$ & $\begin{array}{l}0.745 \\
0.673\end{array}$ & $\begin{array}{l}-3.409 \\
-1.693\end{array}$ & $\begin{array}{l}0.772 \\
0.697\end{array}$ & - & - & $\begin{array}{l}2.257 \\
1.839\end{array}$ & $\begin{array}{l}7.339 \\
7.769\end{array}$ \\
\hline & 4 & $\begin{array}{l}\text { Low } \\
\text { Hlgh }\end{array}$ & $\begin{array}{r}3.36 \times 10^{-11} \\
-6.65 \times 10^{-11}\end{array}$ & $\begin{array}{l}2.92 \times 10^{-4} \\
3.01 \times 10^{-4}\end{array}$ & $\begin{array}{r}-19.34 \\
8.533\end{array}$ & $\begin{array}{l}15.0 \\
15.5\end{array}$ & $\begin{array}{l}60.81 \\
0.138\end{array}$ & $\begin{array}{l}32.3 \\
33.3\end{array}$ & $\begin{array}{l}-34.2 \\
-0.900\end{array}$ & $\begin{array}{l}17.3 \\
17.9\end{array}$ & $\begin{array}{l}1.702 \\
1.813\end{array}$ & $\begin{array}{l}7.285 \\
7.771\end{array}$ \\
\hline & \multicolumn{12}{|c|}{ North Counting Room } \\
\hline \multirow[t]{2}{*}{ Epi } & 3 & $\begin{array}{l}\text { Low } \\
\text { High }\end{array}$ & $\begin{array}{l}1.23 \times 10^{-6} \\
8.85 \times 10^{-7}\end{array}$ & $\begin{array}{l}1.04 \times 10^{-4} \\
8.47 \times 10^{-5}\end{array}$ & $\begin{array}{l}7.606 \\
7.815\end{array}$ & $\begin{array}{l}0.064 \\
0.052\end{array}$ & $\begin{array}{l}-2.263 \\
-2.139\end{array}$ & $\begin{array}{l}0.090 \\
0.073\end{array}$ & - & - & $\begin{array}{l}0.239^{\circ} \\
0.158\end{array}$ & $\begin{array}{l}5.343 \\
5.676\end{array}$ \\
\hline & 4 & $\begin{array}{l}\text { Low } \\
\text { High. }\end{array}$ & $\begin{array}{l}4.55 \times 10^{-7} \\
4.33 \times 10^{-7}\end{array}$ & $\begin{array}{l}7.81 \times 10^{-5} \\
7.55 \times 10^{-5}\end{array}$ & $\begin{array}{l}8.035 \\
8.067\end{array}$ & $\begin{array}{l}0.111 \\
0.108\end{array}$ & $\begin{array}{l}-3.850 \\
-3.069\end{array}$ & $\begin{array}{l}0.378 \\
0.366\end{array}$ & $\begin{array}{l}1.288 \\
0.755\end{array}$ & $\begin{array}{l}0.302 \\
0.292\end{array}$ & $\begin{array}{l}0.128 \\
0.120\end{array}$ & $\begin{array}{l}5.172 \\
5.752\end{array}$ \\
\hline \multirow[t]{2}{*}{ Sub } & 3 & $\begin{array}{l}\text { Luw } \\
\text { High }\end{array}$ & $\begin{array}{l}-8.43 \times 10^{=9} \\
-1.93 \times 10^{-9}\end{array}$ & $\begin{array}{l}3.00 \times 10^{-4} \\
2.81 \times 10^{-4}\end{array}$ & $\begin{array}{l}\mathrm{i} 0.46 \\
9.578\end{array}$ & $\begin{array}{l}0.682 \\
0.638\end{array}$ & $\begin{array}{l}-3.123 \\
-1.881\end{array}$ & $\begin{array}{l}0.706 \\
0.661\end{array}$ & - & - & $\begin{array}{l}1.888 \\
1.655\end{array}$ & $\begin{array}{l}7.336 \\
7.698\end{array}$ \\
\hline & 4 & $\begin{array}{l}\text { Low } \\
\text { High }\end{array}$ & $\begin{array}{r}1.70 \times 10^{-10} \\
-6.15 \times 10^{-11}\end{array}$ & $\begin{array}{l}2.83 \times 10^{-4} \\
2.81 \times 10^{-4}\end{array}$ & $\begin{array}{r}-8.678 \\
6.935\end{array}$ & $\begin{array}{l}14.6 \\
14.5\end{array}$ & $\begin{array}{c}37.52 \\
3.522\end{array}$ & $\begin{array}{l}31.3 \\
31.1\end{array}$ & $\begin{array}{l}-21.5 \\
-2.758\end{array}$ & $\begin{array}{l}16.8 \\
16.6\end{array}$ & $\begin{array}{l}1.598 \\
1.578\end{array}$ & $\begin{array}{l}7.306 \\
7.699\end{array}$ \\
\hline
\end{tabular}




\section{APPENDIX F \\ Experiment Concerning Gamma-ray Scattering \\ and Self-absorption}

In Section V.A, we described an experiment that showed that the correction for scattering and absorption of gamma rays by the foil as it is being counted dèpends on the counting bias used. We mentioned indications that the correction is also a function of whether the activation is due to thermal or resonance-energy neutrons--that is, of the distribution of the activity inside the foil--if the counting bias is low. We will now describe an experiment in support of this statement.

In the experiment, a relatively thin $0.8-\mathrm{cm}$-diam gold foil $(0.23 \mathrm{mil})$ was irradiated and was then counted at three different bias settings. At each. setting, the foil was counted (a) alone on the planchet; (b) resting on two slightly larger 2-mil gold foils that had not been activated; (c) sandwiched between the. two thicker foils; and (d) resting directly on the planchet with the two other foils on top.

The object of the experiment was mainly qualitative: to see whether the combined counting rate of the upper and lower crystals was an observable function of the position of the activated foil in the stack. The reasoning is that, whereas for either detector alone the counting rate will depend on the amount of gold between the foil and the crystal, with the two detectors the average gamma-ray path length through the gold will be the same regardless of the location of the active foil in the stack of three. Thus, the observed combined counting rate for the two detectors would at first be expected to be the same for all three counting configurations. If this is not the case, then the gamma-ray self-absorption correction will be different for thermal and resonance activation of a gold foil that is thick enough so that the resonance self-shielding is appreciable.

The three bias settings used were approximately 380,120 , and $13 \mathrm{keV}$; the high setting was in the valley below the $41 \mathrm{l}$-keV photopeak, and the low one was high enough so that noise was not counted. The amplifier for each of the two detectors fed two single-channel analyzers and scalers. The counting sequence a-d listed above was performed three times with one of the single-channel analyzers for each detector biased at $380 \mathrm{keV}$ and the other at $120 \mathrm{keV}$; then the sequence was repeated four times, with the high bias untouched but the other lowered to about $13 \mathrm{keV}$. The averaged counting results are presented in Table IV, where the data for each detector and each bias setting have been normalized to the highest counting rate. The counting results were reproducible to within $\pm 0.3 \%$. 
TABLE IV. Data from Gamma-ray Self-absorption Test

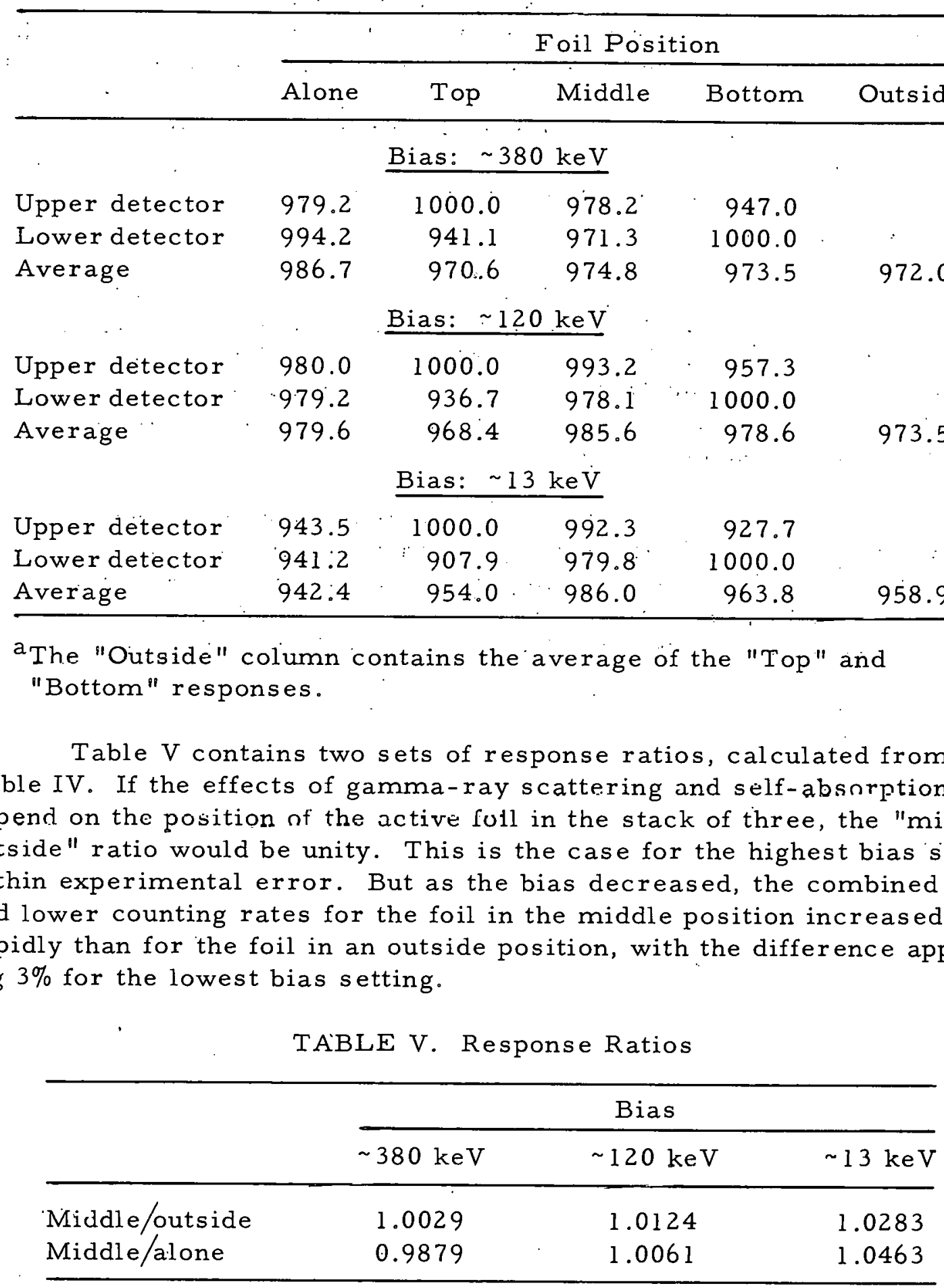

The bottom row of Table $\mathrm{V}$ shows the effect of interposing nonactive gold between the active foil and the detectors. For the high bias setting, the addition of 2 mils of gold on each side of the foil attenuated the gamma rays by $1.2 \%$. For the medium setting, however, the increased detection of 
Compton-scattered gamma rays more than compensated for the attenuation of the primary gamma rays (as discussed in Section V.A). At the lowest bias setting, where $X$ rays would be counted, the extra 2 mils of gold on each side of the foil resulted in a count-rate increase of almost $5 \%$.

For this experiment, the detecting crystals were fairly close to the foil ( $\lesssim l \mathrm{~cm}$ ), and the distance was not varied. One would expect, however, that the relative magnitudes of the various effects would depend on the counting geometry.

The conclusion drawn from this experiment is that the correction curve for gamma-ray scattering and self-absorption as a function of goldfoil thickness depends on the way the activity is distributed in the foil--that is, on the nature of the neutron spectrum in which the foil was irradiated-unless the counting bias is set high enough to exclude the $\mathrm{X}$ rays and the Compton-scattered gamma rays.

Corsequently, experiments involving the gamma counting of activated. gold will be simplified if the counting threshold is roulinely e t at $380 \mathrm{keV}$ or so--just below the $41 \mathrm{l}-\mathrm{keV}$ photopeak: Then a curve such as the "high bias" one of Fig. 4 (which might have to be separately determined for each counting system) can be used for both thermal and epithermal activation. 


\section{ACKNOW LEDGMENTS}

Many people have contributed to the success of this project. Some of the experimental methods were developed by R. S. Stolarski. I. K. Olson and C. E. Cohn provided invaluable assistance and consultation with respect to the computer programming. The evaporated foils were prepared using the facilities supervised by D. J. Henderson of the ANL Chemistry Division, and with his active collaboration. W. R. Robinson and K. E. Freese helped with various aspects of preparing and counting the foils. The cooperation of J. Haugsnes, G. C. Lowe, and R. J. Rutkowski in performing the irradiations with the Argonne Thermal Source Reactor is gratefully acknowledged. 


\section{REFERENCES}

1. G. S. Stanford, Foil Data Thickness Corrections As Affected by Selfshielding and Flux Depression; Trans. Am. Nucl: Soc."5, 33-34 (1962).

2. $\mathrm{R}_{0} \mathrm{H}_{0}$ Ritchie and $\mathrm{H}_{0} \mathrm{~B}_{0}$. Eldridge; Thermal Neutron Flux Depression by Abeorbing Foils, Nucl. Sci. Eng. 8, 300-311 (1960)。

3. R. H. Ritchie and G. R. Dalton, Thermal Neutron Flux Depression by Absorbing Foils. and Flux Perturbations by Thermal Neutron Detectors; Nuc1. Sci。 Eng.'11, 451-452 (1961)。

4. F. H. Helm, Numerical Determination of Flux Perturbation by Foils, Nuc1. Sci。Eng: 16, 235-238 (1963).

5. D. K。 Trubey, T。 V。 Blosser, and G. M. Estabrook, Correction Factors for Foiz-activation Measurements of Neutron Fluxes in Water and Graphite, ORNL-2842 (1959), pp. 204-215.

6. G. S. Stanford, "Computer Techniques for the Investigation of Counting System Deadtime," Reactor Physics Division Annual Report: July 1, 1964 to June 30, 1965, ANL-7110 (Dec 1965), pp.247-251.

7. K。 E。 Plumlee and M。 T. Wiggins, Automatic Foil Activity Counting Facility and Data-reduction Program, ANL-6628 (Oct 1962).

8. G. S。 Stanford, The Codes NURF, COMBO, and. TWOSORCE for Processing Foil Counting Data, ANL-7356 (Aug 1967).

9. G. S. Stanford, "Attenuation of Epicadmịum Neutrons by Cadmium Foil Covers," Reactor Physics Division Annual Report: July 1, 1963 to June 30, 1964, ANL-7010 (Jan 1965).

10. Jo A. DeJuren and R。 K。 Paschall, Thermal-neutron Transmission through Plane Cadmium Covers, Nucl. Sci. Eng. 20, 314-317 (1964).

11. N. P. Baumann, Resonance Integrals and Self-shielding Factors for. Detector Foits, DP-817, E. I. Du Font de Nemours \& Co. (1963).

12. Wo Zobel, Experimental Determination of Corrections to the Neutron Activation of Gold Foils Exposed in Water, ORNL-3407 (April 4, 1963).

13. G. M. Jacks, A Study of Thermal and Resoriance Neutron. Flux Detectoṛs, DP-608, E. I. Du Pont de Nemours \& Co。 (1961). 